\title{
Coupling field and laboratory measurements to estimate the emission factors of identified and unidentified trace gases for prescribed fires
}

\author{
R. J. Yokelson ${ }^{1}$, I. R. Burling ${ }^{1}$, J. B. Gilman ${ }^{2,3}$, C. Warneke ${ }^{2,3}$, C. E. Stockwell ${ }^{1}$, J. de Gouw ${ }^{2,3}$, S. K. Akagi ${ }^{1}$, \\ S. P. Urbanski ${ }^{4}$, P. Veres ${ }^{5}$, J. M. Roberts ${ }^{2,3}$, W. C. Kuster ${ }^{2,3}$, J. Reardon ${ }^{4}$, D. W. T. Griffith ${ }^{6}$, T. J. Johnson ${ }^{7}$, \\ S. Hosseini ${ }^{8}$, J. W. Miller ${ }^{9}$, D. R. Cocker III ${ }^{9}$, H. Jung ${ }^{8}$, and D. R. Weise ${ }^{10}$ \\ ${ }^{1}$ University of Montana, Department of Chemistry, Missoula, MT 59812, USA \\ ${ }^{2}$ Cooperative Institute for Research in Environmental Sciences, University of Colorado, Boulder, CO 80309, USA \\ ${ }^{3}$ Chemical Sciences Division, Earth System Research Laboratory, National Oceanic and Atmospheric Administration, \\ Boulder, CO 80305, USA \\ ${ }^{4}$ USDA Forest Service, Rocky Mountain Research Station, Fire Sciences Laboratory, Missoula, MT 59808, USA \\ ${ }^{5}$ Max Planck Institute for Chemistry, Department of Atmospheric Chemistry, Mainz, 55128, Germany \\ ${ }^{6}$ University of Wollongong, School of Chemistry, Wollongong, New South Wales 2522, Australia \\ ${ }^{7}$ Pacific Northwest National Laboratories, Richland, WA 99354, USA \\ ${ }^{8}$ Department of Mechanical Engineering and College of Engineering, Center for Environmental Research and Technology \\ (CE-CERT), UC Riverside, Riverside, CA, 92521, USA \\ ${ }^{9}$ Department of Chemical and Environmental Engineering and College of Engineering, Center for Environmental Research \\ and Technology (CE-CERT), UC Riverside, Riverside, CA, 92521, USA \\ ${ }^{10}$ USDA Forest Service, Pacific Southwest Research Station, Forest Fire Laboratory, Riverside, CA, USA
}

Correspondence to: R. J. Yokelson (bob.yokelson@umontana.edu)

Received: 6 August 2012 - Published in Atmos. Chem. Phys. Discuss.: 22 August 2012

Revised: 9 December 2012 - Accepted: 11 December 2012 - Published: 7 January 2013

\begin{abstract}
An extensive program of experiments focused on biomass burning emissions began with a laboratory phase in which vegetative fuels commonly consumed in prescribed fires were collected in the southeastern and southwestern US and burned in a series of 71 fires at the US Forest Service Fire Sciences Laboratory in Missoula, Montana. The particulate matter $\left(\mathrm{PM}_{2.5}\right)$ emissions were measured by gravimetric filter sampling with subsequent analysis for elemental carbon (EC), organic carbon (OC), and 38 elements. The trace gas emissions were measured by an open-path Fourier transform infrared (OP-FTIR) spectrometer, proton-transfer-reaction mass spectrometry (PTRMS), proton-transfer ion-trap mass spectrometry (PIT-MS), negative-ion proton-transfer chemical-ionization mass spectrometry (NI-PT-CIMS), and gas chromatography with MS detection (GC-MS). 204 trace gas species (mostly nonmethane organic compounds (NMOC)) were identified and
\end{abstract}

quantified with the above instruments. Many of the 182 species quantified by the GC-MS have rarely, if ever, been measured in smoke before. An additional 153 significant peaks in the unit mass resolution mass spectra were quantified, but either could not be identified or most of the signal at that molecular mass was unaccounted for by identifiable species.

In a second, "field" phase of this program, airborne and ground-based measurements were made of the emissions from prescribed fires that were mostly located in the same land management units where the fuels for the lab fires were collected. A broad variety, but smaller number of species (21 trace gas species and $\mathrm{PM}_{2.5}$ ) was measured on 14 fires in chaparral and oak savanna in the southwestern US, as well as pine forest understory in the southeastern US and Sierra Nevada mountains of California. The field measurements of emission factors (EF) are useful both for modeling 
and to examine the representativeness of our lab fire EF. The lab EF/field EF ratio for the pine understory fuels was not statistically different from one, on average. However, our lab EF for "smoldering compounds" emitted from the semiarid shrubland fuels should likely be increased by a factor of $\sim 2.7$ to better represent field fires. Based on the lab/field comparison, we present emission factors for 357 pyrogenic species (including unidentified species) for 4 broad fuel types: pine understory, semiarid shrublands, coniferous canopy, and organic soil.

To our knowledge this is the most comprehensive measurement of biomass burning emissions to date and it should enable improved representation of smoke composition in atmospheric models. The results support a recent estimate of global NMOC emissions from biomass burning that is much higher than widely used estimates and they provide important insights into the nature of smoke. $31-72 \%$ of the mass of gas-phase NMOC species was attributed to species that we could not identify. These unidentified species are not represented in most models, but some provision should be made for the fact that they will react in the atmosphere. In addition, the total mass of gas-phase NMOC divided by the mass of co-emitted $\mathrm{PM}_{2.5}$ averaged about three (range 2.0-8.7). About 35-64\% of the NMOC were likely semivolatile or of intermediate volatility. Thus, the gas-phase NMOC represent a large reservoir of potential precursors for secondary formation of ozone and organic aerosol. For the single lab fire in organic soil about $28 \%$ of the emitted carbon was present as gas-phase NMOC and $\sim 72 \%$ of the mass of these NMOC was unidentified, highlighting the need to learn more about the emissions from smoldering organic soils. The mass ratio of total NMOC to " $\mathrm{NO}_{\mathrm{x}}$ as NO" ranged from 11 to 267 , indicating that $\mathrm{NO}_{\mathrm{x}}$-limited $\mathrm{O}_{3}$ production would be common in evolving biomass burning plumes. The fuel consumption per unit area was $7.0 \pm 2.3 \mathrm{Mg} \mathrm{ha}^{-1}$ and $7.7 \pm 3.7 \mathrm{Mg} \mathrm{ha}^{-1}$ for pine-understory and semiarid shrubland prescribed fires, respectively.

\section{Introduction}

Biomass burning is considered the main source of primary fine carbonaceous particles in the global atmosphere as well the second largest source of total trace gases (Crutzen and Andreae, 2000; Bond et al., 2004; Akagi et al., 2011). Biomass burning is also estimated to be the second largest global atmospheric source of gas-phase nonmethane organic compounds (NMOC) after biogenic emissions ( $\sim 1000 \mathrm{Tg} \mathrm{yr}^{-1}$, Guenther et al., 2006; Yokelson et al., 2008) contributing $\sim 400-700 \mathrm{Tg} \mathrm{yr}^{-1}$ (Akagi et al., 2011). Previous studies have indicated that a significant fraction of the gas-phase NMOC emitted by biomass burning is still unidentified and that many of the unidentified species have molecular mass $(\mathrm{MM})>\sim 90$ and thus may be semivolatile or of intermediate volatility (Christian et al., 2003; Karl et al., 2007; Warneke et al., 2011). The identified and unidentified NMOC emitted by biomass burning, especially the lower volatility species, are expected to be reactive and contribute to secondary formation of ozone $\left(\mathrm{O}_{3}\right)$ or organic aerosol as observed and/or modeled in many plume aging studies (e.g. Fishman et al., 1991; Andreae et al., 1994; Goode et al., 2000; Abel et al., 2003; Hobbs et al., 2003; Trentmann et al., 2005; Sudo and Akimoto, 2007; Grieshop et al., 2009; Alvarado and Prinn, 2009; Yokelson et al., 2009; Hennigan et al., 2011; Heringa et al., 2011; Akagi et al., 2011, 2012a, b).

Understanding how the NMOC emitted by biomass burning impact the atmosphere is still developing. For example, the extent to which the emitted species can be identified and the initial and evolving ratio of gas-phase organic carbon to condensed phase carbon have only been examined in cursory fashion. The many unknowns limit our ability to model the local to global atmospheric chemistry impacts of both wild and anthropogenic fires and thus manage fire in optimal fashion. Fire is a major, natural disturbance factor in many global ecosystems and has many anthropogenic uses globally that are not formally regulated, including: inexpensive land-clearing, improving grazing, and enhancing soil fertility (Hoy and Isern, 1995; Jordan, 1984; Steinhart and Steinhart, 1974). Prescribed burning is a regulated land management practice used widely in the US, Australia, South Africa, and elsewhere. In the context of wildland management (e.g. natural grasslands, shrublands, forests), prescribed fires are used to restore or maintain the natural, beneficial role of fire; reduce fire risk by consuming accumulated wildland fuels under preferred weather conditions; and accomplish other land management objectives (Biswell, 1989; Hardy et al., 2001; Carter and Foster, 2004). Many desirable, fire-adapted ecosystems depend on the regular occurrence of fire for survival (Keeley et al., 2009). In these ecosystems, land managers may implement prescribed burning as often as every $\sim 1-4 \mathrm{yr}$ under conditions when fuel consumption can be limited and smoke dispersion can be at least partially controlled. Wildfires, in contrast, normally burn when "fire danger" is at high levels and they can consume very large amounts of fuel (Campbell et al., 2007; Turetsky et al., 2011) with few or no options for reducing smoke impacts on populated areas. Unregulated anthropogenic fires (e.g. shifting cultivation), prescribed fires, and wildfires can strongly impact local to regional $\mathrm{O}_{3}$, air quality, health, and visibility on every continent except Antarctica (Reid et al., 1998; Sawa et al., 1999; Schmid et al., 2003; Yokelson et al., 2007; McMeeking et al., 2006; Pfister et al., 2006; Park et al., 2007). Small, unregulated anthropogenic fires in the tropics account for most of the global biomass burning while prescribed fires account for more fuel consumption than wildfires in the southeast US and wildfires consume more fuel than prescribed fires in the western US and globally in boreal ecosystems (Wiedinmyer et al., 2011). The extent to which 
prescribed fires could reduce the fuel consumption by wildfire on the landscape scale and thus potentially reduce the total amount of regional smoke impacts is an active research area (Wiedinmyer and Hurteau, 2010; Cochrane et al., 2012). In any case, an assessment of the trade-offs between ecosystem health, climate, and human health requires a detailed knowledge of smoke chemistry and its evolution and potential toxicity (e.g. http://www.epa.gov/ttn/atw/188polls.html; Sharkey, 1997; Rappold et al., 2011; Roberts et al., 2011).

We recently carried out extensive measurements that focused on better characterization of the emissions from US prescribed fires. The results are also relevant to the broader global issues mentioned above. In this paper we present a retrospective analysis that synthesizes the results from a large-scale lab-study of fire emissions with four field studies of fire emissions. The studies were carried out between February 2009 and March 2010, first at the Fire Sciences Laboratory in Missoula MT (Burling et al., 2010) and then via field campaigns in California, North Carolina (2), and Arizona (Burling et al., 2011). Both the lab and field deployments offer inherent advantages discussed in detail elsewhere (Burling et al., 2011). In the first study (Burling et al., 2010), vegetative fuels commonly consumed in prescribed fires were collected from five locations in the southeastern and southwestern US and burned in a series of 71 fires at the Fire Sciences Laboratory. The particulate matter $\left(\mathrm{PM}_{2.5}\right)$ emissions were measured by gravimetric filter sampling with subsequent analysis for elemental carbon (EC), organic carbon (OC), and 38 elements. The trace gas emissions were measured with a large suite of state-of-the-art instrumentation including an open-path Fourier transform infrared (OPFTIR) spectrometer, proton-transfer-reaction mass spectrometry (PTR-MS), proton-transfer ion-trap mass spectrometry (PIT-MS), negative-ion proton-transfer chemical-ionization mass spectrometry (NI-PT-CIMS), and gas chromatography with MS detection (GC-MS) (Burling et al., 2010; Veres et al., 2010a; Roberts et al., 2010; Warneke et al., 2011; Gilman et al., 2013). One important aspect of the lab study was the deployment of the chemical ionization mass spectrometers (CIMS) mentioned above. Full mass scans with CIMS, when coupled with species identification by GC-MS and FTIR, are particularly helpful for assessing the relative amount of identified and unidentified NMOC. CIMS is very sensitive (ppt detection limits), broadly sensitive when $\mathrm{H}_{3} \mathrm{O}^{+}$is the reagent ion (most NMOC, with the exception of alkanes, can be measured by PIT- or PTR-MS), and the sensitivity typically does not vary by more than about $\pm 50 \%$ between species. In contrast, FTIR, while sensitive to an even broader range of species (e.g. organics and inorganics), has higher detection limits and the sensitivity to individual NMOC can vary by several orders of magnitude (Sharpe et al., 2004). GC-MS sensitivity to individual NMOC can also vary by several orders of magnitude (Gilman et al., 2013). Thus, the amount of substance associated with an unknown peak in an IR spectrum, or a GC-MS chromatogram cannot usually be assigned with a level of certainty near that for CIMS. GC-MS and FTIR techniques can both detect some species not measured by CIMS and both can be useful for assigning at least some of the CIMS signal when more than one species has the same mass at unit mass resolution (Christian et al., 2003; Karl et al., 2007; Warneke et al., 2011; Gilman et al., 2013). Thus, we used "full mass scans" by CIMS, in conjunction with the GC-MS and FTIR to look in unprecedented detail at the fundamental nature of biomass burning emissions - e.g. an assessment of the total mass of initial NMOC gases and what fraction can be identified via the entire suite of instrumentation employed.

The usefulness of the detailed lab results requires verification with field studies. Thus, in the subsequent field campaigns, we employed airborne FTIR and nephelometry to measure a broad variety, but a smaller number of species (21 trace gas species and $\mathrm{PM}_{2.5}$ ) on 14 prescribed fires in chaparral and Emory oak savanna in the southwestern US, as well as pine forest understory in the coastal plain of North Carolina and the Sierra Nevada mountains of California (Burling et al., 2011). The fires sampled in the field were usually in the land management units where the fuels were collected for the lab fire study or in similar, nearby areas. These may be the most extensive field measurements of emissions for temperate biomass burning to date and in addition to their immediate usefulness for modeling, we employ them here to examine the representativeness of our even more extensive lab fire results.

In this paper, we first convert the previously published labfire emission ratios into a large set of lab-fire emission factors (EF, $g$ species emitted per $\mathrm{kg}$ of fuel burned on a dry weight basis) for all the species measured. We then compare the EF measured in the field measurement phase in different ecosystems to each other to establish an appropriate degree of specificity for our subsequent laboratory versus field EF comparisons. Third, we compare the lab EF results with the EF results from the four field deployments and based on the lab/field comparison we recommend application of a normalization factor to adjust some of the lab EF. Finally, we present a synthesized, "validated" set of emission factors for these US prescribed fires, which is also the most comprehensive set of emission factors available from any biomass burning experiment. This series of studies addresses the previous lack of $\mathrm{EF}$ for temperate biomass burning relative to the tropical ecosystems that dominate global biomass burning (van der Werf et al., 2010; Wiedinmyer et al., 2011; Akagi et al., 2011). Perhaps most importantly, the comparison presented here confirms the relevance of our laboratory measurements of important fundamental properties of biomass burning smoke such as the relative abundance of unidentified NMOC species, the gas-phase/condensed-phase carbon ratio, etc. These findings are likely relevant to some extent to all global biomass burning.

While this paper focuses on the calculation, comparison, and interpretation of EFs, the large series of field studies 
resulted in numerous key results presented elsewhere. For example, Akagi et al. (2012a) studied the post-emission chemical evolution of the smoke from one prescribed fire. A fifth, separate field campaign was completed in fall 2011 with a greatly expanded suite of measurements in which the initial emissions were measured from 7 fires and the smoke evolution was measured on four of these fires. The smoke plumes in the fall 2011 campaign were sometimes mixed with urban emissions. The fall 2011 results are presented by Akagi et al. (2012b).

\section{Experimental}

\subsection{Emissions measured in the laboratory and field campaigns}

A complete description of the fires and instrumentation employed in this extensive series of studies is beyond the scope of this paper, but full details are available in the many references cited in the summary provided next.

\subsubsection{Emissions measured during large-scale laboratory burning of biomass}

The lab fires mainly consisted of 3-6 replicate runs for 15 major fuel types relevant to US prescribed burns as shown in Table 1 of Burling et al. (2010). The lab fires also included four that measured the emissions from fresh, green, coniferous canopy fuels; one of burning organic soil; and one of garbage burning. There was very little food waste in the garbage burning simulation and lower emissions of nitrogencontaining species compared to field measurements (Christian et al., 2010), but the data are still useful for non-nitrogen species. A diagram of the US Forest Service combustion lab where the fires were burned is shown in Fig. S1. We measured the mixing ratios of the trace gases in the smoke on the sampling platform $\sim 17 \mathrm{~m}$ above the fires. Open-path FTIR and fire-integrated filter sampling were performed on all the fires and the GC-MS and the three CIMS were deployed on 66 of the 71 total burns. An example showing some of the real time and grab sampled data collected during a typical fire is provided in Fig. 1. The top panel of Fig. 1 shows a few of the species measured on the sampling platform (Fig. S1) during Fire \#32. The $\mathrm{CO}_{2}$ rises first at ignition followed quickly by $\mathrm{CO}$ once the flame front moves and smoldering develops. The flaming-dominated period is shaded yellow. As smoldering increases NMOC levels increase represented here by methanol, which was measured by three of the real time instruments. The GC-MS grab sample time and the GC-MS methanol mixing ratio are also indicated.

The instruments that measured in real-time included the OP-FTIR and the three CIMS instruments. The CIMS had Teflon sample lines that were either heated or fast-flow. The validity of combining the open-path and point-sampled measurements was previously demonstrated by Christian et
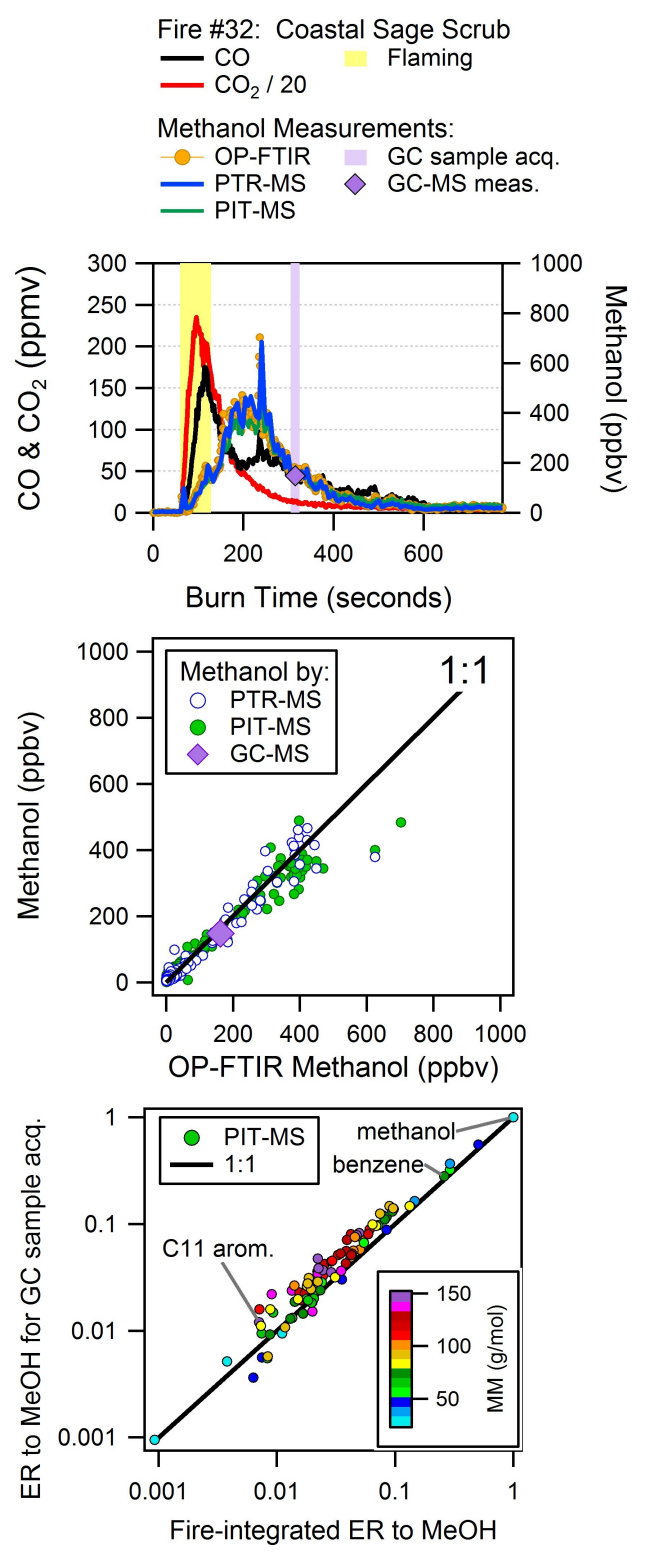

Fig. 1. (top) Time series for $\mathrm{CO}, \mathrm{CO}_{2}$, and methanol for an example burn of coastal sage scrub (Fire \#32). The yellow shading indicates the flaming-dominated period. The purple shading indicates the GC-MS sample acquisition time for this particular fire. (middle) A comparison of all other methanol measurements to the OP-FTIR methanol for Fire \#32. (bottom) NMOC to methanol emission ratios (ER) as measured by the PIT-MS during the GC-MS sample acquisition time versus the ER determined by the PIT-MS during the entire fire for Fire \#32 (see Sect. 2.2).

al. (2004) who showed that the smoke in the facility is well mixed under the conditions we employed. The OP-FTIR system (Burling et al., 2010) provided mixing ratios every $1.5 \mathrm{~s}$ for carbon dioxide $\left(\mathrm{CO}_{2}\right)$, carbon monoxide $(\mathrm{CO})$, methane $\left(\mathrm{CH}_{4}\right)$, ethyne $\left(\mathrm{C}_{2} \mathrm{H}_{2}\right)$, ethene $\left(\mathrm{C}_{2} \mathrm{H}_{4}\right)$, propene $\left(\mathrm{C}_{3} \mathrm{H}_{6}\right)$, formaldehyde $(\mathrm{HCHO})$, formic acid $(\mathrm{HCOOH})$, methanol 
Table 1. Summary of the comparison of emission factors measured in the lab and field and between different ecosystems in the field.

\begin{tabular}{|c|c|c|c|c|c|c|c|c|c|c|c|c|c|}
\hline \multirow[b]{2}{*}{ Species } & \multicolumn{6}{|c|}{ Pine Understory } & \multicolumn{6}{|c|}{ Semiarid Shrublands } & \multirow[b]{2}{*}{$\begin{array}{r}\text { Field } \\
\text { pine avg/ } \\
\text { Field shrub avg }\end{array}$} \\
\hline & $\begin{array}{r}\text { Field } \\
\text { avg EF }\end{array}$ & $\begin{array}{c}\text { Lab eqn } \\
\text { slope }\end{array}$ & $\begin{array}{l}\text { Lab eqn } \\
\text { intercept }\end{array}$ & $\begin{array}{r}\text { Lab eqn EF } \\
\text { predict } \\
\text { at field avg MCE }\end{array}$ & $\begin{array}{r}\text { Lab eqn } \\
\text { predict/field }\end{array}$ & $\begin{array}{l}\text { Lab avg/ } \\
\text { Field avg }\end{array}$ & $\begin{array}{r}\text { Field } \\
\text { avg EF }\end{array}$ & $\begin{array}{r}\text { Lab eqn } \\
\text { slope }\end{array}$ & $\begin{array}{l}\text { Lab eqn } \\
\text { intercept }\end{array}$ & $\begin{array}{r}\text { Lab eqn } \\
\text { EF predict } \\
\text { at field avg MCE }\end{array}$ & $\begin{array}{r}\text { Lab eqn } \\
\text { predict/field }\end{array}$ & $\begin{array}{l}\text { Lab avg/ } \\
\text { Field avg }\end{array}$ & \\
\hline $\mathrm{CO}_{2}$ & 1668 & & & & & 1.08 & 1674 & & & & & 1.05 & 1.00 \\
\hline $\mathrm{CO}$ & 72.1 & & & & & 1.15 & 73.8 & & & & & 0.79 & 0.98 \\
\hline MCE & 0.936 & & & & & 1.00 & 0.935 & & & & & 1.02 & 1.00 \\
\hline NO & 0.88 & & & & & 2.02 & 0.75 & & & & & 3.31 & 1.18 \\
\hline $\mathrm{NO}_{2}$ & 2.68 & & & & & 0.38 & 2.58 & & & & & 0.24 & 1.04 \\
\hline $\mathrm{NO}_{\mathrm{x}}$ as $\mathrm{NO}$ & 2.55 & -5.511 & 7.576 & 2.42 & 0.95 & 0.96 & 2.18 & 11.095 & -7.673 & 2.70 & 1.24 & 1.32 & 1.17 \\
\hline $\mathrm{CH}_{4}$ & 3.02 & -49.129 & 48.593 & 2.61 & 0.86 & 0.93 & 3.69 & -23.124 & 23.308 & 1.68 & 0.46 & 0.36 & 0.82 \\
\hline $\mathrm{C}_{2} \mathrm{H}_{2}$ & 0.30 & -1.971 & 2.021 & 0.18 & 0.59 & 0.61 & 0.21 & -5.565 & 5.437 & 0.23 & 1.09 & 0.68 & 1.41 \\
\hline $\mathrm{C}_{2} \mathrm{H}_{4}$ & 1.16 & -14.017 & 13.965 & 0.85 & 0.73 & 0.77 & 1.01 & -10.453 & 10.339 & 0.56 & 0.56 & 0.39 & 1.15 \\
\hline $\mathrm{C}_{3} \mathrm{H}_{6}$ & 0.40 & -6.332 & 6.248 & 0.32 & 0.80 & 0.86 & 0.53 & -2.616 & 2.614 & 0.17 & 0.31 & 0.24 & 0.75 \\
\hline $\mathrm{HCHO}$ & 1.51 & -25.596 & 24.974 & 1.02 & 0.67 & 0.74 & 1.33 & -11.954 & 11.676 & 0.50 & 0.37 & 0.23 & 1.14 \\
\hline $\mathrm{CH}_{3} \mathrm{OH}$ & 1.05 & -25.218 & 24.531 & 0.93 & 0.88 & 0.97 & 1.35 & -7.141 & 7.070 & 0.39 & 0.29 & 0.21 & 0.78 \\
\hline $\mathrm{HCOOH}$ & 0.09 & -6.197 & 6.026 & 0.23 & 2.40 & 2.65 & 0.08 & -2.194 & 2.144 & 0.09 & 1.20 & 0.75 & 1.21 \\
\hline $\mathrm{CH}_{3} \mathrm{COOH}$ & 1.32 & -43.537 & 42.785 & 2.03 & 1.54 & 1.67 & 1.91 & -12.104 & 12.028 & 0.71 & 0.37 & 0.31 & 0.69 \\
\hline phenol & 0.33 & & & & & & 0.45 & & & & & & 0.73 \\
\hline furan & 0.20 & -6.011 & 5.801 & 0.17 & 0.87 & 0.99 & 0.30 & -2.859 & 2.783 & 0.11 & 0.36 & 0.21 & 0.66 \\
\hline glycolaldehyde & 0.25 & & & & & & 0.25 & & & & & & 0.99 \\
\hline $\mathrm{HCN}$ & 0.59 & -8.610 & 8.314 & 0.26 & 0.43 & 0.49 & 0.75 & -1.009 & 1.016 & 0.07 & 0.10 & 0.08 & 0.79 \\
\hline $\mathrm{NH}_{3}$ & 0.50 & -9.005 & 9.146 & 0.72 & 1.43 & 1.50 & 1.50 & -3.768 & 4.147 & 0.62 & 0.41 & 0.38 & 0.33 \\
\hline HONO & 0.52 & -0.149 & 0.520 & 0.38 & 0.73 & 0.73 & 0.54 & -5.314 & 5.287 & 0.32 & 0.59 & 0.44 & 0.97 \\
\hline $\mathrm{PM}_{2.5}$ & 13.55 & -167.80 & 163.94 & 6.88 & 0.51 & 0.49 & 7.06 & -169.10 & 165.00 & 6.87 & 0.97 & 0.55 & 1.92 \\
\hline \multicolumn{5}{|c|}{ Average ratio smoldering compounds } & 1.01 & 1.10 & & & & & 0.49 & 0.37 & 0.99 \\
\hline \multicolumn{5}{|l|}{ Stdev ratio } & 0.57 & 0.60 & & & & & 0.32 & 0.22 & 0.32 \\
\hline \multicolumn{5}{|c|}{ Fractional uncertainty } & 0.56 & 0.55 & & & & & 0.65 & 0.59 & 0.33 \\
\hline
\end{tabular}

$\left(\mathrm{CH}_{3} \mathrm{OH}\right)$, acetic acid $\left(\mathrm{CH}_{3} \mathrm{COOH}\right)$, furan $\left(\mathrm{C}_{4} \mathrm{H}_{4} \mathrm{O}\right)$, water $\left(\mathrm{H}_{2} \mathrm{O}\right)$, nitric oxide $(\mathrm{NO})$, nitrogen dioxide $\left(\mathrm{NO}_{2}\right)$, nitrous acid (HONO), ammonia $\left(\mathrm{NH}_{3}\right)$, hydrogen cyanide $(\mathrm{HCN})$, hydrogen chloride $(\mathrm{HCl})$, and sulfur dioxide $\left(\mathrm{SO}_{2}\right)$. The NIPT-CIMS instrument used to measure organic and inorganic acids is described in more detail by Roberts et al. (2010) and Veres et al. (2010a). The NI-PT-CIMS provided measurements every $5 \mathrm{~s}$ of $\mathrm{HCOOH}, \mathrm{HONO}$, isocyanic acid (HNCO), acrylic acid, glycolic acid, pyruvic acid, and resorcinol (1,3benzenediol plus 1,2-benzenediol). On a few fires the NI-PTCIMS interrupted the real-time monitoring to run a mass scan from $m / z \quad 10$ to 225. The PTR-MS instrument for NMOC measurements is described in more detail in Warneke et al. (2011) and de Gouw and Warneke (2007). The PTR-MS was operated in selected ion mode providing mixing ratios every $6 \mathrm{~s}$ for $\mathrm{CH}_{3} \mathrm{OH}$; acetonitrile; acetaldehyde; acetone; the sum of $\mathrm{CH}_{3} \mathrm{COOH}$ and other MM60 species; the sum of isoprene, furan, and other MM68 species; species with MM70; the sum of methylethyl ketone and other MM72 species; benzene; toluene; $\mathrm{C}_{8}$-aromatics; $\mathrm{C}_{9}$-aromatics; naphthalene; $\mathrm{C}_{10}$-aromatics; monoterpenes; $\mathrm{C}_{11}$-aromatics; and MM204. The PIT-MS instrument, which is similar to a PTR-MS instrument, is described in detail by Warneke et al. (2005, 2011). The PIT-MS performed full mass scans up to MM213 every $6 \mathrm{~s}$ that overlapped/confirmed many of the known, or multi-species, mass signals on the PTR-MS and also provided data for $>150$ additional mass channels. Examples of these full mass scans can be seen in Warneke et al. (2011). Significant signal was detected at nearly every unit MM during all or most fires up to MM213 though the signal levels tended to decrease from MM $\sim 135$ upward except for a group of larger peaks near MM204 observed mainly dur- ing smoldering combustion (Warneke et al., 2011). Thus, the emissions of species with $\mathrm{MM}>213$ were likely negligible, although one substantial peak was seen at MM220 in at least some NI-PT-CIMS full mass scans (Fig. 4 in Veres et al., 2010a). The PIT-MS was also used to analyze grab samples of smoke from each fire by GC-PIT-MS as an aid in identifying the compounds appearing on some $m / z$. Much of the ion signal in the full mass scans by the PIT-MS remained unassigned to a specific compound even after considering the OP-FTIR, GC-MS, NI-PT-CIMS, and GC-PIT-MS data. Thus, the PIT-MS scans are the primary basis of our estimate of the ratio of unidentified/identified emissions as detailed in Sect. 2.2.

Grab sampling of the emissions was performed using the GC-MS, which contributed most of the species identification. Depending on the duration of the fire, 1-3 "grab" samples were acquired for 20-300 s each at a constant flow rate of $1.2 \mathrm{~mL} \mathrm{~s}^{-1}$ from a Teflon, fast-flow transfer line. The GCMS was used to sample various segments of the fires with the overall goal being to probe the most intense periods that produce the bulk of the emissions. In each grab sample 182 individual NMOC were identified by their retention time and mass spectral fragmentation pattern as described by Gilman et al. (2013).

Fire-integrated sampling was performed with three particle filter sampling systems (hereafter FS1, FS2, UCR) that simultaneously drew stack air through dielectric tubing to a cyclone or impactor, then onto Teflon or quartz filters. The cyclones/impactor cut-offs were aerodynamic diameter $\leq 2.5 \mu \mathrm{m}$ (FS1, UCR) and $\leq 3.5 \mu \mathrm{m}$ (FS2), but the great majority of the fine particle mass is expected to be below $1 \mathrm{mi}-$ cron in diameter (Reid et al., 2005) and thus we take the 
results from all three channels as measurements of $\mathrm{PM}_{2.5}$. During the majority of burns, FS2 was loaded with Teflon filters while FS1 was loaded with quartz filters. UCR collected Teflon and quartz filters for all burns. Teflon filters were analyzed gravimetrically to determine total $\mathrm{PM}_{2.5}$ mass loading. The majority of FS2 filters and one UCR Teflon filter for each fuel type were analyzed with X-ray Fluorescence (XRF), which provided mass loadings of chlorine, bromine, silicon, sulfur, phosphorus, and metals spanning the atomic number range 11-82 (Na-Pb). The UCR quartz filters were analyzed for organic carbon (OC) and elemental carbon (EC) using thermal/optical analysis. Complete details of the laboratory particle measurement and analysis methods for total $\mathrm{PM}_{2.5}, \mathrm{XRF}$, and $\mathrm{OC} / \mathrm{EC}$ can be found in Hosseini et al. (2012). Other particle characterization measurements are published elsewhere and not discussed further here (ChangGraham et al., 2011; Hosseini et al., 2010, 2012; Qi et al., 2013).

\subsubsection{Emissions measured by airborne and ground-based sampling of field fires}

On the 14 prescribed fires in the field campaigns a closed-cell airborne FTIR (AFTIR) system was used to measure the following 21 gases: $\mathrm{H}_{2} \mathrm{O}, \mathrm{CO}_{2}, \mathrm{CO}, \mathrm{CH}_{4}, \mathrm{C}_{2} \mathrm{H}_{2}, \mathrm{C}_{2} \mathrm{H}_{4}, \mathrm{C}_{3} \mathrm{H}_{6}$, $\mathrm{HCHO}, \mathrm{HCOOH}, \mathrm{CH}_{3} \mathrm{OH}, \mathrm{CH}_{3} \mathrm{COOH}, \mathrm{C}_{4} \mathrm{H}_{4} \mathrm{O}$, glycolaldehyde $\left(\mathrm{HOCH}_{2} \mathrm{CHO}\right)$, phenol $\left(\mathrm{C}_{6} \mathrm{H}_{5} \mathrm{OH}\right), \mathrm{NO}, \mathrm{NO}_{2}, \mathrm{HONO}$, $\mathrm{HCN}, \mathrm{NH}_{3}$, peroxyacetyl nitrate $\left(\mathrm{PAN}, \mathrm{CH}_{3} \mathrm{C}(\mathrm{O}) \mathrm{OONO}_{2}\right)$ and ozone $\left(\mathrm{O}_{3}\right)$ as described by Burling et al. (2011). There are a few minor differences between the suite of FTIR species detected in the lab and field fires. $\mathrm{O}_{3}$ and PAN are generated photochemically in the downwind smoke (Akagi et al., 2012a, b), and they would not be expected in the lab fire smoke since it was only $\sim 5-10$ s old. Phenol and glycolaldehyde were also measured by AFTIR in the field, but not by OP-FTIR in the lab fires. In addition, the phenol emissions measured by AFTIR in the field were 2-4 times larger than the phenol emissions measured in the lab by PTR-MS. Lignin is probably the pyrolysis precursor for much of the phenol emissions from biomass fires and phenol may have been undetected by OP-FTIR in the lab fires because of less consumption of rotten wood (Yokelson et al., 1997; Hyde et al., 2011). Two species were only detected by OP-FTIR in the lab fires. $\mathrm{SO}_{2}$ (a flaming compound) was detected at low levels in lab fire smoke and if it had been produced at similar emission ratios to $\mathrm{CO}_{2}$ in the field fires it would have been below our detection limit in the less concentrated smoke encountered from an airborne platform. $\mathrm{HCl}$ (a flaming compound) was observed in the lab fires at an ER to $\mathrm{CO}_{2}$ that would have been detectable in the field smoke samples. Its absence in the field data could potentially reflect losses on the closed pyrex cell used in the field. Closed cell FTIR successfully detected $\mathrm{HCl}$ emitted by garbage burning in Mexico, but the levels were much higher and the cell was coated with Teflon (Christian et al., 2010; Johnson et al., 2003).
The method for measuring $\mathrm{PM}_{2.5}$ differed between the lab experiments and the airborne field measurements. The airborne field measurements of $\mathrm{PM}_{2.5}$ were based on gravimetrically-calibrated light-scattering measurements and they were likely accurate to $\pm 20 \%$ (Burling et al., 2011). In a comparison on one of the field fires (Akagi et al., (2012a), the sum of organic aerosol, chloride, ammonium, nitrate, sulfate, and black carbon measured on the aircraft by an aerosol mass spectrometer (AMS) and single particle soot photometer (SP2) was in qualitative agreement with the $\mathrm{PM}_{2.5}$ inferred from the light-scattering, but the $\mathrm{PM}_{2.5}$ also contained metals not measureable by the AMS or SP2. Thus the lab/field comparison for $\mathrm{PM}_{2.5}$ is informative, but not as direct as for gases.

On two of the prescribed fires in North Carolina and on three more fires in South Carolina in 2011 (Akagi et al., 2012b) we were able to use ground-based FTIR to measure a suite of gases emitted by residual smoldering combustion (RSC) (Burling et al., 2011). RSC can be loosely defined as combustion producing emissions that are not lofted by flame-induced convection. RSC emissions have high general importance because they can account for much or most of the ground-level air quality impacts and fuel consumption by some fires (Greene et al., 2007; Hyde et al., 2011; Turetsky et al., 2011). However, land managers strive to avoid RSC when carrying out prescribed burns and RSC did not consume a significant part of the fuels on the prescribed fires in this study (Burling et al., 2011). Thus, the RSC results are not included in the retrospective analysis in this paper.

\subsubsection{Fuel consumption measurements on field fires}

The available fuels for wildland fire depend strongly on the type of vegetation community. Standard sampling methods recognize these differences and allow fuel loading to be estimated in several categories: foliage; herbaceous fuel; litter and duff; and suspended or down, dead, woody fuel. Down, dead, woody fuel is further stratified into $1 \mathrm{~h}, 10 \mathrm{~h}, 100 \mathrm{~h}$, and $1000 \mathrm{~h}$ time lag classes, which describe how quickly the fuels equilibrate with ambient relative humidity (Deeming et al., 1978; Bradshaw et al., 1984). The time lag classes correlate fairly well with size. For instance $1 \mathrm{~h}$ fuels tend to be $<0.64 \mathrm{~cm}$ in diameter and $1000 \mathrm{~h}$ fuels tend to be $>5 \mathrm{~cm}$ in diameter. The duff and larger down, dead, woody fuel tend to be consumed by smoldering or residual smoldering combustion (Bertschi et al., 2003), while the foliage, herbaceous fuels (grasses), and litter tend to be consumed by flaming combustion. In this suite of studies, due to fuel structure differences and spatial variability, pre- and post-burn fuel loading measurements were conducted with a combination of transect and fixed area sampling techniques (Brown, 1974; Lutes et al., 2006).

For the shrub-dominated southwestern sites, transects $10 \mathrm{~m}$ long containing ten $1 \mathrm{~m}^{2}$ subplots were used to sample canopy fuels. Vegetative fuel loading was estimated using 
destructive sampling on $20 \%$ of the transect subplots and visually estimated on $100 \%$ of the subplots. Ratio estimation (Thompson, 2002) was used to relate the mass of the destructive sample estimate to the visual estimate. A total of 30 transects were installed and permanently marked. Fuel bed height, height to the base of the fuel canopy, and species composition were measured on all 300 subplots. The destructive sample was separated into $<0.63 \mathrm{~cm}$ and $0.63-2.54 \mathrm{~cm}$ diameter classes and wet weights were determined in the field. Two moisture content samples for each fuel size class were collected and subsequently dried in the laboratory. The fuel moisture content was averaged for each size class at each subplot and the dry mass was estimated from the wet field weight. Fuel loadings were summarized by transect and then by fuel type. The oak savanna sites were sampled differently. In the oak savanna, grass and litter samples were collected and dry mass was determined. Grass height was measured. Ratio estimation was used to estimate grass loading, woody loading $<2.54 \mathrm{~cm}$, and percentage of dead fuels.

For the southeastern sites, pre- and post-burn live fuel, suspended dead fuel, and litter and duff on all sites was measured using paired one-square meter plots. Pre-burn samples were collected from one of the plots, oven dried, and weighed. Post-burn fuels were measured on the paired, previously untouched plot. Because of the spatial variation associated with burning litter and duff, consumption of these fuels was also measured using "duff" pins, which are metal rods inserted into the soil to serve as a reference for pre- and post-burn litter and duff depth measurements. The point measurements of consumption based on duff pins were applied to the pre-burn litter and duff loadings to estimate total duff and litter consumption.

Because the collection, drying, and weighing of large amounts of down, dead woody fuel is impractical, the loading of down-woody (time lag) classes was estimated using the planar transect inventory method (Brown, 1974). This method is based on the number of intersections of the various classes along the transect length. Fuel volume is converted to weight by the specific gravity of sound wood. Down woody fuel consumption was then estimated by difference with the post-burn measurement of the same transects.

\subsection{Data reduction approach}

In this paper we present some new fuel consumption data, but the main focus is a retrospective analysis of the previously published trace gas and $\mathrm{PM}_{2.5}$ emissions data. The present analysis is intended to synthesize the suite of studies and derive a consistent set of emission factors for all the species measured based on the carbon mass balance method (Yokelson et al., 1996, 1999). The carbon mass balance method is based on the assumptions that all the carbon in the burned fuel is volatilized and detected and that the fraction of carbon in the fuel is known. With these assumptions, if the three main carbon-containing emissions $\mathrm{CO}_{2}, \mathrm{CO}$, and $\mathrm{CH}_{4}$ are among the quantified emissions and the fuel carbon content is known or can be estimated from the literature, it is straightforward to convert a measured partitioning of carbon emitted as various species into reasonably accurate emission factors (an exception for the smoldering organic soil is discussed later). The implementation of the carbon mass balance method to retrieve emission factors from airborne field measurements was presented in full detail by Yokelson et al. (1999) and its application to the current series of field studies was described by Burling et al. (2011) and Akagi et al. (2012a, b). The implementation of the carbon mass balance method to retrieve emission factors from laboratory fire data was described in full by Yokelson et al. (1996) and its use to calculate emission factors from the 2009 lab OP-FTIR data was described by Burling et al. (2010).

In this paper we use the carbon mass balance method to calculate a new, much larger set of lab-fire emission factors where the total carbon now includes the carbon in the particles and the carbon in the many additional gas-phase species measured by GC-MS and the CIMS instruments. Our calculation is similar to that described by Burling et al. (2010) except that the inclusion of more carbon-containing species implies that each individual compound reported previously by those authors now accounts for a slightly smaller fraction of the total carbon. That in turn generates a small decrease in the EF compared to those previously reported by Burling et al. (2010). Key details of the calculation are given next.

We used OP-FTIR as the primary data source for the species it quantified. This is because the OP-FTIR system had the highest time resolution, has no sample line losses, and it measures all its species simultaneously (including the three most abundant carbon-containing species $\left(\mathrm{CO}_{2}, \mathrm{CO}\right.$, and $\left.\mathrm{CH}_{4}\right)$ ) on the same cross-stack sample volume throughout each fire. $\mathrm{CO}_{2}, \mathrm{CO}$, and $\mathrm{CH}_{4}$ usually account for $>\sim 97-$ $98 \%$ of the total carbon emitted (Akagi et al., 2011; this work). For each of the other instruments we selected one species in common with the OP-FTIR to serve as an internal standard for a calculation of the emission ratio (ER). In step one of the EF calculation, the grab sample or fireintegrated emissions of species measured by GC-MS, PITMS, and PTR-MS were converted to ER to $\mathrm{CH}_{3} \mathrm{OH}$ and the fire-integrated emissions of species measured by NI-PTCIMS were converted to ER to $\mathrm{HCOOH}$. When 2-3 GCMS grab samples were obtained from a fire we used the average of all the grab samples. Excellent agreement between the OP-FTIR and other instruments for the two reference species was demonstrated previously: $\mathrm{CH}_{3} \mathrm{OH}$ (Christian et al., 2004; Karl et al., 2007; Warneke et al., 2011) and $\mathrm{HCOOH}$ (Veres et al., 2010a). The excellent agreement between the instruments for $\mathrm{CH}_{3} \mathrm{OH}$ in this work is also shown in Fig. 1, which helps visualize the data integration process. The middle panel of Fig. 1 shows the mixing ratios for $\mathrm{CH}_{3} \mathrm{OH}$ from PTR-MS, PIT-MS and the GC-MS plotted against the OP-FTIR $\mathrm{CH}_{3} \mathrm{OH}$. Three points below the $1: 1$ line acquired during the spike seen in the top panel likely 
reflect some timing uncertainty, but minimally impact the fire-integrated methanol. Clearly, all four instruments agreed well on $\mathrm{CH}_{3} \mathrm{OH}$ justifying its selection as an internal standard. The bottom panel of Fig. 1 shows a test for possible bias due to the GC-MS grab samples targeting the concentrated emissions. The ERs to $\mathrm{CH}_{3} \mathrm{OH}$ for all the PIT-MS species were calculated for the GC-MS sample time and compared to the PIT-MS ERs to $\mathrm{CH}_{3} \mathrm{OH}$ calculated for the whole fire. The orthogonal regression slope of $1.15 \pm 0.02$ (not shown) indicates that the GC-MS ERs to $\mathrm{CH}_{3} \mathrm{OH}$ for the other 181 NMOC measured by the GC-MS may have been biased slightly upward on Fire \#32. However, a similar comparison for the PTR-MS species on Fire \#16 suggested a $\sim 3 \%$ downward bias could have occurred for the GC-MS ERs to $\mathrm{CH}_{3} \mathrm{OH}$ on that fire. For the study as a whole no significant bias in the GC-MS ERs to $\mathrm{CH}_{3} \mathrm{OH}$ was detected (Gilman et al., 2013).

In step two of the EF calculation, all the ERs to $\mathrm{CH}_{3} \mathrm{OH}$ and $\mathrm{HCOOH}$ were converted to ERs to $\mathrm{CO}$ by multiplying with the OP-FTIR fire-integrated $\mathrm{CH}_{3} \mathrm{OH}$ or $\mathrm{HCOOH}$ ERs to $\mathrm{CO}$. In step three of the EF calculation, after all species (including unidentified species) were expressed as ERs to CO, we then calculated emission factors (EF) using the carbon mass balance method. Several aspects of implementing step three are discussed in the following paragraphs.

The assumptions of the carbon mass balance method are satisfied most rigorously if we account for all the emitted carbon including that in unidentified species. Since the amount of carbon in the unidentified species is unknown we estimated it based on the properties of the identified species. We found empirically that a plot of the number of carbon atoms versus molecular mass for the identified species emitted by the lab fires was well fit with a line (Eq. 1):

$n=0.0824 \times \mathrm{MM}-1.38\left(r^{2}, 0.912\right)$

In Eq. (1), MM is the molecular mass of an identified species and $n$ is the number of carbon atoms in the identified species. The predictions of Eq. (1) have increasing certainty with increasing mass and most of the unidentified species are at higher mass. We used Eq. (1) to estimate the number of carbon atoms in each unidentified species as part of our carbon mass balance.

A major goal of the analysis described here was to generate a reasonably complete estimate of NMOC that does not overlook unidentified species. In many cases, the OPFTIR or NI-PT-CIMS real-time data or the GC-PIT-MS or GC-MS grab samples suggested an identity for part or all of the signal observed at a MM by the PIT-MS, but a rigorous "assignment" of a mass peak requires calibration with standards and consideration of possible fragments (Veres et al., 2010b). In the current analysis our goal is a rough, unbiased estimate of the fraction of the total signal on the PIT-MS that was accounted for by species quantified on other instruments. This is important so that we can avoid two gross errors: (1) "double-counting" when most of the PIT-MS signal could be accounted for by species identified on other instruments, or (2) overlooking an important contribution from an unassigned mass channel when only a small fraction of the PIT-MS signal could have been due to species measured on other instruments. When the "other instrument" was GC-MS it is important to acknowledge that grab sampling and fireintegrated, real-time sampling probe different periods of a dynamic mixture. A simple estimate of the uncertainty this contributes to a synthesis of these two different types of sampling can be obtained from the variability when 2-3 GC-MS grab samples were obtained in the same fire. For a selection of $\sim 20$ GC-MS species generally measured with high signal to noise, the coefficient of variation was approximately $50 \%$. However, as discussed above, the grab sampling procedure used by the GC-MS does not introduce a bias in our results. The two potential errors mentioned above could also have a small impact on the calculation of total carbon and the EF. Thus, to minimize the errors while producing our estimates with a reasonable effort, we sorted all the ER to CO for identified and unidentified species by increasing mass to facilitate comparisons and then applied two filters to the unidentified species.

Filter 1: if the total unidentified contribution at a mass measured by the PIT-MS was more than twice the sum of the identified species measured at that same mass by other instruments, then we retained both the unidentified MM and the identified species at that mass. A more rigorous treatment would make a small downward adjustment to the unidentified contribution to reflect that some of it was known, but this correction would be time-consuming and inexact due to the different sampling approaches. Consequently, application of filter 1 alone would tend to slightly overestimate the total NMOC.

Filter 2: if the total unidentified contribution at a mass as measured by the PIT-MS was less than twice the sum of the species identified by other instruments, then we deleted the unidentified PIT-MS contribution at that mass. (This is only approximately equivalent to considering the peak "assigned.") Filter 2 alone would tend to underestimate total NMOC and thus, offset the error introduced by Filter 1 .

We briefly give some examples of the application of these filters next. After sorting by mass we noted that the studyaverage ER to CO for propyne (MM40) measured by GCMS was actually larger than the study-average ER to CO for "unidentified mass 40" measured by PIT-MS. This can be due to the lack of a calibration of the PIT-MS with propyne. For purposes of this study only, we eliminated the PIT-MS MM40 data and retained the GC-MS propyne data. This effectively informally assigns MM40 to propyne, but a rigorous assignment would require calibrating the PIT-MS with propyne and eliminating other MM40 candidates including 
fragments. The unidentified MM42 via PIT-MS was about double the OP-FTIR propylene, however we retained only the latter. The remainder of the MM42 signal on the PITMS is likely from fragments of several NMOC (e.g. acetone and acetic acid). In similar fashion, the PIT-MS unassigned MM43 was deleted while we retained the NI-PTCIMS HNCO, which was only slightly larger on average for the study. On both MM68 and MM72, the PIT-MS amount was somewhat larger than the sum of identified species and we eliminated the PIT-MS contribution. On these two channels, the PTR-MS amount was in good agreement with the PIT-MS amount and also somewhat larger than the sum of identified species. For these two channels only we computed the additional, unspecified PTR-MS contribution and show it for illustrative purposes. On the other hand, the only identified species at MM114 was n-octane, which was observed by GC-MS. The ER to CO for n-octane was only $\sim 2-16 \%$ of the ER to CO for MM114 measured by the PIT-MS. In addition, octanes are very poorly detected by PIT-MS and thus the much larger PIT-MS MM114 ER almost certainly reflects a very large contribution of species other than octanes, but with the same mass. Therefore, we retained both entries. The case where the unidentified contribution detected by PIT-MS was much larger than the sum of the identified species was far more common in the lab fires as a whole. The PIT-MS or PTR-MS amounts at MM 106, 120, and 134 had already been assigned to $\mathrm{C} 8, \mathrm{C} 9$, and $\mathrm{C} 10$ aromatics, respectively and they consistently agreed well with the sum of individual aromatic species measured at those MM by GC-MS. Thus, we retained only the individual GC-MS species. A few cases were ambiguous in that the PIT-MS amount was more than double the sum of identified species for some fuel types, but equivalent or even smaller for other fuel types. In those cases we retained all the information. In summary, given the inherent uncertainties and complex, variable data, the methodology used to handle overlapping information should yield reasonable results. One other factor affecting the accuracy of our estimates is difficult to assess. An unknown, probably small, amount of gas-phase NMOC were present in the smoke, but could not be detected by any of the instruments we employed. For example, NMOC with proton affinity below that of water that were not quantified by the FTIR, NI-PT-CIMS, or GCMS. The presence of compounds undetected by any instrument is minimized by the complementary nature of GC-MS and proton-transfer MS since "sticky" compounds that are difficult to detect by GC-MS usually have high proton affinity.

The results of the above calculations are shown in Supplement Table 1. A few of the lab fires that were attempted are not included in Table S1 mostly because of very low signal levels caused by poor fuel consumption and also a few instrumental problems. Table S1 shows emission factors for up to 357 species for 71 fires grouped by fuel type (typically 3-6 fires per fuel type) as well as an average and standard deviation for each fuel type. In addition, Table S1 shows a separate overall average and standard deviation for the two main ecosystem types in this study, pine-understory fires and semiarid shrubland fires, and for coniferous canopy fires. The EFs for the single fires in organic soil and garbage are also shown.

\section{Results and discussion}

There is a $1: 1$ correspondence at very high specificity between the fuels in some of the fires sampled in the field with the fuels burned in some of the lab fires. For instance, on 11 November 2009, the Block A fire sampled from the air in the morning and the Block B fire sampled from the air in the afternoon were in "coastal sage scrub" and "maritime chaparral" fuel types, respectively (see Table 1 in Burling et al., 2011). Fuels were collected from both of those land management units and burned in the lab five times each (see Table S1 or Table 1 in Burling et al., 2010). However, the mean EF for these two fuel types did not differ by more than one standard deviation for most compounds in the lab fires. A more general issue is that fifteen different specific prescribed fire fuel types were burned in the lab, but only 14 prescribed fires could be sampled in the field studies. Also, many of the field fires burned several of the lab fuel types either simultaneously or in rapid succession. Thus, we cannot support an analysis of the field data at the same level of fuel-specificity as the lab fires.

\subsection{Comparing the emissions from field fires in different fuel/vegetation types}

We can aggregate our field results into two less detailed vegetation/fuel categories: pine understory fires $(n=8)$ and semiarid shrubland fires $(n=6)$. The comparison is instructive and is shown in Table 1. The last column in Table 1 shows that, with the exception of a few species such as $\mathrm{NH}_{3}$ or $\mathrm{PM}_{2.5}$, the average emission factors measured in the field from the two different major ecosystems were actually fairly similar to each other in this study. This may be surprising because it is well documented that fire emissions are highly variable and there appear to be reproducible differences between the EF for e.g., savanna fires and tropical deforestation fires (Akagi et al., 2011). One way to rationalize the above observations is to postulate that the fuel or vegetation type may not always be a major factor controlling the trace gas emissions of wildland fires. Stated differently, we can consider the possibility that the fuel type may sometimes be less important than the environmental conditions under which the fire occurs. For instance, in a study of 56 wildland fires in Mexico, Yokelson et al. (2011) found that wind speed, deposition of air pollution, season, etc., might be major factors driving EF variability. However, we recognize that in some other studies (or with a larger sample size) the vegetation community could show an effect on the emissions more 
clearly than we observed in this study. It is also well-accepted that terrestrial vegetation communities are associated with a range of environmental conditions under which prescribed fires are safest to implement or wildfires are most likely to propagate. Thus "ecosystems" are tightly coupled to other drivers of fire behavior and emissions (Greene et al., 2007; Keeley et al, 2009). The environmental conditions may also be a major factor influencing the post-emission smoke evolution as discussed by Akagi et al. (2012a). Despite the relative insensitivity of our field trace gas EF to the major ecosystem type, we did find that classification by the major ecosystem type was useful in comparing the lab EF to field EF as detailed next.

\subsection{Comparison of emission factors measured in the lab and the field}

The ability to deploy more instrumentation on the lab fires allowed many more important species to be measured than was possible on the field fires. These additional species, including the unidentified ones, could significantly influence the post-emission smoke plume chemistry if they were present in similar amounts in the smoke from field fires (Trentmann et al., 2005; Alvarado and Prinn, 2009). Thus, it is important to explore how well the EFs measured on lab fires represent the EFs for field fires. Sixteen trace gas species were measured by a similar FTIR-based approach on both the lab and field fires and $\mathrm{PM}_{2.5}$ was also measured on both the lab and field fires. This allows us to make a fairly direct comparison of the lab and field data for a suite of 17 species that includes both organic and inorganic gases and flaming and smoldering compounds. In making the comparison, we recognize that fire emission factors depend on the "modified combustion efficiency" (MCE, in this case fire-integrated $\left.\Delta \mathrm{CO}_{2} /\left(\Delta \mathrm{CO}_{2}+\Delta \mathrm{CO}\right)\right)$, a proxy for the relative amount of flaming and smoldering combustion as discussed elsewhere (Christian et al., 2003; Yokelson et al., 2008). Thus, for a precise comparison we plotted the lab and field EF versus MCE for all 17 species measured in both the lab and field. Each plot compared all the EF from all the lab and field fires together on the same graph for one of the two major ecosystem types (pine-understory and semiarid shrublands). The lab EF were computed via the carbon mass balance method using just the FTIR species for this comparison to avoid a small downward bias on the lab EF. We show typical examples of these plots in Figs. 2 and 3.

We focus first on the lab/field comparison for methane and gas-phase NMOC produced primarily by smoldering combustion (e.g. $\mathrm{CH}_{3} \mathrm{OH}$ and $\mathrm{HCHO}$ ) in the top three rows of Fig. 2. For all three of these species (and others not shown) there is clearly good agreement between the lab and field for the pine-understory fuels (left column), but a large offset to lower EF in the lab for the semiarid shrubland fuels (right column). We speculate that the offset to lower EF for smoldering compounds from the lab semiarid shrubland fires
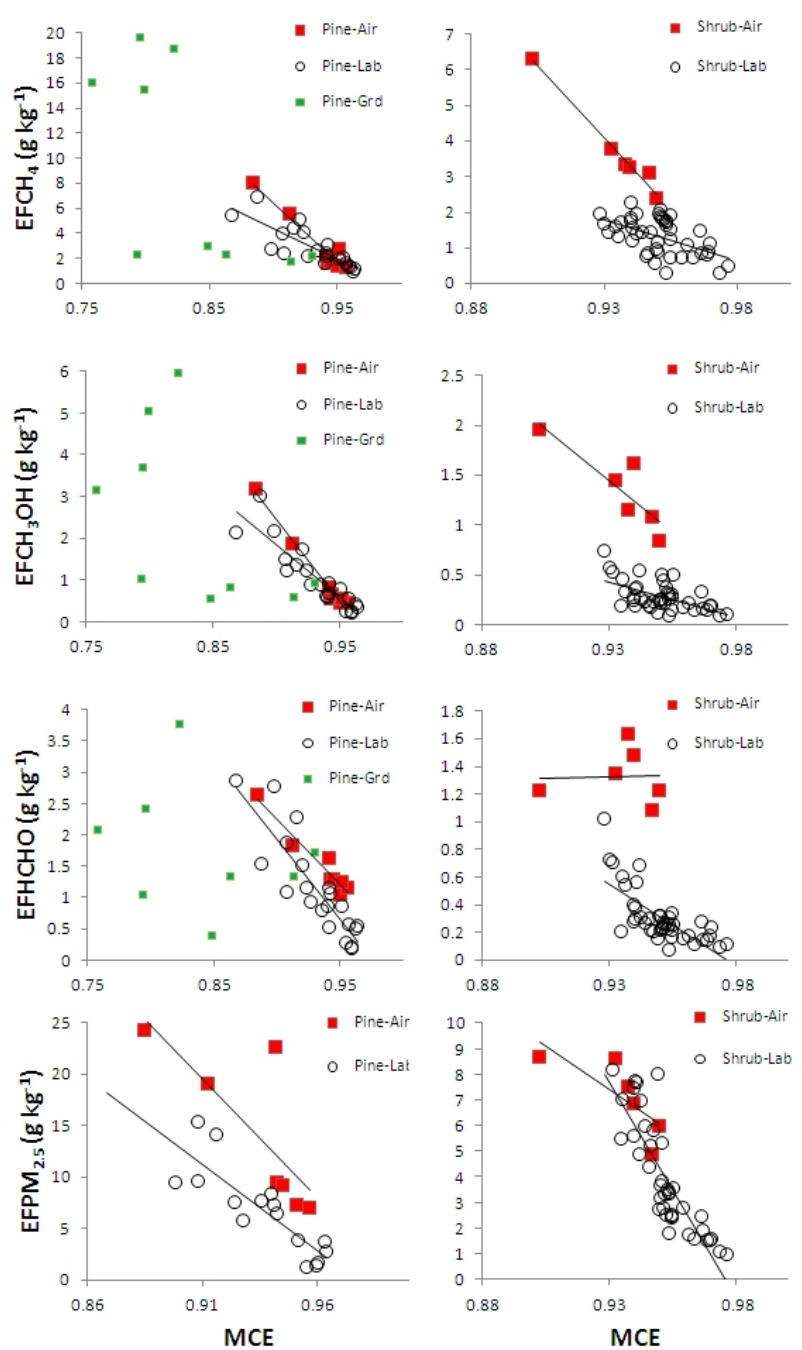

Fig. 2. Comparison of EF versus MCE from the lab and the field fires for smoldering compounds and $\mathrm{PM}_{2.5}$ for pine understory (left column) and semiarid shrubland (right column). The "Grd" (green symbols) indicate data for residual smoldering combustion provided for context (see text).

could have partly resulted from lower fuel moisture in the lab fuels as discussed in more detail in Sect. 3.8. $\mathrm{PM}_{2.5}$ emissions also tend to increase with lower MCE similar to the smoldering NMOC as shown in the bottom row of Fig. 2. However, in the case of $\mathrm{PM}_{2.5}$, the EF for pine-understory fuels are offset to significantly lower values for the lab fires and the $\mathrm{EFPM}_{2.5}$ for semiarid shrubland fuels agree fairly well at lower MCEs when measured in the lab or field.

For the three flaming compounds measured in both the lab and field there was good agreement between the lab and field for both ecosystems. This is illustrated with the plots for $\mathrm{NO}_{\mathrm{x}}, \mathrm{HONO}$, and $\mathrm{C}_{2} \mathrm{H}_{2}$ in the top three rows of Fig. 3. HCN is an important biomass burning tracer that was associated with smoldering combustion or both smoldering and flaming 

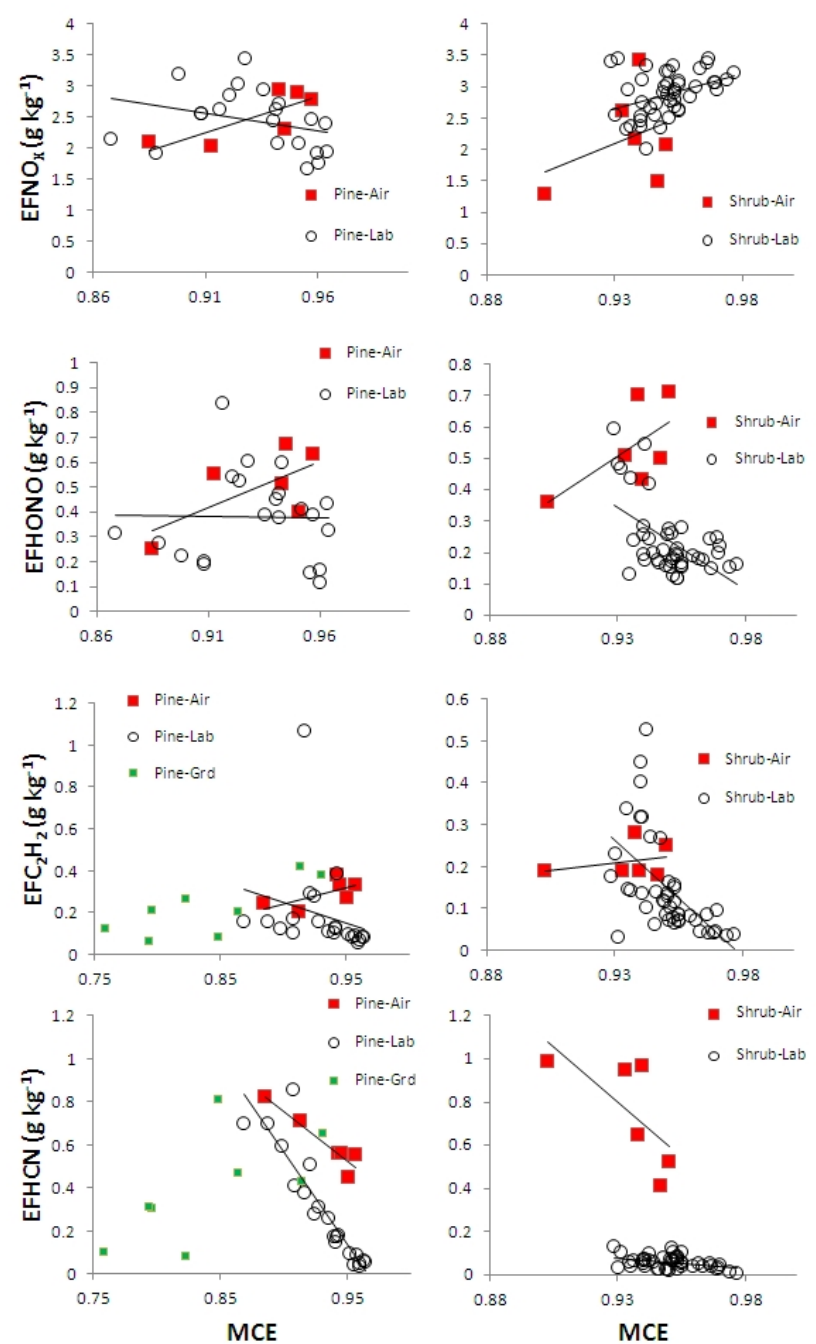

Fig. 3. Comparison of EF versus MCE from the lab and the field fires for flaming compounds and $\mathrm{HCN}$ for pine understory (left column) and semiarid shrubland (right column).

combustion in past studies (Akagi et al., 2011). In this study HCN was strongly associated with smoldering combustion in both the lab and field for both ecosystems as shown by its increasing EF at lower MCE (bottom row Fig. 3). The lab/field comparison for HCN was also similar to the comparison shown for smoldering compounds in Fig. 2.

The plots for the pine-understory fuels in Figs. 2 and 3 also show the RSC EF measured from the ground (Burling et al., 2011) for context and because of the potential high contribution of RSC to air quality impacts and wildfire emissions that we noted earlier. The RSC measurements are of individual smoldering fuel elements rather than a blended convection column and thus do not normally fit the pattern established by airborne measurements (Akagi et al., 2012b). For context and relevance to wildfires, we also present the lab EF we obtained for fires in coniferous canopy fuels and organic soils in this paper. However, the RSC EF shown in Figs. 2 and 3 are not included in the lab/field comparisons in this paper since RSC did not contribute strongly to the prescribed fire emissions in this study.

The lab/field plot-based comparison is systematically summarized in Table 1 for all 17 species measured in both the lab and field using two different mathematical approaches employed previously in the literature and briefly described next. In Christian et al. (2003) the lab EFs for smoldering compounds for African savanna fuels were systematically smaller than the field EFs because the lab fires burned at higher MCE. Thus, they plotted the lab EF versus MCE and used a linear fit to calculate EFs at the average MCE measured in the field on African savanna fires. This approach yielded lab-based projections that were within $15 \%$ of the field values, on average, as shown in Fig. 3 and Table 3 of Christian et al. (2003). In contrast, Yokelson et al. (2008) compared lab and field results for tropical deforestation fires and obtained the lowest error of prediction by simply multiplying the lab results by the average field/lab ratio.

In Table 1 we show the results of treating our current lab and field EF with both approaches previously used to "transform" lab EF to field EF. Specifically, columns 5, 6, 11, and 12 show the predictions of the lab MCE-based equation adjacent to how those predictions compare to the field data for the pine and semi-arid ecosystems, respectively. Columns 7 and 13 show the lab/field EF ratios for the two ecosystems. The inverse of the average ratio for each ecosystem is the simple correction factor in the approach employed by Yokelson et al. (2008). $\mathrm{CO}$ and $\mathrm{CO}_{2}$ predictions from the lab equations fitting EF to MCE are not included in Table 1, because MCE is defined in terms of $\mathrm{CO}$ and $\mathrm{CO}_{2}$. The ratio of the lab-average $\mathrm{EFCO}_{2}$ to the field-average $\mathrm{EFCO}_{2}$ is also not included in Table 1 because this quantity will always be near unity and inflate an assessment of the average agreement for the data set as a whole. For the pine-understory fuels, for both "mapping" approaches, the average value shown at the bottom of Table 1 is close to one, but that good agreement reflects some offset of positive and negative errors. Most noticeably, a large lab value for formic acid is offset by small lab values for $\mathrm{HCN}$ and $\mathrm{PM}_{2.5}$. However, in general the EF based on the lab equation is within $30 \%$ of the field-average $\mathrm{EF}$ for 8 of the 14 smoldering species and the lab average $\mathrm{EF}$ is within $30 \%$ of the field-average EF for 9 of the 14 species considered. The lab-average EFs are, on average, $110 \pm 60 \%$ of the field-average EFs suggesting that a relatively un-biased estimate of the field average EF can be obtained simply and directly from the lab-average EF with about $50 \%$ uncertainty on average. Although the equationbased approach appears to work "perfectly" on average, no statistically significant increase in accuracy results from applying the more complex equation-based mapping approach to the pine-understory data. As a result we suggest that the lab-average EF presented for $\sim 330$ additional smoldering species for pine understory fuels in Table S1 can be used 
directly to estimate the EF for these species from field fires in pine-understory fuels.

For semiarid shrubland fuels, the lab-based equations predict field EFs a bit closer to the EFs measured on the field fires than simply using the lab average EFs. However, both approaches require subsequently applying a large normalization factor to get good agreement and have essentially equal error of prediction. Thus, applying an equation and then a normalization factor, rather than just applying a normalization factor to the lab average EFs for over 300 compounds does not add enough accuracy to justify the added complexity. As a result, we suggest that dividing the lab EFs for smoldering compounds by 0.37 (see the bottom of column 13) or, equivalently, multiplying by 2.7 is the preferred way to predict the EFs expected in the field for semiarid shrubland fires. The normalization factor is large, but we note that applying this factor makes the EF for the lab semiarid shrubland fires closer to the EF for the lab pine-understory fires, which recovers the small EF dependence on ecosystem that was observed in the field.

\subsection{Emission factors for prescribed fires in temperate ecosystems}

In Table 2 we present our best estimate of the emission factors for $\mathrm{PM}_{2.5}$ and all the trace gas species measured in this series of studies (including unidentified species) for prescribed fires in pine forest understory and semiarid shrubland and fires in coniferous canopy fuels and organic soils. The EFs in Table 2 were generated by applying simple selection rules to the lab emissions data in Table S1 and the field emissions data in Table 1 . In Table 2 we selected the average emission factor for a species that was measured on the field fires during the four field deployments for all the species that were measured in the field. We used the average lab fire EFs when no field measurements were made of that species. For the semiarid shrubland fires, the lab EFs for smoldering compounds were multiplied by 2.7 to better represent field fire emissions as discussed above. In practice, this affected all the lab data used from the semiarid shrubland category except alkynes higher than $\mathrm{C}_{2} \mathrm{H}_{2}$ (Akagi et al., 2012b) and $\mathrm{SO}_{2}$, $\mathrm{HCl}$, and $\mathrm{HNCO}$, which were not measured in the field and were identified as flaming species in the lab study by their temporal correlation with $\mathrm{CO}_{2}$ (Burling et al., 2010; Roberts et al., 2010). In a more complex calculation, the field EF for both pine-understory and shrubland fires would be decreased by $1-5 \%$ to account for the addition of more total carbon in the form of species measured only in the lab, but we have ignored that unwieldy, statistically insignificant potential adjustment here. We note also that readers preferring the original un-normalized EF for their application can retrieve those values from Table S1. For the coniferous canopy fuels and organic soil all the data are lab data.

\subsection{Some fundamental characteristics of fresh smoke revealed by full mass scans}

Important impacts of NMOC on smoke plume chemistry include the potential to contribute to $\mathrm{O}_{3}$ and secondary aerosol formation. In broad terms, oxidation of NMOCs in the presence of $\mathrm{NO}_{\mathrm{x}}$ generates both $\mathrm{O}_{3}$ and secondary organic aerosol (SOA). In general, oxidation of the lower MM NMOCs (volatile organic compounds (VOCs)) tends to generate $\mathrm{CO}$ and $\mathrm{CO}_{2}$ as end products and $\mathrm{HO}_{\mathrm{x}}$ as an intermediate that converts $\mathrm{NO}$ to $\mathrm{NO}_{2}$, which photolyzes to produce $\mathrm{O}_{3}$. However, the larger VOCs can also be oxidized to more soluble or less volatile compounds (semivolatile organic compounds or intermediate volatility organic compounds, SVOC and IVOC, respectively). Subsequent oxidation or cooling of IVOC and SVOC can generate $\mathrm{O}_{3}$ and SOA on various time-scales (Finlayson-Pitts and Pitts, 2000). The SVOC and IVOC already present in fresh emissions are perhaps more likely to contribute to SOA on shorter time scales: e.g. during the several hours that many biomass burning plumes exist as coherent isolated entities in the boundary layer (or in smog chamber experiments) (Yokelson et al., 2009; Hennigan et al., 2011). Thus, estimating or modeling the potential for smoke photochemistry to generate $\mathrm{O}_{3}$ or secondary particle mass requires realistic estimates of the relative amounts of total VOC, IVOC, $\mathrm{SVOC}, \mathrm{NO}_{\mathrm{x}}$, etc., in fresh smoke and the chemical behavior of the species in these categories. In Table 3 we address the question of relative amounts by computing estimates of the lumped categories mentioned above that take unidentified species into account. We also show ratios between these lumped categories and/or $\mathrm{NO}_{\mathrm{x}}$ and $\mathrm{PM}_{2.5}$ for each of the four fuel types in our broad classification scheme.

Table 3 shows an average NMOC/PM 2.5 ratio for our two main fuel types of about three with higher values up to about nine possible for organic soil. The gas-phase NMOC to condensed-phase organic aerosol (OA) ratio would be higher since biomass burning $\mathrm{PM}_{2.5}$ is typically about 60-80\% OA (Reid et al., 2005). It is also of interest to estimate the IVOC and SVOC fraction of the gas-phase NMOC to roughly assess the potential amount of SOA production on the time scale of a few hours. Definitions of SVOC and IVOC are not straightforward or identical for all users of these terms. For instance, the EU and USEPA broadly classify SVOC as compounds with boiling points above $250^{\circ}$ and $200^{\circ} \mathrm{C}$, respectively, but the USEPA includes phenol as an SVOC despite it having a boiling point of $182^{\circ} \mathrm{C}$. In a review article on SVOC, Weschler and Nazaroff (2008) adopt a working definition of SVOC as having vapor pressure lower than $10 \mathrm{~Pa}$ at room temperature. We note that toluene is well established as an OA precursor and so we have based a crude estimate of the total intermediate and semivolatile gas-phase organic compounds (IVOC + SVOC) as the sum of species at or above the mass of toluene. With this arbitrary choice, for both main fuel types (i.e. pine understory and semiarid shrubland), we 
Table 2. Best estimate emission factors $\left(\mathrm{g} \mathrm{kg}^{-1}\right)$ for four types of fire: prescribed fires in semiarid shrubland and pine-forest understory, and burning coniferous canopy or organic soils (see text for discussion).

\begin{tabular}{|c|c|c|c|c|c|}
\hline Species & MM & $\begin{array}{r}\text { Semiarid } \\
\text { Shrublands } \\
\text { avg(stdev })\end{array}$ & $\begin{array}{l}\text { Pine-forest } \\
\text { Understory } \\
\text { avg(stdev) }\end{array}$ & $\begin{array}{r}\text { Coniferous } \\
\text { Canopy } \\
\text { avg(stdev })\end{array}$ & $\begin{array}{r}\text { Organic } \\
\text { Soil }\end{array}$ \\
\hline MCE & & $0.935(0.017)$ & $0.936(0.025)$ & $0.925(0.036)$ & 0.850 \\
\hline Methane $\left(\mathrm{CH}_{4}\right)$ & 16 & $3.69(1.36)$ & $3.01(2.43)$ & $3.27(1.42)$ & 7.50 \\
\hline Ammonia $\left(\mathrm{NH}_{3}\right)$ & 17 & $1.5(1.43)$ & $0.499(0.692)$ & $0.936(0.538)$ & 2.67 \\
\hline UnknownPIT_MM25 & 25 & 5.09E-3(3.98E-3) & $5.10 \mathrm{E}-3(5.44 \mathrm{E}-3)$ & $4.09 \mathrm{E}-3(2.31 \mathrm{E}-3)$ & 0.0226 \\
\hline Ethyne $\left(\mathrm{C}_{2} \mathrm{H}_{2}\right)$ & 26 & $0.213(0.041)$ & $0.298(0.067)$ & $0.433(0.251)$ & 0.0969 \\
\hline Hydrogen Cyanide (HCN) & 27 & $0.749(0.255)$ & $0.592(0.133)$ & $0.181(0.14)$ & 1.36 \\
\hline Carbon Monoxide (CO) & 28 & 73.8(18.4) & $72.2(26)$ & $85.3(38.3)$ & 129 \\
\hline Ethene $\left(\mathrm{C}_{2} \mathrm{H}_{4}\right)$ & 28 & $1.01(0.2)$ & $1.16(0.28)$ & $1.56(0.76)$ & 1.43 \\
\hline Nitric Oxide (NO) & 30 & $0.771(0.242)$ & $0.88(0.34)$ & $1.74(0.19)$ & 0.559 \\
\hline $\mathrm{NO}_{\mathrm{x}}$ as $\mathrm{NO}$ & 30 & $2.18(0.78)$ & $2.55(0.41)$ & $2.40(1.47)$ & 0.674 \\
\hline Formaldehyde (HCHO) & 30 & $1.33(0.2)$ & $1.51(0.52)$ & $1.32(0.61)$ & 1.88 \\
\hline Ethane $\left(\mathrm{C}_{2} \mathrm{H}_{6}\right)$ & 30 & $0.48(0.61)$ & $0.541(0.707)$ & $0.417(0.237)$ & 1.339 \\
\hline Methanol $\left(\mathrm{CH}_{3} \mathrm{OH}\right)$ & 32 & $1.35(0.4)$ & $1.05(0.98)$ & $0.99(0.667)$ & 3.24 \\
\hline Hydrochloric Acid ( $\mathrm{HCl})$ & 36 & $0.134(0.149)$ & $0.0643(0.0656)$ & $0.0477(0.0295)$ & - \\
\hline Propyne $\left(\mathrm{C}_{3} \mathrm{H}_{4}\right)$ & 40 & $0.0283(0.0384)$ & $0.0253(0.0218)$ & $0.0696(0.0738)$ & 0.0424 \\
\hline Acetonitrile_PTR $\left(\mathrm{CH}_{3} \mathrm{CN}\right)$ & 41 & $0.146(0.074)$ & $0.132(0.091)$ & $0.139(0.061)$ & 0.739 \\
\hline Propylene $\left(\mathrm{C}_{3} \mathrm{H}_{6}\right)$ & 42 & $0.532(0.216)$ & $0.405(0.277)$ & $0.497(0.228)$ & 1.22 \\
\hline Isocyanic Acid_NI-PT-CIMS (HNCO) & 43 & $0.0815(0.0486)$ & $0.0905(0.0519)$ & $0.168(0.143)$ & 0.271 \\
\hline Carbon Dioxide $\left(\mathrm{CO}_{2}\right)$ & 44 & $1674(38)$ & $1668(72)$ & $1670(128)$ & 1147 \\
\hline Acetaldehyde_PTR $\left(\mathrm{CH}_{3} \mathrm{CHO}\right)$ & 44 & $0.563(0.401)$ & $0.687(0.514)$ & $0.792(0.402)$ & 2.70 \\
\hline Propane $\left(\mathrm{C}_{3} \mathrm{H}_{8}\right)$ & 44 & $0.889(2.067)$ & $0.293(0.245)$ & - & 0.797 \\
\hline UnknownPIT_MM45 & 45 & $0.0923(0.0488)$ & $0.102(0.076)$ & $0.083(0.0193)$ & 0.495 \\
\hline Nitrogen Dioxide $\left(\mathrm{NO}_{2}\right)$ & 46 & $2.58(1.05)$ & $2.68(0.35)$ & $1.01(0.61)$ & 0.176 \\
\hline Formic Acid $(\mathrm{HCOOH})$ & 46 & $0.0775(0.0859)$ & $0.0943(0.0868)$ & $0.216(0.18)$ & 0.733 \\
\hline Ethanol $\left(\mathrm{CH}_{3} \mathrm{CH}_{2} \mathrm{OH}\right)$ & 46 & $0.0553(0.051)$ & $0.156(0.23)$ & $0.0416(0.0209)$ & 0.495 \\
\hline Nitrous Acid (HONO) & 47 & $0.535(0.142)$ & $0.506(0.155)$ & $0.421(0.203)$ & 0.0280 \\
\hline UnknownPIT_MM48 & 48 & $0.0114(0.0091)$ & $0.0157(0.0145)$ & $0.0147(0.0063)$ & 0.137 \\
\hline UnknownPIT_MM49 & 49 & $1.92 \mathrm{E}-3(3.09 \mathrm{E}-3)$ & $2.47 \mathrm{E}-3(2.32 \mathrm{E}-3)$ & $2.28 \mathrm{E}-3(2.83 \mathrm{E}-3)$ & 0.0251 \\
\hline UnknownPIT_MM50 & 50 & 8.07E-3(4.53E-3) & $9.47 \mathrm{E}-3(7.05 \mathrm{E}-3)$ & $7.50 \mathrm{E}-3(4.20 \mathrm{E}-3)$ & 0.0909 \\
\hline 1,3-Butadiyne $\left(\mathrm{C}_{4} \mathrm{H}_{2}\right)$ & 50 & $5.82 \mathrm{E}-3(6.58 \mathrm{E}-3)$ & 8.98E-4(8.91E-4) & $5.37 \mathrm{E}-3(8.58 \mathrm{E}-3)$ & $9.04 \mathrm{E}-3$ \\
\hline UnknownPIT_MM51 & 51 & $7.32 \mathrm{E}-3(6.76 \mathrm{E}-3)$ & $3.50 \mathrm{E}-3(3.40 \mathrm{E}-3)$ & $4.56 \mathrm{E}-3(1.60 \mathrm{E}-3)$ & 0.0208 \\
\hline UnknownPIT_MM52 & 52 & $8.46 \mathrm{E}-3(4.26 \mathrm{E}-3)$ & $6.65 \mathrm{E}-3(8.67 \mathrm{E}-3)$ & $0.0133(0.0082)$ & 0.0342 \\
\hline Butenyne $\left(\mathrm{C}_{4} \mathrm{H}_{4}\right)$ & 52 & $9.35 \mathrm{E}-3(8.63 \mathrm{E}-3)$ & $3.22 \mathrm{E}-3(3.08 \mathrm{E}-3)$ & $0.0102(0.0147)$ & 0.0176 \\
\hline Acrylonitrile_PIT $\left(\mathrm{C}_{3} \mathrm{H}_{3} \mathrm{~N}\right)$ & 53 & $0.026(0.0106)$ & $0.0218(0.022)$ & $0.0282(0.0227)$ & 0.151 \\
\hline 1,3-Butadiene_PTR $\left(\mathrm{C}_{4} \mathrm{H}_{6}\right)$ & 54 & $0.121(0.072)$ & $0.111(0.086)$ & $0.192(0.099)$ & 0.293 \\
\hline 1,2-Butadiene $\left(\mathrm{C}_{4} \mathrm{H}_{6}\right)$ & 54 & $2.50 \mathrm{E}-3(3.15 \mathrm{E}-3)$ & $1.64 \mathrm{E}-3(1.69 \mathrm{E}-3)$ & $5.49 \mathrm{E}-3(4.85 \mathrm{E}-3)$ & $3.62 \mathrm{E}-4$ \\
\hline 1-,2-Butyne $\left(\mathrm{C}_{4} \mathrm{H}_{6}\right)$ & 54 & $8.77 \mathrm{E}-3(5.44 \mathrm{E}-3)$ & $3.95 \mathrm{E}-3(2.93 \mathrm{E}-3)$ & $8.07 \mathrm{E}-3(5.42 \mathrm{E}-3)$ & 0.0135 \\
\hline UnknownPIT_MM55 & 55 & $0.0368(0.0289)$ & $0.0369(0.029)$ & $0.0436(0.0211)$ & 0.317 \\
\hline Propanenitrile $\left(\mathrm{C}_{3} \mathrm{H}_{5} \mathrm{~N}\right)$ & 55 & $0.0117(0.0068)$ & $0.0113(0.0126)$ & $0.0116(0.0112)$ & 0.0235 \\
\hline trans-2-Butene $\left(\mathrm{C}_{4} \mathrm{H}_{8}\right)$ & 56 & $0.0156(0.0199)$ & $0.0304(0.0331)$ & $0.0314(0.0276)$ & 0.125 \\
\hline 1-Butene $\left(\mathrm{C}_{4} \mathrm{H}_{8}\right)$ & 56 & $0.0909(0.0733)$ & $0.1(0.091)$ & $0.172(0.106)$ & 0.311 \\
\hline 2-Methylpropene $\left(\mathrm{C}_{4} \mathrm{H}_{8}\right)$ & 56 & $0.0262(0.0314)$ & $0.0566(0.0656)$ & $0.0356(0.0377)$ & 0.246 \\
\hline cis-2-Butene $\left(\mathrm{C}_{4} \mathrm{H}_{8}\right)$ & 56 & $0.0147(0.0182)$ & $0.0254(0.0265)$ & $0.0277(0.0207)$ & 0.0976 \\
\hline Acrolein $\left(\mathrm{C}_{3} \mathrm{H}_{4} \mathrm{O}\right)$ & 56 & $0.386(0.543)$ & $0.248(0.172)$ & $0.42(0.297)$ & 0.590 \\
\hline UnknownPIT_MM57 & 57 & $0.0391(0.0479)$ & $0.0455(0.0363)$ & $0.0549(0.0268)$ & 0.448 \\
\hline Acetone_PTR $\left(\mathrm{C}_{3} \mathrm{H}_{6} \mathrm{O}\right)$ & 58 & $0.31(0.2)$ & $0.353(0.278)$ & $0.371(0.203)$ & 1.39 \\
\hline i-Butane $\left(\mathrm{C}_{4} \mathrm{H}_{10}\right)$ & 58 & $0.0214(0.0237)$ & $0.0725(0.1307)$ & $0.0152(0.0101)$ & 0.238 \\
\hline n-Butane $\left(\mathrm{C}_{4} \mathrm{H}_{10}\right)$ & 58 & $0.0446(0.0637)$ & $0.101(0.113)$ & $0.0512(0.0361)$ & 0.479 \\
\hline Propanal $\left(\mathrm{C}_{3} \mathrm{H}_{6} \mathrm{O}\right)$ & 58 & $0.0969(0.1297)$ & $0.101(0.083)$ & $0.108(0.053)$ & 0.353 \\
\hline UnknownPIT_MM59 & 59 & $0.0622(0.077)$ & $0.092(0.0859)$ & $0.0946(0.0555)$ & 1.20 \\
\hline Acetic Acid $\left(\mathrm{CH}_{3} \mathrm{COOH}\right)$ & 60 & $1.91(0.94)$ & $1.33(1.27)$ & $1.19(0.98)$ & 7.47 \\
\hline Glycolaldehyde $\left(\mathrm{C}_{2} \mathrm{H}_{4} \mathrm{O}_{2}\right)$ & 60 & $0.199(0.172)$ & $0.242(0.454)$ & - & - \\
\hline
\end{tabular}


Table 2. Continued.

\begin{tabular}{|c|c|c|c|c|c|}
\hline Species & MM & $\begin{array}{r}\text { Semiarid } \\
\text { Shrublands } \\
\operatorname{avg}(\text { stdev })\end{array}$ & $\begin{array}{l}\text { Pine-forest } \\
\text { Understory } \\
\text { avg(stdev) }\end{array}$ & $\begin{array}{r}\text { Coniferous } \\
\text { Canopy } \\
\text { avg(stdev })\end{array}$ & $\begin{array}{r}\text { Organic } \\
\text { Soil }\end{array}$ \\
\hline Methyl Formate $\left(\mathrm{C}_{2} \mathrm{H}_{4} \mathrm{O}_{2}\right)$ & 60 & $0.0732(0.107)$ & $0.0219(0.0149)$ & $0.0265(0.0175)$ & 0.0493 \\
\hline 1,1-Dimethylhydrazine $\left(\mathrm{C}_{2} \mathrm{H}_{8} \mathrm{~N}_{2}\right)$ & 60 & $0.046(0.0807)$ & $0.0329(0.0602)$ & $0.0219(0.0273)$ & - \\
\hline UnknownPIT_MM61 & 61 & $0.0647(0.0864)$ & $0.102(0.086)$ & $0.093(0.0629)$ & 0.722 \\
\hline UnknownPIT_MM62 & 62 & $0.0173(0.0109)$ & $0.0363(0.0287)$ & $0.034(0.0161)$ & 0.368 \\
\hline UnknownPIT_MM63 & 63 & $2.62 \mathrm{E}-3(3.44 \mathrm{E}-3)$ & $7.58 \mathrm{E}-3(6.62 \mathrm{E}-3)$ & $6.74 \mathrm{E}-3(3.82 \mathrm{E}-3)$ & 0.0542 \\
\hline Sulfur Dioxide $\left(\mathrm{SO}_{2}\right)$ & 64 & $0.681(0.146)$ & $1.06(0.39)$ & $1.06(0.41)$ & 1.76 \\
\hline UnknownPIT_MM65 & 65 & $3.08 \mathrm{E}-3(4.32 \mathrm{E}-3)$ & $3.74 \mathrm{E}-3(4.97 \mathrm{E}-3)$ & $3.57 \mathrm{E}-3(4.32 \mathrm{E}-3)$ & 0.0703 \\
\hline 1,3-Cyclopentadiene_PIT $\left(\mathrm{C}_{5} \mathrm{H}_{6}\right)$ & 66 & $0.0257(0.0147)$ & $0.0293(0.0328)$ & $0.0451(0.0329)$ & 0.125 \\
\hline Pentenyne isomers $\left(\mathrm{C}_{5} \mathrm{H}_{6}\right)$ & 66 & 8.23E-3(4.96E-3) & $3.03 \mathrm{E}-3(2.94 \mathrm{E}-3)$ & $9.60 \mathrm{E}-3(7.82 \mathrm{E}-3)$ & 0.0122 \\
\hline UnknownPIT_MM67 & 67 & $0.0318(0.0318)$ & $0.0314(0.0293)$ & $0.0485(0.0329)$ & 0.327 \\
\hline Pyrrole $\left(\mathrm{C}_{4} \mathrm{H}_{5} \mathrm{~N}\right)$ & 67 & $0.0127(0.013)$ & $0.0101(0.0123)$ & $0.0144(0.0138)$ & 0.0509 \\
\hline Furan $\left(\mathrm{C}_{4} \mathrm{H}_{4} \mathrm{O}\right)$ & 68 & $0.302(0.142)$ & $0.197(0.212)$ & $0.16(0.066)$ & 1.00 \\
\hline Unspec_MM68_PTR & 68 & - & $0.155(0.121)$ & $0.207(0.115)$ & 0.558 \\
\hline Isoprene $\left(\mathrm{C}_{5} \mathrm{H}_{8}\right)$ & 68 & $0.0465(0.0332)$ & $0.066(0.0615)$ & $0.097(0.0856)$ & 0.0786 \\
\hline trans-1,3-Pentadiene $\left(\mathrm{C}_{5} \mathrm{H}_{8}\right)$ & 68 & $0.0264(0.0163)$ & $0.0277(0.0229)$ & $0.0338(0.0175)$ & 0.0535 \\
\hline cis-1,3-Pentadiene $\left(\mathrm{C}_{5} \mathrm{H}_{8}\right)$ & 68 & $0.0221(0.0159)$ & $0.0171(0.0142)$ & $0.0236(0.0127)$ & 0.0355 \\
\hline Cyclopentene $\left(\mathrm{C}_{5} \mathrm{H}_{8}\right)$ & 68 & $0.0406(0.0419)$ & $0.0327(0.0298)$ & $0.0386(0.0285)$ & 0.0595 \\
\hline Carbon suboxide $\left(\mathrm{C}_{3} \mathrm{O}_{2}\right)$ & 68 & $1.20 \mathrm{E}-3(1.21 \mathrm{E}-3)$ & $1.03 \mathrm{E}-3(1.04 \mathrm{E}-3)$ & 7.32E-4(7.84E-4) & $3.75 \mathrm{E}-3$ \\
\hline Pentadiene isomer $\left(\mathrm{C}_{5} \mathrm{H}_{8}\right)$ & 68 & $6.17 \mathrm{E}-3(7.80 \mathrm{E}-3)$ & $3.33 \mathrm{E}-3(3.23 \mathrm{E}-3)$ & $6.14 \mathrm{E}-3(5.54 \mathrm{E}-3)$ & 0.0115 \\
\hline UnknownPIT_MM69 & 69 & $0.0372(0.0436)$ & $0.0413(0.0336)$ & $0.0529(0.0294)$ & 0.420 \\
\hline Cyclopentane $\left(\mathrm{C}_{5} \mathrm{H}_{10}\right)$ & 70 & 8.20E-4(9.93E-4) & $2.39 \mathrm{E}-3(2.45 \mathrm{E}-3)$ & $1.58 \mathrm{E}-3(1.10 \mathrm{E}-3)$ & 0.0119 \\
\hline 1-Pentene $\left(\mathrm{C}_{5} \mathrm{H}_{10}\right)$ & 70 & $0.0177(0.0199)$ & $0.0265(0.0275)$ & $0.0325(0.0285)$ & 0.0832 \\
\hline 2-Methyl-1-Butene $\left(\mathrm{C}_{5} \mathrm{H}_{10}\right)$ & 70 & $9.66 \mathrm{E}-3(1.25 \mathrm{E}-2)$ & $1.16 \mathrm{E}-2(1.17 \mathrm{E}-2)$ & $0.0124(0.0083)$ & 0.0256 \\
\hline trans-2-Pentene $\left(\mathrm{C}_{5} \mathrm{H}_{10}\right)$ & 70 & $0.0132(0.0163)$ & $0.0121(0.0121)$ & $0.0165(0.0109)$ & 0.0333 \\
\hline Methacrolein $\left(\mathrm{C}_{4} \mathrm{H}_{6} \mathrm{O}\right)$ & 70 & $0.0426(0.0471)$ & $0.0458(0.0381)$ & $0.0803(0.0666)$ & 0.102 \\
\hline Methyl Vinyl Ketone (MVK, $\left.\mathrm{C}_{4} \mathrm{H}_{6} \mathrm{O}\right)$ & 70 & $0.227(0.328)$ & $0.221(0.172)$ & $0.302(0.196)$ & 0.421 \\
\hline Crotonaldehyde $\left(\mathrm{C}_{4} \mathrm{H}_{6} \mathrm{O}\right)$ & 70 & $0.182(0.238)$ & $0.209(0.167)$ & $0.193(0.109)$ & 0.494 \\
\hline 3-Methyl-1-Butene $\left(\mathrm{C}_{5} \mathrm{H}_{10}\right)$ & 70 & $3.28 \mathrm{E}-3(3.87 \mathrm{E}-3)$ & $4.44 \mathrm{E}-3(5.18 \mathrm{E}-3)$ & 2.69E-3(2.59E-3) & 0.0103 \\
\hline cis-2-Pentene $\left(\mathrm{C}_{5} \mathrm{H}_{10}\right)$ & 70 & $0.0315(0.0274)$ & $0.0446(0.0412)$ & $0.041(0.027)$ & 0.0487 \\
\hline 2-Methyl-2-Butene $\left(\mathrm{C}_{5} \mathrm{H}_{10}\right)$ & 70 & $0.0147(0.0081)$ & $0.0306(0.0293)$ & $0.0261(0.0167)$ & 0.0269 \\
\hline 2,5-Dihydrofuran $\left(\mathrm{C}_{4} \mathrm{H}_{6} \mathrm{O}\right)$ & 70 & $0.0153(0.0259)$ & $3.81 \mathrm{E}-3(9.82 \mathrm{E}-3)$ & $1.27 \mathrm{E}-3(2.54 \mathrm{E}-3)$ & - \\
\hline UnknownPIT_MM71 & 71 & $0.0311(0.0307)$ & $0.0458(0.0398)$ & $0.0612(0.0329)$ & 0.3853 \\
\hline Acrylic Acid_NI_PT_CIMS $\left(\mathrm{C}_{3} \mathrm{H}_{4} \mathrm{O}_{2}\right)$ & 72 & $9.74 \mathrm{E}-3(3.10 \mathrm{E}-2)$ & $0.0388(0.0276)$ & $0.0443(0.0403)$ & 0.153 \\
\hline Unspec_MM72 _PTR & 72 & $3.04 \mathrm{E}-2(2.08 \mathrm{E}-2)$ & $0.0874(0.0689)$ & $0.101(0.067)$ & 0.191 \\
\hline 2,2-Dimethylpropane $\left(\mathrm{C}_{5} \mathrm{H}_{12}\right)$ & 72 & $1.24 \mathrm{E}-4(1.61 \mathrm{E}-4)$ & $3.60 \mathrm{E}-4(7.47 \mathrm{E}-4)$ & $1.89 \mathrm{E}-4(2.19 \mathrm{E}-4)$ & $4.97 \mathrm{E}-3$ \\
\hline i-Pentane $\left(\mathrm{C}_{5} \mathrm{H}_{12}\right)$ & 72 & 8.63E-3(1.31E-2) & $2.73 \mathrm{E}-2(3.58 \mathrm{E}-2)$ & 7.32E-3(5.40E-3) & 0.136 \\
\hline n-Pentane $\left(\mathrm{C}_{5} \mathrm{H}_{12}\right)$ & 72 & $0.0172(0.0239)$ & $0.0368(0.0408)$ & $0.0225(0.018)$ & 0.212 \\
\hline n-Butanal $\left(\mathrm{C}_{4} \mathrm{H}_{8} \mathrm{O}\right)$ & 72 & $0.0226(0.0264)$ & $0.0241(0.0216)$ & $0.0313(0.0182)$ & 0.114 \\
\hline Methyl Ethyl Ketone (MEK, $\left.\mathrm{C}_{4} \mathrm{H}_{8} \mathrm{O}\right)$ & 72 & $0.105(0.143)$ & $0.121(0.112)$ & $0.118(0.062)$ & 0.422 \\
\hline 2-Methylpropanal $\left(\mathrm{C}_{4} \mathrm{H}_{8} \mathrm{O}\right)$ & 72 & $0.0439(0.0519)$ & $0.043(0.048)$ & $0.0256(0.0199)$ & 0.0924 \\
\hline Tetrahydrofuran $\left(\mathrm{C}_{4} \mathrm{H}_{8} \mathrm{O}\right)$ & 72 & $1.59 \mathrm{E}-3(1.31 \mathrm{E}-3)$ & $4.98 \mathrm{E}-4(5.74 \mathrm{E}-4)$ & $1.74 \mathrm{E}-3(1.02 \mathrm{E}-3)$ & $6.37 \mathrm{E}-3$ \\
\hline UnknownPIT_MM73 & 73 & $0.0412(0.0551)$ & $0.0575(0.0515)$ & $0.0791(0.0497)$ & 0.645 \\
\hline UnknownPIT_MM74 & 74 & $0.228(0.17)$ & $0.345(0.323)$ & $0.547(0.408)$ & 3.33 \\
\hline Ethyl Formate $\left(\mathrm{C}_{3} \mathrm{H}_{6} \mathrm{O}_{2}\right)$ & 74 & $0.0126(0.0072)$ & $9.91 \mathrm{E}-3(1.03 \mathrm{E}-2)$ & 7.87E-3(5.40E-3) & 0.0239 \\
\hline 1-Butanol $\left(\mathrm{C}_{4} \mathrm{H}_{10} \mathrm{O}\right)$ & 74 & $0.208(0.268)$ & $0.098(0.118)$ & $0.0292(0.016)$ & 1.18 \\
\hline Methyl Acetate $\left(\mathrm{C}_{3} \mathrm{H}_{6} \mathrm{O}_{2}\right)$ & 74 & $0.259(0.139)$ & $0.17(0.135)$ & $0.0996(0.058)$ & 0.277 \\
\hline UnknownPIT_MM75 & 75 & $0.0177(0.0399)$ & $0.0223(0.0243)$ & $0.0405(0.0223)$ & 0.470 \\
\hline Glycolic Acid_NI_PT_CIMS $\left(\mathrm{C}_{2} \mathrm{H}_{4} \mathrm{O}_{3}\right)$ & 76 & $4.55 \mathrm{E}-3(6.68 \mathrm{E}-3)$ & $0.038(0.039)$ & 0.0184 & 0.0904 \\
\hline UnknownPIT_MM76 & 76 & $0.0158(0.0098)$ & $0.0327(0.0299)$ & $0.0337(0.016)$ & 0.443 \\
\hline UnknownPIT_MM77 & 77 & $0.0312(0.0143)$ & $0.0246(0.0182)$ & $0.022(0.0094)$ & 0.201 \\
\hline Benzene_PTR $\left(\mathrm{C}_{6} \mathrm{H}_{6}\right)$ & 78 & $0.451(0.287)$ & $0.184(0.17)$ & $0.617(0.591)$ & 0.586 \\
\hline Divinylacetylene $\left(\mathrm{C}_{6} \mathrm{H}_{6}\right)$ & 78 & $6.81 \mathrm{E}-3(5.51 \mathrm{E}-3)$ & $2.61 \mathrm{E}-3(2.05 \mathrm{E}-3)$ & $9.16 \mathrm{E}-3(6.40 \mathrm{E}-3)$ & 0.0158 \\
\hline UnknownPIT_MM79 & 79 & $0.0409(0.0418)$ & $0.032(0.0329)$ & $0.0457(0.0296)$ & 0.420 \\
\hline
\end{tabular}


Table 2. Continued.

\begin{tabular}{|c|c|c|c|c|c|}
\hline Species & MM & $\begin{array}{r}\text { Semiarid } \\
\text { Shrublands } \\
\text { avg(stdev })\end{array}$ & $\begin{array}{l}\text { Pine-forest } \\
\text { Understory } \\
\text { avg(stdev) }\end{array}$ & $\begin{array}{r}\text { Coniferous } \\
\text { Canopy } \\
\text { avg(stdev })\end{array}$ & $\begin{array}{r}\text { Organic } \\
\text { Soil }\end{array}$ \\
\hline UnknownPIT_MM80 & 80 & $0.361(0.206)$ & $0.352(0.279)$ & $0.765(0.47)$ & 0.907 \\
\hline Methyl Cyclopentadiene (isomer $1, \mathrm{C}_{6} \mathrm{H}_{8}$ ) & 80 & $5.73 \mathrm{E}-3(5.25 \mathrm{E}-3)$ & $9.00 \mathrm{E}-3(1.20 \mathrm{E}-2)$ & $0.0146(0.0119)$ & 0.0282 \\
\hline Methyl Cyclopentadiene (isomer $2, \mathrm{C}_{6} \mathrm{H}_{8}$ ) & 80 & 5.39E-3(5.59E-3) & $9.11 \mathrm{E}-3(1.21 \mathrm{E}-2)$ & $0.0141(0.0152)$ & 0.0309 \\
\hline Hexenyne $\left(\mathrm{C}_{6} \mathrm{H}_{8}\right)$ & 80 & $6.19 \mathrm{E}-3(4.45 \mathrm{E}-3)$ & $3.73 \mathrm{E}-3(4.74 \mathrm{E}-3)$ & $0.011(0.0085)$ & 0.0208 \\
\hline UnknownPIT_MM81 & 81 & $0.0467(0.0588)$ & $0.0397(0.0341)$ & $0.0641(0.0442)$ & 0.455 \\
\hline 1-Methylpyrrole $\left(\mathrm{C}_{5} \mathrm{H}_{7} \mathrm{~N}\right)$ & 81 & $0.0119(0.0194)$ & $3.44 \mathrm{E}-3(4.51 \mathrm{E}-3)$ & $3.70 \mathrm{E}-3(5.12 \mathrm{E}-3)$ & 0.0147 \\
\hline UnknownPIT_MM82 & 82 & $0.203(0.171)$ & $0.243(0.198)$ & $0.356(0.23)$ & 2.91 \\
\hline 3-Methylfuran $\left(\mathrm{C}_{5} \mathrm{H}_{6} \mathrm{O}\right)$ & 82 & $0.0129(0.0099)$ & $0.0207(0.0173)$ & $0.0291(0.014)$ & 0.0725 \\
\hline cis-1,3-Hexadiene $\left(\mathrm{C}_{6} \mathrm{H}_{10}\right)$ & 82 & $1.89 \mathrm{E}-3(1.52 \mathrm{E}-3)$ & $2.01 \mathrm{E}-3(2.01 \mathrm{E}-3)$ & $1.67 \mathrm{E}-3(6.41 \mathrm{E}-4)$ & $4.46 \mathrm{E}-3$ \\
\hline trans-1,3-Hexadiene $\left(\mathrm{C}_{6} \mathrm{H}_{10}\right)$ & 82 & $3.73 \mathrm{E}-3(2.27 \mathrm{E}-3)$ & 4.37E-3(3.83E-3) & $5.92 \mathrm{E}-3(3.57 \mathrm{E}-3)$ & $7.65 \mathrm{E}-3$ \\
\hline 1-Methylcyclopentene $\left(\mathrm{C}_{6} \mathrm{H}_{10}\right)$ & 82 & $0.0117(0.0069)$ & $0.016(0.0154)$ & $0.0185(0.0116)$ & 0.0194 \\
\hline Cyclohexene $\left(\mathrm{C}_{6} \mathrm{H}_{10}\right)$ & 82 & $0.0116(0.0101)$ & $0.0114(0.0095)$ & $0.015(0.0103)$ & 0.0153 \\
\hline Other $\mathrm{C}_{6} \mathrm{H}_{10}$ (isomer_1) & 82 & $1.50 \mathrm{E}-3(1.62 \mathrm{E}-3)$ & $1.05 \mathrm{E}-3(1.07 \mathrm{E}-3)$ & $1.91 \mathrm{E}-3(2.06 \mathrm{E}-3)$ & $1.42 \mathrm{E}-3$ \\
\hline Other $\mathrm{C}_{6} \mathrm{H}_{10}$ (isomer_2) & 82 & $1.71 \mathrm{E}-3(1.39 \mathrm{E}-3)$ & $1.90 \mathrm{E}-3(1.77 \mathrm{E}-3)$ & $3.60 \mathrm{E}-3(2.60 \mathrm{E}-3)$ & $3.64 \mathrm{E}-3$ \\
\hline Other $\mathrm{C}_{6} \mathrm{H}_{10}$ (isomer_3) & 82 & $0.0155(0.0131)$ & $0.0107(0.0103)$ & $0.0204(0.0125)$ & 0.0162 \\
\hline 2-Methylfuran $\left(\mathrm{C}_{5} \mathrm{H}_{6} \mathrm{O}\right)$ & 82 & $0.159(0.1)$ & $0.213(0.211)$ & $0.199(0.1)$ & 0.537 \\
\hline Other $\mathrm{C}_{6} \mathrm{H}_{10}$ (isomer_4) & 82 & $2.94 \mathrm{E}-3(3.03 \mathrm{E}-3)$ & 4.35E-3(4.57E-3) & 4.38E-3(3.47E-3) & 8.01E-3 \\
\hline Other $\mathrm{C}_{6} \mathrm{H}_{10}$ (isomer_5) & 82 & $1.31 \mathrm{E}-3(1.52 \mathrm{E}-3)$ & $2.04 \mathrm{E}-3(2.07 \mathrm{E}-3)$ & $2.44 \mathrm{E}-3(1.76 \mathrm{E}-3)$ & $3.85 \mathrm{E}-3$ \\
\hline 1-Methylpyrazole $\left(\mathrm{C}_{4} \mathrm{H}_{6} \mathrm{~N}_{2}\right)$ & 82 & $5.09 \mathrm{E}-3(4.56 \mathrm{E}-3)$ & $6.27 \mathrm{E}-3(5.94 \mathrm{E}-3)$ & $6.56 \mathrm{E}-3(4.17 \mathrm{E}-3)$ & 0.0276 \\
\hline Cyclopentenone $\left(\mathrm{C}_{5} \mathrm{H}_{6} \mathrm{O}\right)$ & 82 & $0.0748(0.0994)$ & $0.304(0.414)$ & $0.172(0.13)$ & 0.201 \\
\hline UnknownPIT_MM83 & 83 & $0.0552(0.0812)$ & $0.0615(0.0534)$ & $0.078(0.049)$ & 0.934 \\
\hline 1-Methylcyclopentane $\left(\mathrm{C}_{6} \mathrm{H}_{12}\right)$ & 84 & 4.54E-3(6.39E-3) & $5.66 \mathrm{E}-3(6.84 \mathrm{E}-3)$ & 2.64E-3(1.99E-3) & 0.0151 \\
\hline Pentenone_PIT $\left(\mathrm{C}_{5} \mathrm{H}_{8} \mathrm{O}\right)$ & 84 & $0.231(0.233)$ & $0.335(0.29)$ & $0.474(0.328)$ & 3.78 \\
\hline 2-Methyl-1-Pentene $\left(\mathrm{C}_{6} \mathrm{H}_{12}\right)$ & 84 & $0.0674(0.0643)$ & $0.0603(0.0512)$ & $0.084(0.063)$ & 0.117 \\
\hline 1-Hexene $\left(\mathrm{C}_{6} \mathrm{H}_{12}\right)$ & 84 & $0.0673(0.0561)$ & $0.0622(0.0547)$ & $0.0842(0.0637)$ & 0.0114 \\
\hline Cyclohexene $\left(\mathrm{C}_{6} \mathrm{H}_{12}\right)$ & 84 & $1.74 \mathrm{E}-3(2.31 \mathrm{E}-3)$ & $2.42 \mathrm{E}-3(2.20 \mathrm{E}-3)$ & $9.75 \mathrm{E}-4(6.65 \mathrm{E}-4)$ & $5.68 \mathrm{E}-3$ \\
\hline Hexenes (sum of 3 isomers, $\mathrm{C}_{6} \mathrm{H}_{12}$ ) & 84 & $0.0571(0.0312)$ & $0.063(0.0696)$ & $0.0935(0.0708)$ & $9.60 \mathrm{E}-3$ \\
\hline cis-2-Hexene $\left(\mathrm{C}_{6} \mathrm{H}_{12}\right)$ & 84 & $0.0147(0.0115)$ & $0.0204(0.0259)$ & $0.0271(0.0154)$ & $5.46 \mathrm{E}-3$ \\
\hline Cyclopentanone $\left(\mathrm{C}_{5} \mathrm{H}_{8} \mathrm{O}\right)$ & 84 & $0.0834(0.0425)$ & $0.138(0.147)$ & $0.13(0.079)$ & 0.199 \\
\hline 2-Methyl-2-Butenal $\left(\mathrm{C}_{5} \mathrm{H}_{8} \mathrm{O}\right)$ & 84 & $5.91 \mathrm{E}-3(5.11 \mathrm{E}-3)$ & $8.15 \mathrm{E}-3(7.91 \mathrm{E}-3)$ & $6.96 \mathrm{E}-3(4.24 \mathrm{E}-3)$ & 0.0230 \\
\hline UnknownPIT_MM85 & 85 & $0.0466(0.0867)$ & $0.0481(0.0439)$ & $0.0695(0.0436)$ & 0.768 \\
\hline UnknownPIT_MM86 & 86 & $0.249(0.166)$ & $0.367(0.305)$ & $0.513(0.318)$ & 3.27 \\
\hline 2,2-Dimethylbutane $\left(\mathrm{C}_{6} \mathrm{H}_{14}\right)$ & 86 & 4.41E-5(7.79E-5) & $5.12 \mathrm{E}-5(1.21 \mathrm{E}-4)$ & - & $2.36 \mathrm{E}-3$ \\
\hline n-Hexane $\left(\mathrm{C}_{6} \mathrm{H}_{14}\right)$ & 86 & $9.23 \mathrm{E}-3(1.26 \mathrm{E}-2)$ & $2.11 \mathrm{E}-2(2.62 \mathrm{E}-2)$ & $0.0143(0.0115)$ & 0.110 \\
\hline 2,3-Butadione $\left(\mathrm{C}_{4} \mathrm{H}_{6} \mathrm{O}_{2}\right)$ & 86 & $0.146(0.179)$ & $0.19(0.166)$ & $0.217(0.134)$ & 0.694 \\
\hline 3-Methylpentane $\left(\mathrm{C}_{6} \mathrm{H}_{14}\right)$ & 86 & $3.18 \mathrm{E}-3(5.30 \mathrm{E}-3)$ & 4.91E-3(6.28E-3) & $1.14 \mathrm{E}-3(7.84 \mathrm{E}-4)$ & 0.0142 \\
\hline 2-Methylbutanal $\left(\mathrm{C}_{5} \mathrm{H}_{10} \mathrm{O}\right)$ & 86 & $0.0422(0.0464)$ & $0.0445(0.0547)$ & $0.025(0.0216)$ & 0.0920 \\
\hline 3-Methyl-2-Butanone $\left(\mathrm{C}_{5} \mathrm{H}_{10} \mathrm{O}\right)$ & 86 & $0.0228(0.0239)$ & $0.0284(0.027)$ & $0.0196(0.0116)$ & 0.0390 \\
\hline 2-Pentanone $\left(\mathrm{C}_{5} \mathrm{H}_{10} \mathrm{O}\right)$ & 86 & $0.0524(0.0597)$ & $0.0378(0.0337)$ & $0.0314(0.0185)$ & 0.0966 \\
\hline 3-Pentanone $\left(\mathrm{C}_{5} \mathrm{H}_{10} \mathrm{O}\right)$ & 86 & $0.03(0.0249)$ & $0.0293(0.0278)$ & $0.0238(0.013)$ & 0.0647 \\
\hline Vinyl Acetate $\left(\mathrm{C}_{4} \mathrm{H}_{6} \mathrm{O}_{2}\right)$ & 86 & $3.29 \mathrm{E}-4(9.88 \mathrm{E}-4)$ & - & $1.05 \mathrm{E}-3(2.10 \mathrm{E}-3)$ & - \\
\hline Methyl Acrylate $\left(\mathrm{C}_{4} \mathrm{H}_{6} \mathrm{O}_{2}\right)$ & 86 & $8.45 \mathrm{E}-3(4.82 \mathrm{E}-3)$ & 7.74E-3(5.46E-3) & 8.83E-3(5.98E-3) & 0.0454 \\
\hline 2,3-Dihydro-1,4-Dioxin $\left(\mathrm{C}_{4} \mathrm{H}_{6} \mathrm{O}_{2}\right)$ & 86 & $2.53 \mathrm{E}-3(4.32 \mathrm{E}-3)$ & 2.32E-3(2.72E-3) & 4.16E-3(3.98E-3) & 0.0158 \\
\hline UnknownPIT_MM87 & 87 & $0.0286(0.0402)$ & $0.0326(0.029)$ & $0.0497(0.0258)$ & 0.449 \\
\hline Pyruvic Acid_NI_PT_CIMS $\left(\mathrm{C}_{3} \mathrm{H}_{4} \mathrm{O}_{3}\right)$ & 88 & $8.87 \mathrm{E}-3(1.12 \mathrm{E}-2)$ & $0.0189(0.0218)$ & $0.0128(0.0141)$ & 0.269 \\
\hline UnknownPIT_MM88 & 88 & $0.0593(0.0476)$ & $0.12(0.114)$ & $0.141(0.093)$ & 0.906 \\
\hline Methyl Propanoate $\left(\mathrm{C}_{4} \mathrm{H}_{8} \mathrm{O}_{2}\right)$ & 88 & $9.82 \mathrm{E}-3(1.24 \mathrm{E}-2)$ & 4.77E-3(4.59E-3) & 4.14E-3(2.25E-3) & $2.42 \mathrm{E}-3$ \\
\hline UnknownPIT_MM89 & 89 & $9.93 \mathrm{E}-3(1.19 \mathrm{E}-2)$ & $1.67 \mathrm{E}-2(1.50 \mathrm{E}-2)$ & $2.28 \mathrm{E}-2(1.08 \mathrm{E}-2)$ & 0.286 \\
\hline UnknownPIT_MM90 & 90 & $0.0218(0.0225)$ & $0.0311(0.0261)$ & $0.0486(0.0269)$ & 0.789 \\
\hline UnknownPIT_MM91 & 91 & $0.0256(0.0207)$ & $0.0239(0.0184)$ & $0.0256(0.0099)$ & 0.215 \\
\hline Toluene_PTR $\left(\mathrm{C}_{6} \mathrm{H}_{5} \mathrm{CH}_{3}\right)$ & 92 & $0.174(0.127)$ & $0.141(0.121)$ & $0.249(0.118)$ & 0.488 \\
\hline Heptadiyne (isomer $1, \mathrm{C}_{7} \mathrm{H}_{8}$ ) & 92 & $2.03 \mathrm{E}-3(2.16 \mathrm{E}-3)$ & $1.63 \mathrm{E}-3(1.80 \mathrm{E}-3)$ & $3.91 \mathrm{E}-3(2.91 \mathrm{E}-3)$ & $5.23 \mathrm{E}-3$ \\
\hline Heptadiyne (isomer $2, \mathrm{C}_{7} \mathrm{H}_{8}$ ) & 92 & $2.41 \mathrm{E}-3(2.28 \mathrm{E}-3)$ & $3.54 \mathrm{E}-4(5.33 \mathrm{E}-4)$ & $4.96 \mathrm{E}-3(4.49 \mathrm{E}-3)$ & $1.57 \mathrm{E}-3$ \\
\hline
\end{tabular}


Table 2. Continued.

\begin{tabular}{|c|c|c|c|c|c|}
\hline Species & MM & $\begin{array}{r}\text { Semiarid } \\
\text { Shrublands } \\
\text { avg(stdev) }\end{array}$ & $\begin{array}{l}\text { Pine-forest } \\
\text { Understory } \\
\text { avg(stdev) }\end{array}$ & $\begin{array}{r}\text { Coniferous } \\
\text { Canopy } \\
\text { avg(stdev) }\end{array}$ & $\begin{array}{r}\text { Organic } \\
\text { Soil }\end{array}$ \\
\hline UnknownPIT_MM93 & 93 & $0.0477(0.0723)$ & $0.0388(0.0357)$ & $0.0543(0.0381)$ & 0.684 \\
\hline Phenol $\left(\mathrm{C}_{6} \mathrm{H}_{5} \mathrm{OH}\right)$ & 94 & $0.453(0.192)$ & $0.335(0.377)$ & - & - \\
\hline UnknownPIT_MM94 & 94 & $0.183(0.219)$ & $0.168(0.152)$ & $0.424(0.346)$ & 2.08 \\
\hline Methyl Diazine (isomer $1, \mathrm{C}_{5} \mathrm{H}_{6} \mathrm{~N}_{2}$ ) & 94 & $0.0105(0.0056)$ & $0.0139(0.0131)$ & $0.013(0.0067)$ & 0.0435 \\
\hline Methyl Diazine (isomer $2, \mathrm{C}_{5} \mathrm{H}_{6} \mathrm{~N}_{2}$ ) & 94 & $9.24 \mathrm{E}-3(1.20 \mathrm{E}-2)$ & 6.23E-3(5.34E-3) & $5.32 \mathrm{E}-3(9.95 \mathrm{E}-4)$ & $8.96 \mathrm{E}-3$ \\
\hline Methyl Diazine (isomer $3, \mathrm{C}_{5} \mathrm{H}_{6} \mathrm{~N}_{2}$ ) & 94 & $2.21 \mathrm{E}-3(3.05 \mathrm{E}-3)$ & $3.29 \mathrm{E}-3(5.85 \mathrm{E}-3)$ & $4.90 \mathrm{E}-3(3.52 \mathrm{E}-3)$ & - \\
\hline UnknownPIT_MM95 & 95 & $0.0962(0.1441)$ & $0.0776(0.0746)$ & $0.111(0.08)$ & 0.982 \\
\hline UnknownPIT_MM96 & 96 & $0.456(0.507)$ & $0.613(0.593)$ & $0.812(0.619)$ & 8.72 \\
\hline 2-Ethylfuran $\left(\mathrm{C}_{6} \mathrm{H}_{8} \mathrm{O}\right)$ & 96 & $9.38 \mathrm{E}-3(7.36 \mathrm{E}-3)$ & $1.36 \mathrm{E}-2(1.45 \mathrm{E}-2)$ & $0.0156(0.0074)$ & 0.0482 \\
\hline 1-Methylcyclohexene $\left(\mathrm{C}_{7} \mathrm{H}_{12}\right)$ & 96 & $6.99 \mathrm{E}-3(4.81 \mathrm{E}-3)$ & 9.87E-3(9.63E-3) & 8.30E-3(5.50E-3) & 0.0104 \\
\hline 2,5-Dimethylfuran $\left(\mathrm{C}_{6} \mathrm{H}_{8} \mathrm{O}\right)$ & 96 & $0.0208(0.0141)$ & $0.0346(0.0364)$ & $0.0358(0.0216)$ & 0.0763 \\
\hline 3-Furaldehyde $\left(\mathrm{C}_{5} \mathrm{H}_{4} \mathrm{O}_{2}\right)$ & 96 & $0.0118(0.0087)$ & $0.0214(0.0217)$ & $0.0142(0.0093)$ & 0.0588 \\
\hline 2-Furaldehyde $\left(\mathrm{C}_{5} \mathrm{H}_{4} \mathrm{O}_{2}\right)$ & 96 & $0.279(0.249)$ & $0.521(0.562)$ & $0.266(0.179)$ & 0.647 \\
\hline Cyclopentenedione $\left(\mathrm{C}_{5} \mathrm{H}_{4} \mathrm{O}_{2}\right)$ & 96 & $6.84 \mathrm{E}-3(8.33 \mathrm{E}-3)$ & $0.012(0.016)$ & $9.50 \mathrm{E}-3(8.30 \mathrm{E}-3)$ & 0.0189 \\
\hline UnknownPIT_MM97 & 97 & $0.0928(0.1799)$ & $0.0822(0.0787)$ & $0.12(0.09)$ & 1.45 \\
\hline UnknownPIT_MM98 & 98 & $0.185(0.23)$ & $0.292(0.26)$ & $0.4(0.301)$ & 3.32 \\
\hline 1-Heptene $\left(\mathrm{C}_{7} \mathrm{H}_{14}\right)$ & 98 & $0.0524(0.049)$ & $0.047(0.0434)$ & $0.0566(0.0399)$ & 0.0881 \\
\hline 1-Methylcyclohexane $\left(\mathrm{C}_{7} \mathrm{H}_{14}\right)$ & 98 & $2.81 \mathrm{E}-3(3.45 \mathrm{E}-3)$ & 4.42E-3(4.42E-3) & $2.26 \mathrm{E}-3(1.56 \mathrm{E}-3)$ & $8.57 \mathrm{E}-3$ \\
\hline UnknownPIT_MM99 & 99 & $0.0338(0.055)$ & $0.0471(0.0424)$ & $0.0676(0.0493)$ & 0.591 \\
\hline UnknownPIT_MM100 & 100 & $0.143(0.128)$ & $0.285(0.267)$ & $0.386(0.265)$ & 2.12 \\
\hline n-Hexanal $\left(\mathrm{C}_{6} \mathrm{H}_{12} \mathrm{O}\right)$ & 100 & $0.0163(0.0173)$ & $0.0257(0.0278)$ & $0.0166(0.0122)$ & 0.159 \\
\hline n-Heptane $\left(\mathrm{C}_{7} \mathrm{H}_{16}\right)$ & 100 & $0.0211(0.0241)$ & $0.027(0.0279)$ & $0.0168(0.0138)$ & 0.0481 \\
\hline Methyl Methacrylate $\left(\mathrm{C}_{5} \mathrm{H}_{8} \mathrm{O}_{2}\right)$ & 100 & $0.0326(0.0271)$ & $0.0374(0.0329)$ & $0.0272(0.0153)$ & 0.0759 \\
\hline 3-Hexanone $\left(\mathrm{C}_{6} \mathrm{H}_{12} \mathrm{O}\right)$ & 100 & $0.033(0.0289)$ & $0.0308(0.0267)$ & $0.0352(0.0231)$ & 0.0536 \\
\hline 2-Hexanone $\left(\mathrm{C}_{6} \mathrm{H}_{12} \mathrm{O}\right)$ & 100 & $0.0153(0.0172)$ & $0.0134(0.0127)$ & $0.0106(0.0077)$ & $9.67 \mathrm{E}-3$ \\
\hline UnknownPIT_MM101 & 101 & $0.0265(0.0344)$ & $0.0398(0.0362)$ & $0.0532(0.0352)$ & 0.548 \\
\hline UnknownPIT_MM102 & 102 & $0.104(0.101)$ & $0.174(0.163)$ & $0.227(0.172)$ & 1.73 \\
\hline Methyl Butanoate $\left(\mathrm{C}_{5} \mathrm{H}_{10} \mathrm{O}_{2}\right)$ & 102 & $2.68 \mathrm{E}-3(1.93 \mathrm{E}-3)$ & $0.0157(0.0358)$ & 2.94E-3(1.59E-3) & 4.20E-3 \\
\hline Ethynyl Benzene $\left(\mathrm{C}_{8} \mathrm{H}_{6}\right)$ & 102 & $0.0526(0.0776)$ & $6.55 \mathrm{E}-3(5.70 \mathrm{E}-3)$ & $0.0163(0.0198)$ & 0.0425 \\
\hline UnknownPIT_MM103 & 103 & $0.0807(0.0657)$ & $0.0692(0.0421)$ & $0.0865(0.0598)$ & 0.989 \\
\hline Benzenenitrile $\left(\mathrm{C}_{7} \mathrm{H}_{5} \mathrm{~N}\right)$ & 103 & $0.0557(0.0392)$ & $0.0596(0.0609)$ & $0.0308(0.0221)$ & 0.101 \\
\hline UnknownPIT_MM104 & 104 & $0.0711(0.0516)$ & $0.0697(0.0581)$ & $0.11(0.07)$ & 0.720 \\
\hline Styrene $\left(\mathrm{C}_{8} \mathrm{H}_{8}\right)$ & 104 & $0.0881(0.1051)$ & $0.0491(0.0386)$ & $0.0783(0.0747)$ & 0.117 \\
\hline UnknownPIT_MM105 & 105 & $0.03(0.0278)$ & $0.0238(0.0217)$ & $0.0402(0.0173)$ & 0.262 \\
\hline Ethylbenzene $\left(\mathrm{C}_{8} \mathrm{H}_{10}\right)$ & 106 & $0.0401(0.0507)$ & $0.0385(0.04)$ & $0.0396(0.0294)$ & 0.104 \\
\hline m,p-Xylenes $\left(\mathrm{C}_{8} \mathrm{H}_{10}\right)$ & 106 & $0.0692(0.0742)$ & $0.0978(0.1049)$ & $0.111(0.08)$ & 0.178 \\
\hline o-Xylene $\left(\mathrm{C}_{8} \mathrm{H}_{10}\right)$ & 106 & $0.0308(0.0369)$ & $0.0343(0.0372)$ & $0.0308(0.0176)$ & 0.101 \\
\hline Benzaldehyde $\left(\mathrm{C}_{7} \mathrm{H}_{6} \mathrm{O}\right)$ & 106 & $0.243(0.398)$ & $0.194(0.181)$ & $0.155(0.093)$ & 0.583 \\
\hline UnknownPIT_MM107 & 107 & $0.0428(0.0558)$ & $0.0342(0.0285)$ & $0.0539(0.0383)$ & 0.626 \\
\hline UnknownPIT_MM108 & 108 & $0.226(0.297)$ & $0.162(0.138)$ & $0.348(0.279)$ & 2.60 \\
\hline 2-Ethylpyrazine $\left(\mathrm{C}_{6} \mathrm{H}_{8} \mathrm{~N}_{2}\right)$ & 108 & 4.14E-3(3.23E-3) & $6.95 \mathrm{E}-3(7.03 \mathrm{E}-3)$ & $6.72 \mathrm{E}-3(3.82 \mathrm{E}-3)$ & 0.0212 \\
\hline UnknownPIT_MM109 & 109 & $0.0569(0.1257)$ & $0.0427(0.0383)$ & $0.0765(0.0595)$ & 0.724 \\
\hline Resorcinol_NI_PT_CIMS $\left(\mathrm{C}_{6} \mathrm{H}_{6} \mathrm{O}_{2}\right)$ & 110 & $0.189(0.197)$ & $1.37(1.24)$ & $1.15(1.04)$ & 2.69 \\
\hline UnknownPIT_MM110 & 110 & $0.172(0.29)$ & $0.242(0.218)$ & $0.472(0.41)$ & 4.86 \\
\hline Octadiene $\left(\mathrm{C}_{8} \mathrm{H}_{14}\right)$ & 110 & $0.0231(0.0154)$ & $0.0284(0.0252)$ & $0.0308(0.0173)$ & 0.0503 \\
\hline UnknownPIT_MM111 & 111 & $0.0392(0.0685)$ & $0.0414(0.0413)$ & $0.0898(0.0755)$ & 0.867 \\
\hline UnknownPIT_MM112 & 112 & $0.138(0.179)$ & $0.268(0.259)$ & $0.397(0.32)$ & 3.06 \\
\hline 1-Octene $\left(\mathrm{C}_{8} \mathrm{H}_{16}\right)$ & 112 & $0.0522(0.0531)$ & $0.0476(0.0476)$ & $0.0388(0.0273)$ & 0.0867 \\
\hline UnknownPIT_MM113 & 113 & $0.0348(0.0488)$ & $0.0477(0.0468)$ & $0.0744(0.0588)$ & 0.677 \\
\hline UnknownPIT_MM114 & 114 & $0.116(0.159)$ & $0.215(0.21)$ & $0.299(0.231)$ & 2.35 \\
\hline n-Octane $\left(\mathrm{C}_{8} \mathrm{H}_{18}\right)$ & 114 & $0.019(0.0205)$ & $0.024(0.0237)$ & $0.0125(0.0088)$ & 0.0390 \\
\hline UnknownPIT_MM115 & 115 & $0.0307(0.0386)$ & $0.0465(0.04)$ & $0.0663(0.0508)$ & 0.548 \\
\hline UnknownPIT_MM116 & 116 & $0.139(0.205)$ & $0.175(0.158)$ & $0.34(0.255)$ & 2.13 \\
\hline Indene $\left(\mathrm{C}_{9} \mathrm{H}_{8}\right)$ & 116 & $0.0305(0.0292)$ & $0.0204(0.0198)$ & $0.0333(0.0369)$ & 0.0506 \\
\hline
\end{tabular}


Table 2. Continued.

\begin{tabular}{|c|c|c|c|c|c|}
\hline Species & MM & $\begin{array}{r}\text { Semiarid } \\
\text { Shrublands } \\
\text { avg(stdev) }\end{array}$ & $\begin{array}{l}\text { Pine-forest } \\
\text { Understory } \\
\text { avg(stdev) }\end{array}$ & $\begin{array}{r}\text { Coniferous } \\
\text { Canopy } \\
\text { avg(stdev })\end{array}$ & $\begin{array}{r}\text { Organic } \\
\text { Soil }\end{array}$ \\
\hline UnknownPIT_MM117 & 117 & $0.0407(0.0547)$ & $0.0355(0.0299)$ & $0.0592(0.0379)$ & 0.486 \\
\hline Benzofuran_PIT $\left(\mathrm{C}_{8} \mathrm{H}_{6} \mathrm{O}\right)$ & 118 & $0.103(0.102)$ & $0.0874(0.0736)$ & $0.167(0.113)$ & 0.908 \\
\hline Indane $\left(\mathrm{C}_{9} \mathrm{H}_{10}\right)$ & 118 & 8.70E-3(6.85E-3) & 7.11E-3(6.13E-3) & 6.39E-3(3.70E-3) & 0.0102 \\
\hline 1-Propenylbenzene $\left(\mathrm{C}_{9} \mathrm{H}_{10}\right)$ & 118 & 4.60E-3(4.95E-3) & $2.38 \mathrm{E}-3(2.66 \mathrm{E}-3)$ & $3.82 \mathrm{E}-3(2.66 \mathrm{E}-3)$ & $1.16 \mathrm{E}-3$ \\
\hline alpha-Methylstyrene $\left(\mathrm{C}_{9} \mathrm{H}_{10}\right)$ & 118 & $4.69 \mathrm{E}-3(2.89 \mathrm{E}-3)$ & 3.39E-3(3.34E-3) & $6.23 \mathrm{E}-3(4.82 \mathrm{E}-3)$ & $3.89 \mathrm{E}-3$ \\
\hline 3-Methylstyrene $\left(\mathrm{C}_{9} \mathrm{H}_{10}\right)$ & 118 & $0.02(0.0128)$ & $0.0169(0.0171)$ & $0.022(0.016)$ & 0.0342 \\
\hline 2-Methylstyrene $\left(\mathrm{C}_{9} \mathrm{H}_{10}\right)$ & 118 & $0.0135(0.0093)$ & $0.01(0.0101)$ & $0.011(0.0071)$ & 0.0194 \\
\hline 2-Propenylbenzene $\left(\mathrm{C}_{9} \mathrm{H}_{10}\right)$ & 118 & 5.95E-3(4.77E-3) & 5.99E-3(5.80E-3) & $6.03 \mathrm{E}-3(3.61 \mathrm{E}-3)$ & $8.69 \mathrm{E}-3$ \\
\hline 4-Methylstyrene $\left(\mathrm{C}_{9} \mathrm{H}_{10}\right)$ & 118 & $6.21 \mathrm{E}-3(4.64 \mathrm{E}-3)$ & 8.49E-3(9.25E-3) & 7.66E-3(3.90E-3) & 0.0134 \\
\hline UnknownPIT_MM119 & 119 & $0.0315(0.036)$ & $0.0238(0.0223)$ & $0.0587(0.0386)$ & 0.577 \\
\hline 1-Ethyl-3-,4-Methylbenzene $\left(\mathrm{C}_{9} \mathrm{H}_{12}\right)$ & 120 & $0.0163(0.0183)$ & $0.0228(0.0238)$ & $0.0323(0.0264)$ & 0.0433 \\
\hline 1,2,4-Trimethylbenzene $\left(\mathrm{C}_{9} \mathrm{H}_{12}\right)$ & 120 & $0.0166(0.0209)$ & $0.0242(0.0254)$ & $0.0212(0.0134)$ & 0.0555 \\
\hline 1-Ethyl-2-Methylbenzene $\left(\mathrm{C}_{9} \mathrm{H}_{12}\right)$ & 120 & $0.0111(0.0094)$ & $9.71 \mathrm{E}-3(1.04 \mathrm{E}-2)$ & $9.50 \mathrm{E}-3(6.20 \mathrm{E}-3)$ & 0.0122 \\
\hline 1,2,3-Trimethylbenzene $\left(\mathrm{C}_{9} \mathrm{H}_{12}\right)$ & 120 & $0.0183(0.0138)$ & $0.0314(0.0366)$ & $0.0231(0.0196)$ & 0.0291 \\
\hline Isopropylbenzene $\left(\mathrm{C}_{9} \mathrm{H}_{12}\right)$ & 120 & $6.08 \mathrm{E}-3(4.42 \mathrm{E}-3)$ & $6.03 \mathrm{E}-3(6.05 \mathrm{E}-3)$ & 8.08E-3(7.33E-3) & $6.43 \mathrm{E}-3$ \\
\hline n-Propylbenzene $\left(\mathrm{C}_{9} \mathrm{H}_{12}\right)$ & 120 & $9.60 \mathrm{E}-3(6.30 \mathrm{E}-3)$ & $1.05 \mathrm{E}-2(9.64 \mathrm{E}-3)$ & $8.60 \mathrm{E}-3(6.20 \mathrm{E}-3)$ & 0.0124 \\
\hline 1,3,5-Trimethylbenzene $\left(\mathrm{C}_{9} \mathrm{H}_{12}\right)$ & 120 & $0.0143(0.016)$ & $0.0139(0.0147)$ & $0.0104(0.0064)$ & 0.0212 \\
\hline UnknownPIT_MM121 & 121 & $0.0343(0.0504)$ & $0.0317(0.0273)$ & $0.0676(0.0501)$ & 0.525 \\
\hline UnknownPIT_MM122 & 122 & $0.114(0.145)$ & $0.129(0.11)$ & $0.332(0.272)$ & 2.02 \\
\hline UnknownPIT_MM123 & 123 & $0.0442(0.0643)$ & $0.0487(0.0479)$ & $0.0954(0.0624)$ & 1.13 \\
\hline UnknownPIT_MM124 & 124 & $0.139(0.227)$ & $0.216(0.203)$ & $0.465(0.406)$ & 5.10 \\
\hline Nonadiene $\left(\mathrm{C}_{9} \mathrm{H}_{16}\right)$ & 124 & $2.06 \mathrm{E}-3(2.25 \mathrm{E}-3)$ & 3.37E-3(3.45E-3) & $4.80 \mathrm{E}-3(3.10 \mathrm{E}-3)$ & - \\
\hline UnknownPIT_MM125 & 125 & $0.0425(0.076)$ & $0.0401(0.0391)$ & $0.118(0.089)$ & 2.93 \\
\hline UnknownPIT_MM126 & 126 & $0.116(0.195)$ & $0.151(0.143)$ & $0.28(0.223)$ & 2.74 \\
\hline 1-Nonene $\left(\mathrm{C}_{9} \mathrm{H}_{18}\right)$ & 126 & $0.0103(0.0083)$ & $0.012(0.0135)$ & $0.0117(0.0082)$ & 0.0230 \\
\hline UnknownPIT_MM127 & 127 & $0.04(0.041)$ & $0.0368(0.0336)$ & $0.0806(0.0602)$ & 0.725 \\
\hline Naphthalene_PTR $\left(\mathrm{C}_{10} \mathrm{H}_{8}\right)$ & 128 & $0.173(0.097)$ & $0.199(0.182)$ & $0.286(0.19)$ & 0.815 \\
\hline Nonane $\left(\mathrm{C}_{9} \mathrm{H}_{20}\right)$ & 128 & $0.013(0.0164)$ & $0.0143(0.0159)$ & $9.20 \mathrm{E}-3(7.70 \mathrm{E}-3)$ & 0.0225 \\
\hline UnknownPIT_MM129 & 129 & $0.0564(0.0478)$ & $0.0528(0.0481)$ & $0.0998(0.0712)$ & 0.834 \\
\hline UnknownPIT_MM130 & 130 & $0.0844(0.1141)$ & $0.116(0.111)$ & $0.225(0.175)$ & 1.87 \\
\hline 1-,3-Methyl Indene $\left(\mathrm{C}_{10} \mathrm{H}_{10}\right)$ & 130 & $1.43 \mathrm{E}-3(1.13 \mathrm{E}-3)$ & $1.90 \mathrm{E}-4(4.92 \mathrm{E}-4)$ & $2.49 \mathrm{E}-3(2.25 \mathrm{E}-3)$ & $1.75 \mathrm{E}-3$ \\
\hline 1,2-Dihydronaphthalene $\left(\mathrm{C}_{10} \mathrm{H}_{10}\right)$ & 130 & $6.83 \mathrm{E}-3(4.60 \mathrm{E}-3)$ & 6.87E-3(8.79E-3) & 7.83E-3(4.84E-3) & $6.44 \mathrm{E}-3$ \\
\hline 1,3-Dihydronaphthalene $\left(\mathrm{C}_{10} \mathrm{H}_{10}\right)$ & 130 & 7.39E-3(4.65E-3) & 7.88E-3(9.53E-3) & $0.01(0.0057)$ & $7.24 \mathrm{E}-3$ \\
\hline UnknownPIT_MM131 & 131 & $0.0374(0.0555)$ & $0.0305(0.0276)$ & $0.0587(0.0419)$ & 0.387 \\
\hline UnknownPIT_MM132 & 132 & $0.126(0.168)$ & $0.0988(0.085)$ & $0.24(0.19)$ & 1.33 \\
\hline 1-Butenylbenzene $\left(\mathrm{C}_{10} \mathrm{H}_{14}\right)$ & 132 & $2.49 \mathrm{E}-3(2.57 \mathrm{E}-3)$ & $2.69 \mathrm{E}-3(4.86 \mathrm{E}-3)$ & $4.22 \mathrm{E}-3(2.15 \mathrm{E}-3)$ & $1.92 \mathrm{E}-3$ \\
\hline Methylbenzofuran (isomer $4, \mathrm{C}_{9} \mathrm{H}_{8} \mathrm{O}$ ) & 132 & $8.72 \mathrm{E}-4(2.62 \mathrm{E}-3)$ & - & $2.66 \mathrm{E}-3(3.95 \mathrm{E}-3)$ & - \\
\hline Ethylstyrene $\left(\mathrm{C}_{10} \mathrm{H}_{12}\right)$ & 132 & 4.34E-3(3.49E-3) & $3.95 \mathrm{E}-3(5.65 \mathrm{E}-3)$ & $5.66 \mathrm{E}-3(3.55 \mathrm{E}-3)$ & $2.10 \mathrm{E}-3$ \\
\hline 1-Methyl-1-Propenylbenzene $\left(\mathrm{C}_{10} \mathrm{H}_{12}\right)$ & 132 & $0.0321(0.0551)$ & $0.0142(0.0172)$ & $0.0131(0.0106)$ & $5.23 \mathrm{E}-3$ \\
\hline Methylbenzofuran (isomer $1, \mathrm{C}_{9} \mathrm{H}_{8} \mathrm{O}$ ) & 132 & $0.0121(0.0076)$ & $0.0135(0.0156)$ & $0.0114(0.0041)$ & 0.0235 \\
\hline Methylbenzofuran (isomer $2, \mathrm{C}_{9} \mathrm{H}_{8} \mathrm{O}$ ) & 132 & $0.019(0.0118)$ & $0.0229(0.0284)$ & $0.0187(0.0064)$ & 0.0380 \\
\hline Methylbenzofuran (isomer $3, \mathrm{C}_{9} \mathrm{H}_{8} \mathrm{O}$ ) & 132 & $0.0324(0.026)$ & $0.0323(0.0418)$ & $0.0222(0.0073)$ & 0.0517 \\
\hline UnknownPIT_MM133 & 133 & $0.0675(0.1622)$ & $0.033(0.0303)$ & $0.0659(0.0508)$ & 0.357 \\
\hline p-Cymene $\left(\mathrm{C}_{10} \mathrm{H}_{14}\right)$ & 134 & $0.117(0.323)$ & $0.056(0.075)$ & $0.0509(0.0519)$ & 0.059 \\
\hline $\mathrm{C}_{10} \mathrm{H}_{14}$ non-aromatic (e.g., hexahydronaphthalene) & 134 & $2.39 \mathrm{E}-3(2.19 \mathrm{E}-3)$ & 3.54E-3(5.04E-3) & $4.84 \mathrm{E}-3(3.26 \mathrm{E}-3)$ & - \\
\hline Isobutylbenzene $\left(\mathrm{C}_{10} \mathrm{H}_{14}\right)$ & 134 & $5.06 \mathrm{E}-3(5.18 \mathrm{E}-3)$ & 7.89E-3(9.35E-3) & $7.31 \mathrm{E}-3(5.61 \mathrm{E}-3)$ & $7.55 \mathrm{E}-3$ \\
\hline Methyl-n-Propylbenzene (isomer $1, \mathrm{C}_{10} \mathrm{H}_{14}$ ) & 134 & $4.38 \mathrm{E}-3(3.50 \mathrm{E}-3)$ & 8.70E-3(1.02E-2) & $6.99 \mathrm{E}-3(4.40 \mathrm{E}-3)$ & $2.45 \mathrm{E}-3$ \\
\hline Methyl-n-Propylbenzene (isomer $2, \mathrm{C}_{10} \mathrm{H}_{14}$ ) & 134 & $3.69 \mathrm{E}-3(2.96 \mathrm{E}-3)$ & 7.41E-3(8.61E-3) & $5.39 \mathrm{E}-3(3.45 \mathrm{E}-3)$ & $1.73 \mathrm{E}-3$ \\
\hline n-Butylbenzene $\left(\mathrm{C}_{10} \mathrm{H}_{14}\right)$ & 134 & $6.61 \mathrm{E}-3(6.03 \mathrm{E}-3)$ & 1.19E-2(1.34E-2) & $9.90 \mathrm{E}-3(6.52 \mathrm{E}-3)$ & 0.0131 \\
\hline 1,4-Diethylbenzene $\left(\mathrm{C}_{10} \mathrm{H}_{14}\right)$ & 134 & $1.54 \mathrm{E}-3(2.03 \mathrm{E}-3)$ & $2.72 \mathrm{E}-3(4.86 \mathrm{E}-3)$ & $5.68 \mathrm{E}-3(3.50 \mathrm{E}-3)$ & $1.76 \mathrm{E}-3$ \\
\hline Ethyl Xylene (isomer $1, \mathrm{C}_{10} \mathrm{H}_{14}$ ) & 134 & $6.29 \mathrm{E}-3(6.11 \mathrm{E}-3)$ & 8.76E-3(1.18E-2) & 7.31E-3(4.06E-3) & $2.68 \mathrm{E}-3$ \\
\hline Ethyl Xylene (isomer $2, \mathrm{C}_{10} \mathrm{H}_{14}$ ) & 134 & $4.12 \mathrm{E}-3(4.10 \mathrm{E}-3)$ & 4.77E-3(5.98E-3) & $4.54 \mathrm{E}-3(2.71 \mathrm{E}-3)$ & $1.88 \mathrm{E}-3$ \\
\hline UnknownPIT_MM135 & 135 & $0.0432(0.0663)$ & $0.0395(0.0378)$ & $0.18(0.161)$ & 0.526 \\
\hline Monoterpenes_PTR $\left(\mathrm{C}_{10} \mathrm{H}_{16}\right)$ & 136 & $0.146(0.083)$ & $0.253(0.238)$ & $0.619(0.46)$ & 0.695 \\
\hline
\end{tabular}


Table 2. Continued.

\begin{tabular}{|c|c|c|c|c|c|}
\hline Species & MM & $\begin{array}{r}\text { Semiarid } \\
\text { Shrublands } \\
\text { avg(stdev) }\end{array}$ & $\begin{array}{l}\text { Pine-forest } \\
\text { Understory } \\
\text { avg(stdev) }\end{array}$ & $\begin{array}{r}\text { Coniferous } \\
\text { Canopy } \\
\text { avg(stdev })\end{array}$ & $\begin{array}{r}\text { Organic } \\
\text { Soil }\end{array}$ \\
\hline beta-Pinene $\left(\mathrm{C}_{10} \mathrm{H}_{16}\right)$ & 136 & $0.0133(0.0258)$ & $0.0182(0.0238)$ & $0.053(0.0574)$ & 0.0915 \\
\hline D-Limonene $\left(\mathrm{C}_{10} \mathrm{H}_{16}\right)$ & 136 & $0.0249(0.0227)$ & $0.0665(0.0884)$ & $0.277(0.425)$ & 0.0848 \\
\hline Myrcene $\left(\mathrm{C}_{10} \mathrm{H}_{16}\right)$ & 136 & $0.0102(0.0095)$ & $5.51 \mathrm{E}-3(5.99 \mathrm{E}-3)$ & $0.0437(0.0665)$ & 0.0355 \\
\hline 3-Carene $\left(\mathrm{C}_{10} \mathrm{H}_{16}\right)$ & 136 & $0.0189(0.0403)$ & $0.0179(0.0242)$ & $0.0513(0.0765)$ & 0.0226 \\
\hline gamma-Terpinene $\left(\mathrm{C}_{10} \mathrm{H}_{16}\right)$ & 136 & $5.33 \mathrm{E}-3(2.52 \mathrm{E}-3)$ & $4.81 \mathrm{E}-3(7.48 \mathrm{E}-3)$ & $0.0109(0.0123)$ & $3.93 \mathrm{E}-3$ \\
\hline Terpinolene $\left(\mathrm{C}_{10} \mathrm{H}_{16}\right)$ & 136 & $6.80 \mathrm{E}-3(3.17 \mathrm{E}-3)$ & 7.51E-3(1.06E-2) & $0.0114(0.0158)$ & $6.69 \mathrm{E}-3$ \\
\hline alpha-Pinene $\left(\mathrm{C}_{10} \mathrm{H}_{16}\right)$ & 136 & $0.0163(0.0295)$ & $0.0518(0.0884)$ & $0.272(0.429)$ & 0.0837 \\
\hline Camphene $\left(\mathrm{C}_{10} \mathrm{H}_{16}\right)$ & 136 & $9.46 \mathrm{E}-3(1.53 \mathrm{E}-2)$ & $2.66 \mathrm{E}-2(5.49 \mathrm{E}-2)$ & $0.039(0.0529)$ & 0.0812 \\
\hline iso-Limonene $\left(\mathrm{C}_{10} \mathrm{H}_{16}\right)$ & 136 & $2.87 \mathrm{E}-4(8.60 \mathrm{E}-4)$ & $5.76 \mathrm{E}-3(6.72 \mathrm{E}-3)$ & 7.37E-3(7.69E-3) & $1.80 \mathrm{E}-3$ \\
\hline UnknownPIT_MM137 & 137 & $0.0316(0.0481)$ & $0.0462(0.046)$ & $0.172(0.15)$ & 0.737 \\
\hline UnknownPIT_MM138 & 138 & $0.0789(0.1041)$ & $0.16(0.156)$ & $0.325(0.265)$ & 3.55 \\
\hline UnknownPIT_MM139 & 139 & $0.0257(0.0357)$ & $0.0277(0.0284)$ & $0.0611(0.0499)$ & 0.676 \\
\hline UnknownPIT_MM140 & 140 & $0.0572(0.0842)$ & $0.0749(0.0678)$ & $0.148(0.117)$ & 1.22 \\
\hline 1-Decene $\left(\mathrm{C}_{10} \mathrm{H}_{20}\right)$ & 140 & $0.0125(0.011)$ & $0.0174(0.02)$ & $0.0227(0.0142)$ & 0.0218 \\
\hline UnknownPIT_MM141 & 141 & $0.0252(0.0298)$ & $0.0305(0.0279)$ & $0.0453(0.0301)$ & 0.556 \\
\hline UnknownPIT_MM142 & 142 & $0.108(0.163)$ & $0.115(0.098)$ & $0.254(0.196)$ & 2.25 \\
\hline n-Decane $\left(\mathrm{C}_{10} \mathrm{H}_{22}\right)$ & 142 & $0.0148(0.0207)$ & $0.0131(0.0154)$ & $8.68 \mathrm{E}-3(6.85 \mathrm{E}-3)$ & 0.0265 \\
\hline UnknownPIT_MM143 & 143 & $0.0308(0.0553)$ & $0.0374(0.0328)$ & $0.0629(0.0509)$ & 0.681 \\
\hline UnknownPIT_MM144 & 144 & $0.102(0.25)$ & $0.195(0.209)$ & $0.271(0.231)$ & 3.88 \\
\hline UnknownPIT_MM145 & 145 & $0.0276(0.0513)$ & $0.0294(0.0264)$ & $0.0583(0.0446)$ & 0.550 \\
\hline UnknownPIT_MM146 & 146 & $0.0764(0.1249)$ & $0.0773(0.0673)$ & $0.192(0.149)$ & 1.26 \\
\hline UnknownPIT_MM147 & 147 & $0.024(0.0463)$ & $0.0191(0.018)$ & $0.0528(0.04)$ & 0.378 \\
\hline $\mathrm{C}_{11}$ Aromatics_PTR & 148 & $0.0547(0.0331)$ & $0.0844(0.0722)$ & $0.105(0.07)$ & 0.228 \\
\hline UnknownPIT_MM149 & 149 & $0.0227(0.0436)$ & $0.0232(0.022)$ & $0.0558(0.0389)$ & 0.376 \\
\hline UnknownPIT_MM150 & 150 & $0.0565(0.0795)$ & $0.0894(0.0873)$ & $0.216(0.174)$ & 1.59 \\
\hline UnknownPIT_MM151 & 151 & $0.0215(0.0322)$ & $0.0237(0.0221)$ & $0.0575(0.0406)$ & 0.418 \\
\hline UnknownPIT_MM152 & 152 & $0.0792(0.079)$ & $0.0976(0.0929)$ & $0.274(0.207)$ & 2.29 \\
\hline UnknownPIT_MM153 & 153 & $0.0356(0.0374)$ & $0.0282(0.021)$ & $0.0779(0.0511)$ & 0.574 \\
\hline UnknownPIT_MM154 & 154 & $0.0675(0.0923)$ & $0.0614(0.0496)$ & $0.148(0.1)$ & 1.13 \\
\hline 1-Undecene $\left(\mathrm{C}_{11} \mathrm{H}_{22}\right)$ & 154 & $0.0136(0.0125)$ & $0.0222(0.0301)$ & $0.0203(0.0096)$ & 0.0364 \\
\hline UnknownPIT_MM155 & 155 & $0.0206(0.0335)$ & $0.0151(0.015)$ & $0.0447(0.0285)$ & 0.340 \\
\hline UnknownPIT_MM156 & 156 & $0.0638(0.1101)$ & $0.0589(0.0478)$ & $0.146(0.11)$ & 1.20 \\
\hline n-Undecane $\left(\mathrm{C}_{11} \mathrm{H}_{24}\right)$ & 156 & $0.0189(0.02)$ & $0.0287(0.0353)$ & $0.014(0.0078)$ & 0.0429 \\
\hline UnknownPIT_MM157 & 157 & $0.0183(0.0356)$ & $0.0149(0.0154)$ & $0.0333(0.0215)$ & 0.257 \\
\hline UnknownPIT_MM158 & 158 & $0.0363(0.0641)$ & $0.0428(0.0397)$ & $0.09(0.063)$ & 0.623 \\
\hline UnknownPIT_MM159 & 159 & $0.0139(0.0301)$ & $0.0128(0.0156)$ & $0.0242(0.0149)$ & 0.225 \\
\hline UnknownPIT_MM160 & 160 & $0.0372(0.0788)$ & $0.0392(0.0387)$ & $0.0994(0.0766)$ & 0.846 \\
\hline UnknownPIT_MM161 & 161 & $0.0131(0.0341)$ & $9.18 \mathrm{E}-3(1.27 \mathrm{E}-2)$ & $0.0365(0.0267)$ & 0.326 \\
\hline UnknownPIT_MM162 & 162 & $0.0375(0.0819)$ & $0.0466(0.0399)$ & $0.112(0.088)$ & 1.11 \\
\hline UnknownPIT_MM163 & 163 & 8.51E-3(2.69E-2) & $0.0104(0.0115)$ & $0.0312(0.0208)$ & 0.253 \\
\hline UnknownPIT_MM164 & 164 & $0.0284(0.0485)$ & $0.0423(0.0391)$ & $0.114(0.08)$ & 0.942 \\
\hline UnknownPIT_MM165 & 165 & $0.0112(0.0202)$ & $9.60 \mathrm{E}-3(1.16 \mathrm{E}-2)$ & $0.0299(0.019)$ & 0.240 \\
\hline UnknownPIT_MM166 & 166 & $0.0271(0.0413)$ & $0.0301(0.0301)$ & $0.0917(0.0627)$ & 0.700 \\
\hline UnknownPIT_MM167 & 167 & $0.016(0.0274)$ & $0.0126(0.0096)$ & $0.0354(0.0242)$ & 0.362 \\
\hline UnknownPIT_MM168 & 168 & $0.0504(0.081)$ & $0.0347(0.0286)$ & $0.125(0.071)$ & 0.747 \\
\hline UnknownPIT_MM169 & 169 & $0.0165(0.0313)$ & 8.29E-3(9.87E-3) & $0.0344(0.0198)$ & 0.314 \\
\hline UnknownPIT_MM170 & 170 & $0.0333(0.0791)$ & $0.0306(0.0268)$ & $0.0819(0.0582)$ & 0.624 \\
\hline UnknownPIT_MM171 & 171 & $0.015(0.0326)$ & 7.82E-3(8.37E-3) & $0.0204(0.0139)$ & 0.155 \\
\hline UnknownPIT_MM172 & 172 & $0.0252(0.0495)$ & $0.0358(0.0338)$ & $0.0524(0.0428)$ & 0.396 \\
\hline UnknownPIT_MM173 & 173 & $9.54 \mathrm{E}-3(2.28 \mathrm{E}-2)$ & $5.22 \mathrm{E}-3(7.33 \mathrm{E}-3)$ & $0.0124(0.0112)$ & 0.157 \\
\hline UnknownPIT_MM174 & 174 & $0.0304(0.0711)$ & $0.0296(0.0293)$ & $0.0557(0.0465)$ & 0.527 \\
\hline UnknownPIT_MM175 & 175 & $9.19 \mathrm{E}-3(3.06 \mathrm{E}-2)$ & $7.90 \mathrm{E}-3(9.28 \mathrm{E}-3)$ & $0.0157(0.0109)$ & 0.176 \\
\hline UnknownPIT_MM176 & 176 & $0.0189(0.0526)$ & $0.0194(0.0195)$ & $0.0551(0.0437)$ & 0.501 \\
\hline UnknownPIT_MM177 & 177 & 7.09E-3(2.04E-2) & $4.78 \mathrm{E}-3(7.85 \mathrm{E}-3)$ & $0.0209(0.0122)$ & 0.131 \\
\hline
\end{tabular}


Table 2. Continued.

\begin{tabular}{|c|c|c|c|c|c|}
\hline Species & MM & $\begin{array}{r}\text { Semiarid } \\
\text { Shrublands } \\
\text { avg(stdev })\end{array}$ & $\begin{array}{r}\text { Pine-forest } \\
\text { Understory } \\
\text { avg(stdev) }\end{array}$ & $\begin{array}{r}\text { Coniferous } \\
\text { Canopy } \\
\text { avg(stdev })\end{array}$ & $\begin{array}{r}\text { Organic } \\
\text { Soil }\end{array}$ \\
\hline UnknownPIT_MM178 & 178 & $0.019(0.0466)$ & $0.016(0.015)$ & $0.0681(0.0444)$ & 0.376 \\
\hline UnknownPIT_MM179 & 179 & $8.55 \mathrm{E}-3(3.60 \mathrm{E}-2)$ & $4.52 \mathrm{E}-3(5.58 \mathrm{E}-3)$ & $0.0315(0.0196)$ & 0.104 \\
\hline UnknownPIT_MM180 & 180 & $0.0137(0.0379)$ & $0.0111(0.0137)$ & $0.0435(0.0236)$ & 0.383 \\
\hline UnknownPIT_MM181 & 181 & 8.55E-3(2.37E-2) & $6.13 \mathrm{E}-3(1.10 \mathrm{E}-2)$ & $0.0227(0.011)$ & 0.260 \\
\hline UnknownPIT_MM182 & 182 & $0.0243(0.0475)$ & $0.0167(0.0178)$ & $0.0648(0.0411)$ & 0.531 \\
\hline UnknownPIT_MM183 & 183 & $8.70 \mathrm{E}-3(2.53 \mathrm{E}-2)$ & $5.05 \mathrm{E}-3(4.86 \mathrm{E}-3)$ & $0.015(0.0092)$ & 0.114 \\
\hline UnknownPIT_MM184 & 184 & $0.0142(0.041)$ & $0.0156(0.018)$ & $0.0448(0.0303)$ & 0.327 \\
\hline UnknownPIT_MM185 & 185 & $5.65 \mathrm{E}-3(2.07 \mathrm{E}-2)$ & $3.67 \mathrm{E}-3(6.91 \mathrm{E}-3)$ & $0.0099(0.0115)$ & 0.120 \\
\hline UnknownPIT_MM186 & 186 & $0.0116(0.0383)$ & $0.0119(0.0135)$ & $0.0318(0.0233)$ & 0.345 \\
\hline UnknownPIT_MM187 & 187 & $4.86 \mathrm{E}-3(1.92 \mathrm{E}-2)$ & $2.46 \mathrm{E}-4(5.54 \mathrm{E}-3)$ & $0.0119(0.0103)$ & 0.120 \\
\hline UnknownPIT_MM188 & 188 & $0.0149(0.05)$ & $0.0153(0.0142)$ & $0.0302(0.0323)$ & 0.356 \\
\hline UnknownPIT_MM189 & 189 & $4.85 \mathrm{E}-3(3.19 \mathrm{E}-2)$ & $6.18 \mathrm{E}-3(8.40 \mathrm{E}-3)$ & 7.71E-3(1.13E-2) & 0.203 \\
\hline UnknownPIT_MM190 & 190 & $0.0131(0.053)$ & $0.0154(0.0164)$ & $0.0365(0.0337)$ & 0.334 \\
\hline UnknownPIT_MM191 & 191 & 8.84E-3(3.35E-2) & $4.56 \mathrm{E}-3(9.08 \mathrm{E}-3)$ & $0.0132(0.0104)$ & 0.120 \\
\hline UnknownPIT_MM192 & 192 & $9.50 \mathrm{E}-3(2.86 \mathrm{E}-2)$ & $4.60 \mathrm{E}-3(8.33 \mathrm{E}-3)$ & $0.0238(0.0156)$ & 0.295 \\
\hline UnknownPIT_MM193 & 193 & $2.26 \mathrm{E}-3(1.99 \mathrm{E}-2)$ & 7.74E-4(1.02E-2) & $8.10 \mathrm{E}-3(8.90 \mathrm{E}-3)$ & 0.135 \\
\hline UnknownPIT_MM194 & 194 & $6.19 \mathrm{E}-3(2.61 \mathrm{E}-2)$ & $6.79 \mathrm{E}-3(1.21 \mathrm{E}-2)$ & $0.0191(0.0119)$ & 0.209 \\
\hline UnknownPIT_MM195 & 195 & $6.74 \mathrm{E}-3(1.88 \mathrm{E}-2)$ & 4.81E-3(9.40E-3) & $0.0138(0.009)$ & 0.146 \\
\hline UnknownPIT_MM196 & 196 & $0.0121(0.0333)$ & $9.34 \mathrm{E}-3(1.21 \mathrm{E}-2)$ & $0.0334(0.0262)$ & 0.324 \\
\hline UnknownPIT_MM197 & 197 & $4.49 \mathrm{E}-3(2.13 \mathrm{E}-2)$ & $3.04 \mathrm{E}-3(6.63 \mathrm{E}-3)$ & $9.20 \mathrm{E}-3(1.06 \mathrm{E}-2)$ & 0.183 \\
\hline UnknownPIT_MM198 & 198 & $3.86 \mathrm{E}-3(2.05 \mathrm{E}-2)$ & 7.38E-3(9.91E-3) & $0.0234(0.0214)$ & 0.262 \\
\hline UnknownPIT_MM199 & 199 & $2.08 \mathrm{E}-3(1.79 \mathrm{E}-2)$ & - & $0.0103(0.0051)$ & 0.131 \\
\hline UnknownPIT_MM200 & 200 & $3.29 \mathrm{E}-3(1.84 \mathrm{E}-2)$ & 7.78E-3(1.21E-2) & $0.0216(0.0161)$ & 0.160 \\
\hline UnknownPIT_MM201 & 201 & 4.80E-3(1.99E-2) & $2.22 \mathrm{E}-3(8.58 \mathrm{E}-3)$ & $4.60 \mathrm{E}-3(9.30 \mathrm{E}-3)$ & 0.122 \\
\hline UnknownPIT_MM202 & 202 & 7.55E-3(3.19E-2) & $0.014(0.0189)$ & $0.0186(0.0122)$ & 0.258 \\
\hline UnknownPIT_MM203 & 203 & $3.85 \mathrm{E}-3(3.19 \mathrm{E}-2)$ & $4.53 \mathrm{E}-3(1.46 \mathrm{E}-2)$ & $0.0128(0.0076)$ & 0.138 \\
\hline Sesquiterpenes_PIT $\left(\mathrm{C}_{15} \mathrm{H}_{24}\right)$ & 204 & $0.0167(0.014)$ & $0.0502(0.0758)$ & $0.0448(0.0251)$ & 0.0949 \\
\hline UnknownPIT_MM205 & 205 & $9.44 \mathrm{E}-3(3.70 \mathrm{E}-2)$ & $0.0232(0.0386)$ & $0.0197(0.0189)$ & 0.344 \\
\hline UnknownPIT_MM206 & 206 & $5.45 \mathrm{E}-3(1.81 \mathrm{E}-2)$ & 8.24E-3(1.26E-2) & $0.0118(0.0132)$ & 0.224 \\
\hline UnknownPIT_MM207 & 207 & 7.02E-3(1.68E-2) & $1.52 \mathrm{E}-3(8.22 \mathrm{E}-3)$ & $0.0154(0.0102)$ & 0.121 \\
\hline UnknownPIT_MM208 & 208 & 8.02E-3(1.46E-2) & 4.07E-3(1.05E-2) & $0.0132(0.0163)$ & 0.128 \\
\hline UnknownPIT_MM209 & 209 & $5.26 \mathrm{E}-3(1.94 \mathrm{E}-2)$ & $1.89 \mathrm{E}-3(1.01 \mathrm{E}-2)$ & $0.0117(0.0107)$ & 0.0775 \\
\hline UnknownPIT_MM210 & 210 & 8.78E-3(1.99E-2) & $3.88 \mathrm{E}-3(9.93 \mathrm{E}-3)$ & $0.0174(0.0139)$ & 0.210 \\
\hline UnknownPIT_MM211 & 211 & 8.55E-3(3.06E-2) & $2.00 \mathrm{E}-3(1.12 \mathrm{E}-2)$ & $0.0149(0.0143)$ & 0.234 \\
\hline UnknownPIT_MM212 & 212 & $2.05 \mathrm{E}-3(1.05 \mathrm{E}-2)$ & - & $7.38 \mathrm{E}-3(1.08 \mathrm{E}-2)$ & 0.0942 \\
\hline UnknownPIT_MM213 & 213 & $3.12 \mathrm{E}-4(3.52 \mathrm{E}-3)$ & $7.75 \mathrm{E}-4(3.16 \mathrm{E}-3)$ & $1.34 \mathrm{E}-3(3.82 \mathrm{E}-4)$ & $3.45 \mathrm{E}-3$ \\
\hline $\mathrm{PM}_{2.5}$ & & $7.06(1.5)$ & $13.6(7.5)$ & $7.44(5.83)$ & 20.6 \\
\hline
\end{tabular}

estimate that $\sim 38 \%$ of the mass of total NMOC fall in the intermediate to semi volatile range and that IVOC + SVOC are roughly equal in abundance to initial $\mathrm{PM}_{2.5}$. If we assume OA is $70 \%$ of $\mathrm{PM}_{2.5}$ and a SOA yield of $40 \%$ for the IVOC and SVOC, then OA could increase by $\sim 60 \%$ on short time scales just from the co-emitted IVOC and SVOC alone. This is not unreasonable and a little below the highest level of SOA formation observed to date in real biomass burning plumes (e.g. factor of two in Yokelson et al., 2009). It's not likely that maximum SOA would occur in all plumes (e.g. a small initial decrease in OA was observed by Akagi et al., 2012a) dependent on factors such as dilution rate, temperature, humidity, oxidant levels, etc. Investigating the com- plex factors governing plume evolution is the province of plume evolution measurements and models. Here we simply provide a realistic estimate of the amount of precursors that includes rarely measured species or those that are presently unidentified. We also note that higher precursor/OA ratios are suggested by Table 3 for the coniferous canopy and organic soil fuels which are thought to be relatively more important in wildfires.

Secondary inorganic aerosol (SIA) could be formed primarily from nitrogen containing gases $\left(\mathrm{NH}_{3}\right.$ to ammonium and $\mathrm{NO}_{\mathrm{x}}$ to nitrate) and $\mathrm{SO}_{2}$ (to sulfate). The emissions of these precursor gases are heavily dependent on fuel chemistry with foliage and crop residue having elevated levels. In 
Table 3. Calculation of some lumped categories in $\mathrm{g} \mathrm{kg}^{-1}$ and indicated mass ratios or percentages (see text for category definitions).

\begin{tabular}{|c|c|c|c|c|c|}
\hline Quantity or Ratio & $\begin{array}{r}\text { Semiarid } \\
\text { Shrublands }\end{array}$ & $\begin{array}{r}\text { Pine } \\
\text { Understory }\end{array}$ & $\begin{array}{r}\text { Average } \\
\text { Pine\&Shrub }\end{array}$ & $\begin{array}{r}\text { Coniferous } \\
\text { Canopy }\end{array}$ & $\begin{array}{r}\text { Organic } \\
\text { Soil }\end{array}$ \\
\hline $\mathrm{PM}_{2.5}$ & 7.06 & 13.55 & 10.31 & 7.44 & 20.60 \\
\hline "NO ${ }_{\mathrm{x}}$ as NO" & 2.18 & 2.55 & 2.37 & 2.40 & 0.67 \\
\hline$\Sigma \mathrm{NMOC}$ & 25.24 & 27.64 & 26.44 & 34.45 & 178.89 \\
\hline$\Sigma($ IVOC+SVOC $)$ & 8.71 & 11.26 & 9.99 & 17.10 & 114.78 \\
\hline$\Sigma$ Unidentified NMOC & 7.81 & 8.62 & 8.21 & 16.20 & 129.29 \\
\hline$\Sigma \mathrm{NMOC} \mathrm{PM}_{2.5}$ & 3.58 & 2.04 & 2.81 & 4.63 & 8.68 \\
\hline$\Sigma(\mathrm{IVOC}+\mathrm{SVOC}) / \mathrm{PM}_{2.5}$ & 1.23 & 0.83 & 1.03 & 2.30 & 5.57 \\
\hline$\Sigma(\mathrm{IVOC}+\mathrm{SVOC}) / \Sigma \mathrm{NMOC}$ & 0.35 & 0.41 & 0.38 & 0.50 & 0.64 \\
\hline$\Sigma \mathrm{NMOC}^{\prime} \mathrm{NO}_{\mathrm{x}}$ as NO” & 11.58 & 10.84 & 11.21 & 14.35 & 267.00 \\
\hline Percent NMOC Unidentified & 31 & 31 & 31 & 47 & 72 \\
\hline
\end{tabular}

this study the emission factors of the $\mathrm{NH}_{3}, \mathrm{NO}_{\mathrm{x}}$, and $\mathrm{SO}_{2}$ sum to about $4 \mathrm{~g} \mathrm{~kg}^{-1}$ compared to a generic $\mathrm{EFPM}_{2.5}$ of $\sim 10 \mathrm{~g} \mathrm{~kg}^{-1}$, suggesting that SIA should not be neglected in smoke plume models. Substantial SIA has been measured in the field in biomass burning plumes (Yokelson et al., 2009; Alvarado et al., 2010; Akagi et al., 2012a).

The initial $\mathrm{NMOC} / \mathrm{NO}_{\mathrm{x}}$ mass ratio is $\sim 11$ for the two main fuel types investigated in both the lab and field with much higher values $(\sim 267)$ observed in the lab for smoldering organic soil. Since $\mathrm{NO}_{\mathrm{x}}$ is rapidly converted to PAN and particle nitrate downwind (Yokelson et al., 2009; Alvarado et al., 2010; Akagi et al., 2012a) it is likely that $\mathrm{O}_{3}$ formation would be $\mathrm{NO}_{\mathrm{x}}$-limited over most of the lifetime of smoke plumes in the absence of mixing with additional $\mathrm{NO}_{\mathrm{x}}$ sources (Akagi et al., 2012b). Low $\mathrm{NO}_{\mathrm{x}}$ levels also favor SOA formation when biomass burning smoke is photochemically aged in chamber experiments (e.g. Grieshop et al., 2009).

The prospects for fully mechanistic modeling of smoke plumes and the adequacy of using only known, measured species can be assessed from Table 3 as well. For the two main fuel types $\sim 31 \%$ of the NMOC mass is unidentified and $\sim 72 \%$ of the mass of NMOC is unidentified for the one lab fire in smoldering Alaskan organic soil. In addition, the majority of unidentified NMOC are in our "IVOC+SVOC" category suggesting the need to model SOA with semiempirical approaches for some time to come (Robinson et al., 2007).

Two important examples of how this data set could improve modeling of global biomass burning are described next. (1) Peat combustion is a major global type of biomass combustion especially in El-Niño years (Page et al., 2002; Akagi et al., 2011). In that light, we note that our laboratory smoldering organic soil fire had the largest $\mathrm{PM}_{2.5}$ emissions $\left(20.6 \mathrm{~g} \mathrm{~kg}^{-1}\right)$, the largest EFNMOC $\left(179 \mathrm{~g} \mathrm{~kg}^{-1}\right)$, the largest ratio of $\mathrm{NMOC}$ to $\mathrm{PM}_{2.5}(\sim 8.7)$, and the largest fraction of NMOC in our "IVOC + SVOC" category (0.64). This fuel type may have very high potential for SOA, but it is also the least well characterized. Tables 2 and 3 provide important new emissions data for smoldering organic soils, but also highlight the need for further study of this source. (2) Akagi et al. (2011) estimated global NMOC emissions from biomass burning using only previously available information. Their estimate of total EFNMOC (including unmeasured species) for temperate forests of $23.7 \mathrm{~g} \mathrm{~kg}^{-1}$ (their Table S4) is close to the total EFNMOC measured in this work for the pine-forest understory fires $\left(\sim 27.6 \mathrm{~g} \mathrm{~kg}^{-1}\right)$. Akagi et al. (2011) derived an estimate of total EFNMOC of $97.3 \mathrm{~g} \mathrm{~kg}^{-1}$ for peatland fires, which is actually well below the value of $179 \mathrm{~g} \mathrm{~kg}^{-1}$ measured for smoldering organic soils in this work. The global NMOC estimate of Akagi et al. (2011) was 4-7 times larger than some previous estimates of organic trace gas emissions from fires that ignored oxygenated organic compounds and unidentified species, but it is strongly supported by this work suggesting that global model runs with much larger NMOC emissions per unit mass of biomass burned are needed.

\subsection{Gas-phase hazardous air pollutants present in initial prescribed fire smoke}

The health effects of smoke constituents are an important aspect of understanding the impact of prescribed burning. A number of compounds that were measured in this study appear on the USEPA list of hazardous air pollutants (HAPS) (U.S. EPA, 2005) and many are also on the USFDA list of harmful and potentially harmful constituents of tobacco smoke (HPHC) (U.S. FDA, 2012). The list of compounds identified in this study common to each list is given in Table 4. Isocyanic acid (HNCO) is not on either list, but has been connected to smoke-related health effects through detailed biochemical studies (Wang et al., 2007). A previous publication has noted this connection and pointed out the need for additional research on this compound (Roberts et al., 2011). The exposure to toxic compounds in the initial smoke produced by prescribed fires could be estimated using the EFs in Table 2 of this work. Alternatively, Sharkey et al. (1997) coupled a few literature measurements of emission ratios to $\mathrm{CO}$ for air toxics in smoke with measurements 
of wildland firefighter exposure to $\mathrm{CO}$ to estimate firefighter exposure to those air toxics and then compared that with permissible exposure limits as set by NIOSH or OSHA. Following that approach a more comprehensive assessment of firefighter exposure is now available based on the data we present in Table 2 coupled with measurements of $\mathrm{CO}$ on the perimeter of South Carolina prescribed fires (Akagi et al., 2013). We note however, that comparisons to exposure limits for individual species ignore possible synergistic effects of multiple pollutants acting in concert (Menser and Heggestad, 1966). Further, additional air toxics could be present among the unidentified species and the mix of air toxics evolves rapidly as smoke ages since e.g. 1,3-butadiene has a lifetime of several hours while substantial PAN and $\mathrm{O}_{3}$ can form in smoke plumes on similar time scales (Akagi et al., 2012a; Gregg et al., 2003). A reasonable assessment of smoke health effects would also necessarily include consideration of the health effects of the particles (Pope and Dockery, 2006). Since smoke could affect health via numerous, poorly understood, coupled mechanisms, empirical studies that relate exposure to health outcomes are also valuable for assessing risk (Rappold et al., 2011). In summary, a complete assessment of smoke health effects is clearly beyond the scope of this paper, but the data in Table 2 contributes to such an effort.

\subsection{Particle elemental carbon emission factors and metal profiles}

Extrapolation of laboratory PM measurements to field fires in the natural environment should consider MCE, fuel chemistry, and potential differences in the condensation rates of SVOC (and possibly inorganics) due to the different dilution/cooling environments experienced by emissions in the lab and in a natural setting. In our laboratory burns the average $\mathrm{EC} / \mathrm{TC}(\mathrm{TC}=\mathrm{EC}+\mathrm{OC})$ ratio measured for the semiarid shrubland fuels was much larger than that measured for the pine-forest understory fuels, $0.44 \pm 0.15$ vs. $0.13 \pm 0.11$, and initially seems quite high compared to field studies. For example, the review of Reid et al. (2005) reports EC/TC of 0.04-0.30 for fires in grass/savanna and temperate forest fuels. However, our EC/TC result for these fuels is in agreement with the laboratory study of McMeeking et al. (2009) who measured an EC/TC of 0.53 for chaparral and desert fuels. In our lab burns (Hosseini et al., 2012) and in McMeeking et al. (2009), EF for OC and total $\mathrm{PM}_{2.5}$ were found to be inversely dependent on MCE, while particulate-phase $\mathrm{EF}$ for EC, metals, and other elements showed little correlation. These findings suggest the discord with field observations could stem in part from higher MCE in the lab experiments. Akagi et al. (2012a) made field measurements of aerosol OC and EC or black carbon (BC) from one of the same semiarid shrubland fuel types we sampled in the lab as part of the series of studies synthesized in this paper. Their study measured a fire-average refractory $\mathrm{BC}(\mathrm{rBC})$ to $\mathrm{TC}$ (where
Table 4. The list of compounds identified in this study that are also considered either hazardous air pollutants (EPA) or harmful and potentially harmful constituents in tobacco smoke (FDA).

\begin{tabular}{lrcc}
\hline Compound & $\begin{array}{r}\text { Molecular } \\
\text { Wt. }\end{array}$ & $\begin{array}{c}\text { EPA } \\
\text { HAP }\end{array}$ & $\begin{array}{r}\text { FDA } \\
\text { HPHC }\end{array}$ \\
\hline Ammonia & 17 & No & Yes \\
Hydrogen Cyanide & 27 & Yes & Yes \\
Formaldehyde & 30 & Yes & Yes \\
Methanol & 32 & Yes & No \\
Hydrochloric Acid & 36.5 & Yes & No \\
Acetonitrile & 41 & Yes & No \\
Acetaldehyde & 44 & Yes & Yes \\
Acrylonitrile & 53 & Yes & Yes \\
1,3-Butadiene & 54 & Yes & Yes \\
Acrolein & 56 & Yes & Yes \\
Propionaldehyde & 58 & Yes & Yes \\
Acetone & 58 & No & Yes \\
1,1-Dimethylhydrazine & 60 & Yes & No \\
Furan & 68 & No & Yes \\
Crotonaldehyde & 70 & No & Yes \\
Acrylic Acid & 72 & Yes & No \\
Methyl Ethyl Ketone & 72 & No & Yes \\
Benzene & 78 & Yes & Yes \\
Vinyl Acetate & 86 & Yes & Yes \\
Hexane & 86 & Yes & No \\
Toluene & 92 & Yes & Yes \\
Phenol & 94 & Yes & Yes \\
Methyl Methacrylate & 100 & Yes & No \\
Styrene & 104 & Yes & Yes \\
Xylenes & 106 & Yes & No \\
Ethylbenzene & 106 & Yes & Yes \\
Catechol & 110 & Yes & Yes \\
Naphthalene & 128 & Yes & Yes \\
\hline & & & \\
& & & \\
& 51 & &
\end{tabular}

$\mathrm{TC}$ is taken as $\mathrm{rBC}+\mathrm{OC}$ ) ratio of 0.26 (at $\mathrm{MCE}=0.933$ ) for a prescribed fire in central California chaparral. The two studies quantify the main types of carbonaceous aerosol differently, but it is worth noting that extrapolation of our laboratory EFOC to an MCE of 0.933 (using the lab EFOC versus MCE relationship reported in Hosseini et al., 2012) predicts $\mathrm{EFOC}=4.31 \mathrm{~g} \mathrm{~kg}^{-1}$, which when combined with our mean lab chaparral shrubland EFEC of $1.02 \mathrm{~g} \mathrm{~kg}^{-1}$ (Table S2) provides $\mathrm{EC} / \mathrm{TC}=0.19$, similar to the $\mathrm{rBC} / \mathrm{TC}$ reported by Akagi et al. (2012a).

Emissions of $\mathrm{K}, \mathrm{Cl}$, and $\mathrm{Na}$ varied greatly across sites. Chaparral fuels from Vandenberg Air Force Base (VAFB) and Fort Hunter-Liggett (FHL) had the largest EFK, EFCl, and EFNa and the southeast fuels had the smallest, while $\mathrm{EFCl}$ and EFK for the oak savanna fuels at Fort Huachuca fell in the middle (Table S2). Particulate emissions of inorganic constituents are expected to depend heavily on fuel chemistry (Kabata-Pendias, 2010), and we found that differences in $\mathrm{K}, \mathrm{Cl}$, and $\mathrm{Na}$ emissions can be explained largely by the chemical composition of the fuels (see Hosseini et al., 
2012). Both the location of origin and the vegetation community comprising the fuel beds influenced the chemical composition of fuels and the emissions. Despite being in the same region, $\mathrm{EF}$ for $\mathrm{K}, \mathrm{Cl}, \mathrm{Na}$, and $\mathrm{Br}$ were significantly higher at VAFB compared to FHL. Given that VAFB is on the coast, while FHL is $\sim 10 \mathrm{~km}$ inland, this difference may reflect a strong gradient in sea-salt deposition. These findings suggest that PM source apportionment studies that use these elements as source category tracers (e.g. $\mathrm{K}$ for biomass burning and $\mathrm{K}$ and $\mathrm{Cl}$ for sea-salt) may face additional difficulties in quantifying the contribution of fires to PM pollution in California.

We believe the lab measured EF for EC, metals, and other elements are relevant to prescribed burning at the respective Department of Defense sites. However, the EFOC and EFPM $_{2.5}$ are likely low due mostly to the relatively high MCE of the lab burns (especially for the semiarid shrubland fuels). Therefore, the mass fractions of the emissions composed of EC or metals implied by the lab EF are almost certainly higher than would occur on field fires.

\subsection{Field measurements of fuel consumption on prescribed fires}

Table 5 presents all the available fuel consumption measurements from the prescribed fires in the pine-forest understory during the two North Carolina 2010 field campaigns (at or near Camp Lejeune), the 2009 chaparral fires at Vandenberg Air Force Base, the 2010 oak savanna fire at Fort Huachuca, and the 2011 pine-understory fires at Fort Jackson, SC. (The emissions data for the Fort Jackson fires is presented separately by Akagi et al., 2012b.) Due to last-minute site access, the pre-fire fuel loading measurements at Fort Jackson were incomplete. In addition, at Fort Jackson, the pre- and postfire transects for dead and down woody fuels were not statistically different. The 2010-2011 pine-understory data is supplemented with the fuel consumption measured on two prescribed fires in 1997 at Camp Lejeune, NC where the fuel loads were impacted by hurricane blowdown (Yokelson et al., 1999). In principle, the 2010 and 2011 data can be compared to each other and the 1997 data. However, there are differences in vegetation and the fuel consumption measured on the 2010 burns was during an unusually wet spring, while the measured fuel consumption in the fall 2011 burns was after several months of drought. In the simplest analysis, a generic fuel consumption of $\sim 7.0 \pm 2.3(1 \sigma) \mathrm{Mg} \mathrm{ha}^{-1}$ can be retrieved from this data for modeling pine understory prescribed fires. In similar fashion, a generic fuel consumption of $\sim 7.7 \pm 3.7(1 \sigma) \mathrm{Mg} \mathrm{ha}^{-1}$ can be retrieved from this data for modeling semiarid shrubland prescribed fires. Both of these prescribed fire fuel consumption estimates can be compared to reports of much higher fuel consumption on wildfires (e.g. $\sim 38 \mathrm{Mg} \mathrm{ha}^{-1}$, Campbell et al., 2007; 20 $70 \mathrm{Mg} \mathrm{ha}^{-1}$ (Cofer et al., 1988); 50-100 $\mathrm{Mg} \mathrm{ha}^{-1}$ via RSC alone in Turetsky et al., 2011).

\subsection{Relevance of laboratory fires and context for this work}

It is worthwhile to briefly examine the level of agreement we observed between the lab and field fires in a broader context and to consider the possible impact of the major differences between lab and field fires. To put our comparison results in context, we note that the high level of agreement for smoldering compounds emitted by pine-understory fires applies specifically to this work; in which pine understory fuels were sampled in January 2009, burned in lab fires in February 2009, and then compared to field fires sampled in FebruaryMarch of 2010. In the 2011 field work, carried out under different environmental conditions during the fall prescribed fire season in the southeastern US, significantly higher EF were observed for all NMOC in pine understory fuels (Akagi et al., 2012b). Thus, while we apparently simulated the emissions from the southeastern US spring prescribed fire season reasonably well, the total variability in emissions over the course of a full year is a separate issue discussed elsewhere (Akagi et al., 2012b). In addition, the poor agreement observed for smoldering compounds in semiarid shrubland fuels is for a scenario where the fuels were sampled in January 2009, burned in the lab in February 2009, and compared to field fires sampled in November of 2009. A possible factor in this comparison could be the atmospheric river that impacted our field study sites in California on 13-14 October of 2009 (http://www.usgs.gov/newsroom/article.asp?ID= 2327). Up to $53 \mathrm{~cm}$ per day of rain impacted the region. The abnormal moisture made it difficult for land managers to ignite fires and probably contributed to fuel consumption that was lower than average for prescribed fires in chaparral ecosystems. In Table 5 the average fuel consumption for our November 2009 chaparral fires of $7.7 \pm 3.7 \mathrm{Mg} \mathrm{ha}^{-1}$ is lower than the average fuel consumption measurements we find for chaparral prescribed fires in the literature: $24.5 \mathrm{Mg} \mathrm{ha}^{-1}$ (Hardy et al., 1996), $15 \mathrm{Mg} \mathrm{ha}^{-1}$ (Ottmar et al., 2000). However, we do not know if the weather and low fuel consumption impacted the emissions since the $\mathrm{EF}$ we measured in California in November 2009 actually agreed well with the EF measured on other chaparral fires that had higher fuel consumption (Burling et al., 2011). Thus, the field fires have higher relevance, but the variability in field EF is not wellknown and the impact of environmental changes on emissions is complex and not well understood.

An obvious difference between field and laboratory fires is the ubiquitous presence of wind in the field to assist fire propagation. Spread rates measured in the field are typically $0.2-1.6 \mathrm{~m} \mathrm{~s}^{-1}$ for grass fires (Shea et al., 1996; Stocks et al., 1996), 0.06-0.23 $\mathrm{m} \mathrm{s}^{-1}$ for chamise and mixed chaparral fires (Chandler, 1963), and $0.01-0.05 \mathrm{~m} \mathrm{~s}^{-1}$ for prescribed understory fires (Yokelson et al., 1999). On a one meter fuel bed in the lab, spread rates this high would lead to fires that last only $\sim 0.6-100 \mathrm{~s}$. Further, unpublished early work carried out by one author (RJY) found that generating faster 
Table 5. Prescribed fire fuel consumption measurements from 1997, 2010, and 2011 for southeastern (SE) US and 2009-2010 for southwestern (SW) US.

\begin{tabular}{|c|c|c|c|c|c|c|c|}
\hline Year & $\begin{array}{l}\text { Date } \\
\text { dd-mon }\end{array}$ & Location & $\begin{array}{l}\text { Fuel } \\
\text { Type }\end{array}$ & $\begin{array}{l}\text { Fuel } \\
\text { Moisture } \\
\% \text { (dry weight) }\end{array}$ & $\begin{array}{l}\text { Pre-fire } \\
\text { Total Fuel } \\
\mathrm{Mg} \mathrm{ha}^{-1}\end{array}$ & $\begin{array}{l}\text { Total Fuel } \\
\text { Consumed } \\
\mathrm{Mg} \mathrm{ha}^{-1}\end{array}$ & $\begin{array}{l}\text { Fuel } \\
\text { Consumption } \\
\%\end{array}$ \\
\hline $1997^{\mathrm{a}}$ & 14-Apr & Camp Lejeune & pine-understory & $\mathrm{nm}$ & 9.0 & 5.6 & 62 \\
\hline $1997^{\mathrm{a}}$ & 26-Apr & Camp Lejeune & pine-understory & $\mathrm{nm}$ & 11.0 & $\mathrm{~nm}$ & $\mathrm{~nm}$ \\
\hline $2010^{b}$ & $11-\mathrm{Feb}$ & Camp Lejeune & pine-understory & $\mathrm{nm}$ & 8.47 & .893 & 11 \\
\hline $2010^{b}$ & 1-Mar & Camp Lejeune & pine-understory & $\mathrm{nm}$ & 16.8 & 10.2 & 61 \\
\hline $2011^{\mathrm{c}}$ & 30-Oct & Fort Jackson & pine-understory & $\mathrm{nm}$ & $\mathrm{nm}$ & 8.6 & $\mathrm{~nm}$ \\
\hline $2011^{\mathrm{c}}$ & 1-Nov & Fort Jackson & pine-understory & $\mathrm{nm}$ & 8.5 & 5.7 & 67 \\
\hline \multirow[t]{2}{*}{$2011^{c}$} & 2-Nov & Fort Jackson & pine-understory & $\mathrm{nm}$ & 11.9 & 4.7 & 40 \\
\hline & & & SE US Field Average: & $\mathrm{nm}$ & $11.4(3.3)$ & $6.95(2.32)$ & $48(23)$ \\
\hline $2009^{d}$ & Feb-Mar & $\mathrm{Lab}$ & SE US Lab Average: & $17.6(14.6)$ & $20.9(15.4)$ & $14.9(10.1)$ & $76(17)$ \\
\hline $2009^{b}$ & 11-Nov & Vandenberg & coastal sage scrub & 67 & 12.6 & 7.9 & 63 \\
\hline $2009^{b}$ & 11-Nov & Vandenberg & maritime chaparral & 67 & 15.6 & 11.3 & 72 \\
\hline \multirow[t]{2}{*}{$2010^{b}$} & 29-Mar & Fort Huachuca & oak savanna & $58(12)$ & 8.8 & 3.8 & 43 \\
\hline & & & SW US Field Average: & $64(5)$ & $12.6(3.5)$ & $7.67(3.67)$ & $59(15)$ \\
\hline $2009^{d}$ & Feb-Mar & $\mathrm{Lab}$ & SW US Lab Average: & $14(9.1)$ & $27.5(6.55)$ & $23.0(9.86)$ & $82(26)$ \\
\hline
\end{tabular}

a Additional site and emissions data in Yokelson et al., (1999). ${ }^{\mathrm{b}}$ This work, Camp Lejeune (loblolly pine) and SW as shown with additional details in Burling et al., (2011). ${ }^{\mathrm{c}}$ This work, Fort Jackson (longleaf pine) with emissions data in Akagi et al. (2012b). ${ }^{\mathrm{d}}$ This work, lab data with additional details in Burling et al. (2010).

spread rates with a fan causes much of the smoke to miss the collecting stack and can lead to a more patchy burn with lower MCE, potentially impacting emissions measurements. In the lab fires reported here we initially oriented the fuels in a natural vertical position at loadings consistent with literature values, but only the pine understory fuels burned well in this arrangement. To get greater than approximately ten percent fuel consumption for the semiarid shrubland fuels in the lab (in the absence of wind) it was necessary to stack them horizontally. The fuel moisture was also different between the lab and field. Live fuel moistures were 40-70\% for semiarid shrubland fuels in the field and the lab fuels burned at $18 \pm 15 \%$ and $14 \pm 9.1 \%$ for the pine understory and semiarid shrubland fuels, respectively. The overall fuel consumption in the lab (field) was $15 \pm 10(7.0 \pm 2.3) \mathrm{Mg} \mathrm{ha}^{-1}$ and $23 \pm 10(7.7 \pm 3.7) \mathrm{Mg} \mathrm{ha}^{-1}$ for pine-understory and semiarid shrubland, respectively. Thus, our pine-understory lab fires had a total fuel consumption that was closer to what we observed in the field, but the fuel consumption on our lab semiarid shrubland fires was still close to the literature average for field fires. Another difference between field and lab fires is that the emissions measured on the sampling platform in the lab were sometimes briefly at temperatures as high as $330 \mathrm{~K}$, whereas the coolest plume samples in the field were as low as $280 \mathrm{~K}$. Huffman et al. (2009) found that about $20-25 \%$ of biomass burning organic aerosol could be volatilized by a sustained $50^{\circ} \mathrm{C}$ increase in a thermodenuder. However, aerosol, as noted above, is predominantly a smoldering species and most of the aerosol in the lab fires was measured when the smoke plume was near room tempera- ture. Thus it is unlikely that temperature differences caused significant lab/field differences. After a detailed consideration of the relevant data we conclude that the fuel moisture differences between the lab and field may contribute the most to observed differences, but that the lab data, after normalization for the semiarid shrubland fuels, provide a useful representation of the somewhat variable emissions from field fires.

\section{Conclusions}

We present a detailed retrospective analysis of a series of studies that included measurements of biomass burning trace gas emissions with the most comprehensive selection of instrumentation to date as well as measurements of fine particle emissions, selected particle species (including elemental carbon), and biomass fuel consumption per unit area on prescribed fires. We have confirmed that studying laboratory biomass fires can significantly increase our understanding of wildland fires, especially when laboratory and field results are carefully combined and compared. The analysis presented here provides a set of emission factors (Table 2) for modeling prescribed fire smoke photochemistry and air quality impacts that is greatly expanded beyond what was previously available. The new set of emission factors includes data for hazardous air pollutants (Table 4) and numerous precursors for the formation of ozone and secondary aerosol. New measurements of the mass of fuel consumed per unit area are presented in Table 5 that should be useful for model predictions of the amount of smoke produced by prescribed burns. Profiles of the elemental composition of prescribed fire particulate matter are presented in Table S2 that can be used to 
estimate prescribed fire contribution to ambient $\mathrm{PM}_{2.5}$ (Reff et al., 2009). The results of this series of studies can be applied most confidently to understanding springtime pineunderstory prescribed fires in the southeastern US and to a lesser extent to prescribed fires in semiarid shrublands of the southwestern US. Representing prescribed fire emissions in models with similar confidence for other seasons (Akagi et al., 2012b), other areas (e.g. Alves et al., 2010), or for wildfires will require more work as will understanding the factors driving variability in emissions.

Several important conclusions about biomass burning in general resulted primarily from the full mass scans performed on the lab fire emissions. For instance, the organic carbon initially contained in the gas phase is typically about four times greater than the organic carbon contained in the particle phase. Much of this gas-phase organic carbon has potential to partition to the particles through various secondary organic aerosol formation processes (Robinson et al., 2007). In fact, a few studies have documented the OA evolution in isolated, wildland biomass burning plumes. A small loss of OA was observed in one study (cool-dry plume - Akagi et al., 2012a) while an increase in OA by more than a factor of two was observed in another (warm-wet plume - Yokelson et al., 2009). Less direct field measurements and lab studies also show variable outcomes as discussed elsewhere (de Gouw and Jimenez, 2009; Hennigan et al., 2011; Akagi et al., 2012a) and more work is needed to understand "typical" SOA yields for biomass burning and the forces controlling the variability. Meanwhile this study provides an estimate of the amount of gas-phase organic precursors that includes a more quantitative assessment of the large contribution of unidentified organic trace gases than was previously available. In addition, including the unidentified species in a calculation of the $\mathrm{NO}_{\mathrm{x}} / \mathrm{NMOC}$ ratio; and recognizing the rapid, post-emission conversion of $\mathrm{NO}_{\mathrm{x}}$ to PAN and other species (also documented in these studies) suggests that $\mathrm{O}_{3}$ formation in biomass fire plumes will usually be $\mathrm{NO}_{\mathrm{x}}$-limited. Similarly, OA evolution would normally occur under low- $\mathrm{NO}_{\mathrm{x}}$ conditions.

The studies were primarily focused on quantitative measurement of the NMOC emissions, yet they confirm that up to $\sim 72 \%$ of the NMOCs emitted by some fuel types are unidentified using current technology. The unidentified species are likely to be at least as reactive as the identified species and some provision for their presence should improve photochemical models. However, given the lack of quantitative knowledge of the properties of the unidentified species they can only be recognized in models in qualitative fashion. Thus we have a potentially unsettling clash between a quantitative and qualitative theme, which will persist until instrumental advances eliminate this issue. Meanwhile this work advances our knowledge of identified species so they can be treated more rigorously and it quantifies the relative abundance of unidentified species so they can be represented in models at realistic levels. Some smoke pho- tochemistry models have already incorporated unidentified species in a fashion that is roughly consistent with our measurements of their relative abundance including Trentmann et al. (2005) and Alvarado and Prinn (2009). Both those studies noted improved model simulations of formation of ozone or organic aerosol when provision for the unidentified species was added. Ongoing efforts to better characterize the chemistry and oxidation products of the species that were identified in this work (Gilman et al., 2013) should improve models and also allow us to make a more-informed estimate of the properties of the remaining unidentified species. Identifying a greater fraction of the NMOC and better estimates of the properties of those species that remain unidentified can be addressed via new analytical techniques as they become available. For example, high resolution mass spectrometry could advance the elemental analysis of the organic trace gases and examine the effects of oxidation, temperature, and humidity on full mass scans.

\section{Supplementary material related to this article is available online at: http://www.atmos-chem-phys.net/13/ 89/2013/acp-13-89-2013-supplement.zip.}

Acknowledgements. This work was supported by the Strategic Environmental Research and Development Program (SERDP) projects RC-1648 and RC-1649 and administered partly through Forest Service Research Joint Venture Agreement 08JV11272166039, and we thank the sponsors for their support. J. Gilman, W. Kuster, P. Veres, J. M. Roberts, C. Warneke, and J. de Gouw were supported in part by National Science Foundation (NSF) Grant No. ATM 1542457, the CIRES Innovative Research Program, and NOAA's Health of the Atmosphere and Climate Goals Programs. We appreciate the efforts of Joey Chong, Bonni Corcoran, Amy Olson, Violet Holley, Signe Leirfallom, Anna Lahde, Jehn Rawling, Greg Cohen, and Emily Lincoln to sample/harvest the wildland fuels and/or assemble the laboratory fuel beds for this study. Adaptation of the USFS Twin Otter for research flights was supported primarily by NSF Grant No. ATM 0513055. R. Y., S. A., and multiple instruments aboard the Twin Otter were also supported by NSF Grant No. ATM 0936321. Shawn Urbanski was supported partially by Joint Fire Science Program grant 08-1-6-09. Special thanks to our pilots Scott Miller and Aaron Knobloch and Twin Otter mechanic Kevin Bailey. The cooperation of Dan Ardoin and personnel at Vandenberg AFB, Jeff Minetti and personnel at Ft. Hunter-Liggett, Andrew Leiendecker and personnel at Ft. Huachuca, John Maitland and personnel at Fort Jackson, and Danny Becker, Susan Cohen, and Wayne Gray at Camp Lejeune is greatly appreciated. We greatly appreciate other collaborators and support on the ground including: Gary Curcio (North Carolina Division of Forest Resources), Phillip Inman and Miller Casion (NC county rangers), Andrew Robillard (San Luis Jet Center), Jason McCarty (SBCFD), Brendan Ripley (VCFD), Angie Carl (The Nature Conservancy), and additional fuels characterization assistance from Gloria Burke, Ania Wrona, and Jesse Lozano.

Edited by: J. N. Crowley 


\section{References}

Abel, S. J., Haywood, J. M., Highwood, E. J., Li, J., and Buseck, P. R.: Evolution of biomass burning aerosol properties from an agricultural fire in southern Africa, Geophys. Res. Lett., 30, 1783, doi:10.1029/2003GL017342, 2003.

Akagi, S. K., Yokelson, R. J., Wiedinmyer, C., Alvarado, M. J., Reid, J. S., Karl, T., Crounse, J. D., and Wennberg, P. O.: Emission factors for open and domestic biomass burning for use in atmospheric models, Atmos. Chem. Phys., 11, 4039-4072, doi:10.5194/acp-11-4039-2011, 2011.

Akagi, S. K., Craven, J. S., Taylor, J. W., McMeeking, G. R., Yokelson, R. J., Burling, I. R., Urbanski, S. P., Wold, C. E., Seinfeld, J. H., Coe, H., Alvarado, M. J., and Weise, D. R.: Evolution of trace gases and particles emitted by a chaparral fire in California, Atmos. Chem. Phys., 12, 1397-1421, doi:10.5194/acp-12-13972012, 2012a.

Akagi, S. K., Yokelson, R. J., Burling, I. R., Meinardi, S., Simpson, I., Blake, D. R., McMeeking, G. R., Sullivan, A., Lee, T., Kreidenweis, S., Urbanski, S., Reardon, J., Griffith, D. W. T., Johnson, T. J., and Weise, D. R.: Measurements of reactive trace gases and variable $\mathrm{O}_{3}$ formation rates in some South Carolina biomass burning plumes, Atmos. Chem. Phys. Discuss., 12, 25255-25328, doi:10.5194/acpd-12-25255-2012, 2012b.

Akagi, S. K., Burling, I. R., Johnson, T. J., Cameron, M., Griffith, D. W. T., Mendoza, A., Weise, D. R., Reardon, J., Maitland, J., and Yokelson, R. J.: Field measurements of trace gases emitted by prescribed fires in southeastern US pine forests using an openpath FTIR system, Atmos. Chem. Phys. Discuss., in preparation, 2013.

Alvarado, M. J. and Prinn, R. G.: Formation of ozone and growth of aerosols in young smoke plumes from biomass burning: 1. Lagrangian parcel studies, J. Geophys. Res., 114, D09306, doi:10.1029/2008JD011144, 2009.

Alvarado, M. J., Logan, J. A., Mao, J., Apel, E., Riemer, D., Blake, D., Cohen, R. C., Min, K.-E., Perring, A. E., Browne, E. C., Wooldridge, P. J., Diskin, G. S., Sachse, G. W., Fuelberg, H., Sessions, W. R., Harrigan, D. L., Huey, G., Liao, J., Case-Hanks, A., Jimenez, J. L., Cubison, M. J., Vay, S. A., Weinheimer, A. J., Knapp, D. J., Montzka, D. D., Flocke, F. M., Pollack, I. B., Wennberg, P. O., Kurten, A., Crounse, J., Clair, J. M. St., Wisthaler, A., Mikoviny, T., Yantosca, R. M., Carouge, C. C., and Le Sager, P.: Nitrogen oxides and PAN in plumes from boreal fires during ARCTAS-B and their impact on ozone: an integrated analysis of aircraft and satellite observations, Atmos. Chem. Phys., 10, 9739-9760, doi:10.5194/acp-10-9739-2010, 2010.

Alves, C. A., Gonçalves, C., Pio, C. A., Mirante, F., Caseiro, A., Tarelho, L., Freitas, M. C., and Viegas, D. X.: Smoke emissions from biomass burning in a Mediterranean shrubland, Atmos. Environ., 44, 3024-3033, 2010.

Andreae, M. O., Anderson, B. E., Blake, D. R., Bradshaw, J. D., Collins, J. E., Gregory, G. L., Sachse, G. W., and Shipham, M. C.: Influence of plumes from biomass burning on atmospheric chemistry over the equatorial and tropical South Atlantic during CITE 3, J. Geophys Res., 99, 12793-12808, doi:10.1029/94JD00263, 1994.

Bertschi, I. T., Yokelson, R. J., Ward, D. E., Babbitt, R. E., Susott, R. A., Goode, J. G., and Hao, W. M.: Trace gas and particle emissions from fires in large diameter and belowground biomass fuels, J. Geophys. Res., 108, 8472, doi:10.1029/2002JD002100,
2003.

Biswell, H.: Prescribed Burning in California Wildlands Vegetation Management, University of California Press, Berkeley, CA, 1989.

Bond, T. C., Streets, D. G., Yarber, K. F., Nelson, S. M., Woo, J.-H., and Klimont, Z.: A technology-based global inventory of black and organic carbon emissions from combustion, J. Geophys. Res., 109, D14203, doi:10.1029/2003JD003697, 2004.

Bradshaw, L. S., Deeming, J. E., Burgan, R. E., and Cohen, J. D.: The 1978 National Fire-Danger Rating System: Technical Documentation, Gen. Tech. Rep., USDA Forest Service, Ogden, UT, 1984.

Brown, J. K.: Handbook for inventorying down woody material, General Technical Report INT-16, U.S. Department of Agriculture, Forest Service Intermountain Forest and Range Experiment Station, Ogden, UT, 23 pp. 1974.

Burling, I. R., Yokelson, R. J., Griffith, D. W. T., Johnson, T. J., Veres, P., Roberts, J. M., Warneke, C., Urbanski, S. P., Reardon, J., Weise, D. R., Hao, W. M., and de Gouw, J.: Laboratory measurements of trace gas emissions from biomass burning of fuel types from the southeastern and southwestern United States, Atmos. Chem. Phys., 10, 11115-11130, doi:10.5194/acp10-11115-2010, 2010.

Burling, I. R., Yokelson, R. J., Akagi, S. K., Urbanski, S. P., Wold, C. E., Griffith, D. W. T., Johnson, T. J., Reardon, J., and Weise, D. R.: Airborne and ground-based measurements of the trace gases and particles emitted by prescribed fires in the United States, Atmos. Chem. Phys., 11, 12197-12216, doi:10.5194/acp11-12197-2011, 2011.

Campbell, J., Donato, D., Azuma, D., and Law, B.: Pyrogenic carbon emissions from a large wildfire in Oregon, United States, J. Geophys. Res., 112, 04014, doi:10.1029/2007JG000451, 2007.

Carter, M. C. and Foster, C. D.: Prescribed burning and productivity in southern pine forests: a review, Forest Ecol. Manag., 191, 185197, doi:10.1016/j.foreco.2003.11.006, 2004.

Chandler, C. C., Storey, T. G., and Tangren, C. D.: Prediction of fire spread following nuclear explosions, USDA Forest Service Research Paper PSW-RP-5, Pacific Southwest Forest and Range Experiment Station, Berkeley, CA, http://www.treesearch.fs.fed. us/pubs/28743 (last access: June 2012), 1963.

Chang-Graham, A. L., Profeta, L. T. M., Johnson, T. J., Yokelson, R. J., Laskin, A., and Laskin, J.: A case study of water soluble metal containing organic constituents of biomass burning aerosol, Environ. Sci. Technol., 45, 1257-1263, doi:10.1021/es103010j, 2011.

Christian, T., Kleiss, B., Yokelson, R. J., Holzinger, R., Crutzen, P. J., Hao, W. M., Saharjo, B. H., and Ward, D. E.: Comprehensive laboratory measurements of biomass-burning emissions: 1 . Emissions from Indonesian, African, and other fuels, J. Geophys. Res., 108, 4719, doi:10.1029/2003JD003704, 2003.

Christian, T. J., Kleiss, B., Yokelson, R. J., Holzinger, R., Crutzen, P. J., Hao, W. M., Shirai, T., and Blake, D. R.: Comprehensive laboratory measurements of biomass-burning emissions: 2, First intercomparison of open path FTIR, PTR-MS, GC-MS/FID/ECD, J. Geophys. Res., 109, D02311, doi:10.1029/2003JD003874, 2004.

Christian, T. J., Yokelson, R. J., Cárdenas, B., Molina, L. T., Engling, G., and Hsu, S.-C.: Trace gas and particle emissions from domestic and industrial biofuel use and garbage burning in cen- 
tral Mexico, Atmos. Chem. Phys., 10, 565-584, doi:10.5194/acp10-565-2010, 2010.

Cochrane, M. A., Moran, C. J., Wimberly, M. C., Baer, A. D., Finney, M. A., Beckendorf, K. L., Eidenshink, J., and Zhu, Z.: Estimation of wildfire size and risk changes due to fuels treatments, Int. J. Wildland Fire, published online 9 March 2012.

Cofer III., W. R., Levine, J. S., Riggan, P. J., Sebacher, D. I., Winstead, E. L., Shaw, Jr., E. F., Brass, J. A., and Ambrosia, V. G.: Trace gas emissions from a mid-latitude prescribe chaparral fire, J. Geophys. Res., 93, 1653-1658, 1988.

Crutzen, P. J. and Andreae, M. O.: Biomass burning in the tropics: Impact on atmospheric chemistry and biogeochemical cycles, Science, 250, 1669-1678, 1990.

Deeming, J. E., Burgan, R. E., and Cohen, J. D.: The 1978 National Fire-Danger Rating System, Gen. Tech. Rep. INT-39, USDA Forest Service, Ogden, UT, 1978.

de Gouw, J. and Jimenez, J. L.: Organic aerosols in the Earth's atmosphere, Environ. Sci. Technol., 43, 7614-7618, 2009.

EPA: Compendium of Methods for the Determination of Inorganic Compounds in Ambient Air, US Environmental Protection Agency, Cincinnati, OH, EPA/625/R-96/010a, Chapter IO-5, 1999.

Finlayson-Pitts, B. J. and Pitts Jr., J. N.: Chemistry of the Upper and Lower Atmosphere, Academic Press, San Diego, USA, 2000.

Fishman, J., Fakhruzzaman, K., Cros, B., and Nganga, D.: Identification of widespread pollution in the Southern Hemisphere deduced from satellite analyses, Science, 252, 1693-1696, 1991.

Gilman, J. B., Kuster, W. C., Goldan, P. D., Veres, P., Roberts, J. M., Warneke, C., de Gouw, J. A., Burling, I. R., and Yokelson, R. J.: Characterization of volatile organic compounds (VOCs) and other trace gases measured in controlled laboratory biomass burns of fuel types common to the United States, in preparation, 2013.

Goode, J. G., Yokelson, R. J., Ward, D. E., Susott, R. A., Babbitt, R. E., Davies, M. A., and Hao, W. M.: Measurements of excess $\mathrm{O}_{3}, \mathrm{CO}_{2}, \mathrm{CO}, \mathrm{CH}_{4}, \mathrm{C}_{2} \mathrm{H}_{4}, \mathrm{C}_{2} \mathrm{H}_{2}, \mathrm{HCN}, \mathrm{NO}, \mathrm{NH}_{3}$, $\mathrm{HCOOH}, \mathrm{CH}_{3} \mathrm{COOH}, \mathrm{HCHO}$, and $\mathrm{CH}_{3} \mathrm{OH}$ in 1997 Alaskan biomass burning plumes by airborne Fourier transform infrared spectroscopy (AFTIR), J. Geophys. Res., 105, 22147-22166, doi:10.1029/2000JD900287, 2000.

Greene, D. F., Macdonald, S. E., Hauessler, S., Domenicano, S., Noel, J., Jayen, K., Charron, I., Guathier, S., Hunt, S., Gielau, E. T., Bergeron, Y., and Swift, L.: The reduction of organic-layer depth by wildfire in the North American boreal forest and its effect on tree recruitment by seed, Can. J. For. Res., 37, 10121023, 2007

Gregg, J. W., Jones, C. G., and Dawson, T. E.: Urbanization effects on tree growth in the vicinity of New York City, Nature, 424, 183-187 doi:10.1038/nature01728, 2003.

Grieshop, A. P., Logue, J. M., Donahue, N. M., and Robinson, A. L.: Laboratory investigation of photochemical oxidation of organic aerosol from wood fires 1: measurement and simulation of organic aerosol evolution, Atmos. Chem. Phys., 9, 1263-1277, doi:10.5194/acp-9-1263-2009, 2009.

Guenther, A., Karl, T., Harley, P., Wiedinmyer, C., Palmer, P. I., and Geron, C.: Estimates of global terrestrial isoprene emissions using MEGAN (Model of Emissions of Gases and Aerosols from Nature), Atmos. Chem. Phys., 6, 3181-3210, doi:10.5194/acp-63181-2006, 2006.
Hardy, C. C., Conard, S. G., Regelbrugge, J. C., and Teesdale, D. R.: Smoke emissions from prescribed burning of southern California chaparral, Res. Pap. PNW-RP-486, U.S. Department of Agriculture, Forest Service, Pacific Northwest Research Station, Portland, OR., 37, 1996.

Hardy, C. C., Ottmar, R. D., Peterson, J. L., Core, J. E., and Seamon, P.: Smoke management guide for prescribed and wildland fire: 2001 edition, available at: http://www.treesearch.fs.fed.us/ pubs/5388 (last access: 4 August 2011), National Wildfire Coordination Group, Boise, ID, 2001.

Hennigan, C. J., Miracolo, M. A., Engelhart, G. J., May, A. A., Presto, A. A., Lee, T., Sullivan, A. P., McMeeking, G. R., Coe, H., Wold, C. E., Hao, W.-M., Gilman, J. B., Kuster, W. C., de Gouw, J., Schichtel, B. A., J. L. Collett Jr., Kreidenweis, S. M., and Robinson, A. L.: Chemical and physical transformations of organic aerosol from the photo-oxidation of open biomass burning emissions in an environmental chamber, Atmos. Chem. Phys., 11, 7669-7686, doi:10.5194/acp-11-7669-2011, 2011.

Heringa, M. F., DeCarlo, P. F., Chirico, R., Tritscher, T., Dommen, J., Weingartner, E., Richter, R., Wehrle, G., Prévôt, A. S. H., and Baltensperger, U.: Investigations of primary and secondary particulate matter of different wood combustion appliances with a high-resolution time-of-flight aerosol mass spectrometer, Atmos. Chem. Phys., 11, 5945-5957, doi:10.5194/acp-11-59452011, 2011.

Hobbs, P. V., Sinha, P., Yokelson, R. J., Christian, T. J., Blake, D. R., Gao, S., Kirchstetter, T. W., Novakov, T., and Pilewskie, P.: Evolution of gases and particles from a savanna fire in South Africa, J. Geophys. Res., 108, 8485, doi:10.1029/2002JD002352, 2003.

Hosseini, S., Li, Q., Cocker, D., Weise, D., Miller, A., Shrivastava, M., Miller, J. W., Mahalingam, S., Princevac, M., and Jung, H.: Particle size distributions from laboratory-scale biomass fires using fast response instruments, Atmos. Chem. Phys., 10, 80658076, doi:10.5194/acp-10-8065-2010, 2010.

Hosseini, S., Urbanski, S., Dixit, P., Li, Q., Burling, I., Yokelson, R., Johnson, T., Shrivastava, M. K., Jung, H., Weise, D., Miller, W., and Cocker III, D.: Laboratory characterization of PM emissions from combustion of wildland biomass fuels, J. Geophys. Res., submitted, 2012.

Hoy, J. and Isern, T.: Bluestem and tussock fire and pastoralism in the Flint Hills of Kansas and the tussock grasslands of New Zealand, Great Plains Q., 15, 169-184, 1995.

Huffman, J. A., Docherty, K. S., Aiken, A. C., Cubison, M. J., Ulbrich, I. M., DeCarlo, P. F., Sueper, D., Jayne, J. T., Worsnop, D. R., Ziemann, P. J., and Jimenez, J. L.: Chemically-resolved aerosol volatility measurements from two megacity field studies, Atmos. Chem. Phys., 9, 7161-7182, doi:10.5194/acp-9-71612009, 2009.

Hyde, J. C., Smith, A. M. S., Ottmar, R. D., Alvarado, E. C., and Morgan, P.: The combustion of sound and rotten coarse woody debris: a review, Int. J. Wildland Fire, 20, 163-174, 2011.

Johnson, T. J., Disselkamp, R. S., Su, Y.-F., Fellows, R. J., Alexander, M. L., and Driver, C. L.: Gas-phase hydrolysis of SOCl2: Implications for its atmospheric fate, J. Phys. Chem. A, 107, 61836190, 2003.

Jordan, C. F.: Nutrient Cycling in Tropical Forest Ecosystems, John Wiley, New York, 1985.

Kabata-Pendias, A.: Trace Elements in Soils and Plants, 4th ed., CRC Press, Boca Raton, FL, USA, 548 pp., 2010. 
Karl, T. G., Christian, T. J., Yokelson, R. J., Artaxo, P., Hao, W. M., and Guenther, A.: The Tropical Forest and Fire Emissions Experiment: method evaluation of volatile organic compound emissions measured by PTR-MS, FTIR, and GC from tropical biomass burning, Atmos. Chem. Phys., 7, 5883-5897, doi:10.5194/acp-7-5883-2007, 2007.

Keeley, J. E., Aplet, G. H., Christensen, N. L., Conard, S. G., Johnson, E. A., Omi, P. N., Peterson, D. L., and Swetnam, T. W.: Ecological foundations for fire management in North American forest and shrubland ecosystems, Gen. Tech. Rep., U.S. Department of Agriculture, Forest Service, Pacific Northwest Research Station, Portland, OR, available at: http://www.treesearch.fs.fed. us/pubs/32483 (last access: 16 August 2012), 2009.

Lutes, D. C., Keane, R. E., Carratti, J. F, Key, C. H, Benson, N. C, Sutherland, S., and Ganji, L. J.: FIREMON: Fire Effects monitoring and inventory system, General Technical Report: RMRS GTR-164-CD, U.S. Department of Agriculture, Forest Service, Rocky Mountain Research Station, Fort Collins CO, compact disk, 2006.

McMeeking, G. R., Kreidenweis, S. M., Lunden, M., Carrillo, J., Carrico, C. M., Lee, T., Herckes, P., Engling, G., Day, D. E., Hand, J., Brown, N., Malm, W. C., and Collett Jr., J. L.: Smokeimpacted regional haze in California during the summer of 2002, Agr. Forest Meteorol., 137, 25-42, 2006.

McMeeking, G. R., Kreidenweis, S. M., Baker, S., Carrico, C. M., Chow, J. C., Collet Jr., J. L., Hao, W. M., Holden, A. S., Kirchstetter, T. W., Malm, W. C., Moosmüller, H., Sullivan, A. P., and Wold, C. E.: Emissions of trace gases and aerosols during the open combustion of biomass in the laboratory, J. Geophys. Res., 114, D19210, doi:10.1029/2009JD011836, 2009.

Menser, H. A. and Heggestad, H. E.: Ozone and sulfur dioxide synergism: Injury to tobacco plants, Science, 153, 424-425, doi:10.1126/science.153.3734.424, 1966.

Ottmar, R. D., Vihnanek, R. E., and Regelbrugge, J. C.: Stereo photo series for quantifying natural fuels, Volume IV: pinyonjuniper, sagebrush, and chaparral types in the Southwestern United States, National Wildfire Coordinating Group, National Interagency Fire Center, Boise, ID., 97, 2000.

Page, S. E., Siegert, F., Rieley, J. O., Boehm, H. D. V., Jaya, A., and Limin, S.: The amount of carbon released from peat and forest fires in Indonesia during 1997, Nature, 420, 61-65, 2002.

Park, R. J., Jacob, D. J., and Logan, J. A.: Fire and biofuel contributions to annual mean aerosol concentrations in the United States, Atmos. Environ., 41, 7389-7400, 2007.

Pfister, G. G., Emmons, L. K., Hess, P. G., Honrath, R., Lamarque, J.-F., Val Martin, M., Owen, R. C., Avery, M. A., Browell, E. V., Holloway, J. S., Nedelec, P., Purvis, R., Ryerson, T. B., Sachse, G. W., and Schlager, H.: Ozone production from the 2004 North American boreal fires, J. Geophys. Res., 111, D24S07, doi:10.1029/2006JD007695, 2006.

Pope, C. A. III, and Dockery, D. W.: Health effects of fine particulate air pollution: lines that connect, J. Air Waste Manag. Assoc., 56, 709-742, 2006.

Qi, L., Hosseini, S., Jung, H., Weise, D., Miller, W., Cocker, D., and Huang, H.: Chemical characterization of particle emissions from controlled burns of biomass fuels using a high resolution timeof-flight aerosol mass spectrometer, Atmos. Environ., in preparation, 2013.
Rappold, A. G., Stone, S. L., Cascio, W. E., Neas, L. M., Kilaru, V. J., Carraway, M. S., Szykman, J. J., Ising, A., Cleve, W. E., Meredith, J. T., Vaughan-Batten, H., Deyneka, L., and Devlin. R. B.: Peat bog wildfire smoke exposure in rural North Carolina is associated with cardiopulmonary emergency department visits assessed through syndromic surveillance, Environ. Health Perspect., 119, 1415-1420, 2011.

Reff, A., Bhave, P. V., Simon, H., Pace, T. G., Pouliot, G. A., Mobley, D., and Houyoux, M.: Emissions inventory of $\mathrm{PM}_{2.5}$ trace elements across the United States, Environ. Sci. Technol., 43, 5790-5796, 2009.

Reid, J. S., Hobbs, P. V., Ferek, R. J., Martins, J. V., Blake, D. R., Dunlap, M. R., and Liousse, C.: Physical, chemical, and radiative characteristics of the smoke dominated regional hazes over Brazil, J. Geophys. Res., 103, 32059-32080, 1998.

Reid, J. S., Koppmann, R., Eck, T. F., and Eleuterio, D. P.: A review of biomass burning emissions part II: intensive physical properties of biomass burning particles, Atmos. Chem. Phys., 5, 799825, doi:10.5194/acp-5-799-2005, 2005.

Roberts, J. M., Veres, P., Warneke, C., Neuman, J. A., Washenfelder, R. A., Brown, S. S., Baasandorj, M., Burkholder, J. B., Burling, I. R., Johnson, T. J., Yokelson, R. J., and de Gouw, J.: Measurement of HONO, HNCO, and other inorganic acids by negative-ion proton-transfer chemical-ionization mass spectrometry (NI-PT-CIMS): application to biomass burning emissions, Atmos. Meas. Tech., 3, 981-990, doi:10.5194/amt-3-981-2010, 2010.

Roberts, J. M., Veres, P. R., Cochran, A. K., Warneke, C., Burling, I. R., Yokelson, R. J., Lerner, B., Holloway, J. S., Fall, R., and de Gouw, J.: Isocyanic acid in the atmosphere: Sources, concentrations and sinks, and potential health effects, P. Natl. Acad. Sci., 108, 8966-8971, doi:10.1073/pnas.1103352108, 2011.

Robinson, A. L., Donahue, N. M., Shrivastava, M. K., Weitkamp, E. A., Sage, A. M., Grieshop, A. P., Lane, T. E., Pierce, J. R., and Pandis, S. N.: Rethinking organic aerosols: Semivolatile emissions and photochemical aging, Science, 315, 1259-1262, 2007.

Sawa, Y., Matsueda, H., Tsutsumi, Y., Jensen, J. B., Inoue, H. Y., and Makino, Y.: Tropospheric carbon monoxide and hydrogen measurements over Kalimantan in Indonesia and northern Australia during October, 1997, Geophys. Res. Lett., 26, 1389-1392, doi:10.1029/1999GL900247, 1999.

Schmid, B., Redemann, J., Russell, P. B., Hobbs, P. V., Hlavka, D. L., McGill, M. J., Holben, B. N., Welton, E. J., Campbell, J. R., Torres, O., Kahn, R. A., Diner, D. J., Helmlinger, M. C., Chu, D. A., Robles-Gonzalez, C., and de Leeuw, G.: Coordinated airborne, spaceborne, and ground-based measurements of massive thick aerosol layers during the dry season in southern Africa, J. Geophys. Res., 108, 8496, doi:10.1029/2002JD002297, 2003.

Sharkey, B. (Ed.): Health hazards of smoke: Recommendations of the April 1997 consensus conference, Tech. Rep. 9751-2836MTDC, USDA, Forest Service, Missoula, Technology and Development Center, 84 pp., Missoula, MT, 1997.

Sharpe, S. W., Johnson, T. J., Sams, R. L., Chu, P. M., Rhoderick, G. C., and Johnson, P. A.: Gas-phase databases for quantitative infrared spectroscopy, Appl. Spectroscopy., 58, 1452-1461, 2004.

Shea, R. W., Shea, B. W., Kauffman, J. B., Ward, D. E., Haskins, C. I., and Scholes, M. C.: Fuel biomass and combustion factors associated with fires in savanna ecosystems of South Africa and Zambia, J. Geophys Res., 101, 23551-23568, 1996. 
Steinhart, J. S. and Steinhart, C. E.: Energy use in the U.S. food system, Science, 184, 307-316, 1974.

Stocks, B. J., van Wilgen, B. W., Trollope, W. S. W., McRae, D. J., Mason, J. A., Weirich, F., and Potgieter, A. L. F.: Fuels and fire behavior dynamics on large-scale savanna fires in Kruger National Park, South Africa, J. Geophys. Res., 101, 23541-23550, doi:10.1029/95JD01734, 1996.

Sudo, K. and Akimoto, H.: Global source attribution of tropospheric ozone: Long-range transport from various source regions, J. Geophys. Res., 112 D12302, doi:10.1029/2006JD007992, 2007.

Thompson, S. K.: Sampling, 2nd ed., John Wiley, New York, 2002.

Trentmann, J., Yokelson, R. J., Hobbs, P. V., Winterrath, T., Christian, T. J., Andreae, M. O., and Mason, S. A.: An analysis of the chemical processes in the smoke plume from a savanna fire, J. Geophys. Res., 110, D12301, doi:10.1029/2004JD005628, 2005.

Turetsky, M. R., Kane, E. S., Harden, J. W., Ottmar, R. D., Manies, K. L., Hoy E., and Kasischke, E. S.: Recent acceleration of biomass burning and carbon losses in Alaskan forests and peatlands, Nature Geosci., 4, 27-31, doi:10.1038/ngeo1027, 2011.

U.S. EPA: The Clean Air Act Amendments of 1990 List of Hazardous Air Pollutants, available at: http://www.epa.gov/ttn/atw/ orig189.html (last access: 16 August 2012), modified, 2005.

U.S. FDA: Harmful and Potentially Harmful Constituents in Tobacco Products and Tobacco Smoke: Established List, http://www.fda.gov/TobaccoProducts/ GuidanceComplianceRegulatoryInformation/ucm297786.htm (16 August 2012), 2012.

van der Werf, G. R., Randerson, J. T., Giglio, L., Collatz, G. J., Mu, M., Kasibhatla, P. S., Morton, D. C., DeFries, R. S., Jin, Y., and van Leeuwen, T. T.: Global fire emissions and the contribution of deforestation, savanna, forest, agricultural, and peat fires (19972009), Atmos. Chem. Phys., 10, 11707-11735, doi:10.5194/acp10-11707-2010, 2010.

Veres, P., Roberts, J. M., Burling, I. R., Warneke, C., de Gouw, J., and Yokelson, R. J.: Measurements of gas-phase inorganic and organic acids from biomass fires by negative-ion proton-transfer chemical-ionization mass spectrometry, J. Geophys. Res., 115, D23302, doi:10.1029/2010JD014033, 2010a.

Veres, P., Gilman, J. B., Roberts, J. M., Kuster, W. C., Warneke, C., Burling, I. R., and de Gouw, J.: Development and validation of a portable gas phase standard generation and calibration system for volatile organic compounds, Atmos. Meas. Tech., 3, 683-691, doi:10.5194/amt-3-683-2010, 2010b.

Wang, Z., Nicholls, S. J., Rodriguez, E. R., Kummu, O., Hörkkö, S., Barnard, J., Reynolds, W. F., Topol, E. J., DiDonato, J. A., and Hazen, S. L.: Protein carbamylation links inflammation, smoking, uremia, and atherogenesis, Nature Medicine, 13, 11761184, 2007.

Warneke, C., de Gouw, J. A., Lovejoy, E. R., Murthy, P. C., Kuster, W. C., and Fall, R.: Development of proton-transfer ion trap-mass spectrometry: on-line detection and identification of volatile organic compounds in air, J. Am. Soc. Mass Spectrom., 16, 13161324, 2005.
Warneke, C., Roberts, J. M., Veres, P., Gilman, J., Kuster, W. C., Burling, I., Yokelson, R. J., and de Gouw, J. A.: VOC identification and inter-comparison from laboratory biomass burning using PTR-MS and PIT-MS, Int. J. Mass Spectrom. Ion Proc., 303, 6-14, doi:10.1016/j.ijms.2010.12.002, 2011.

Weschler, C. J. and Nazaroff, W. W.: Semivolatile organic compounds in indoor environments, Atmos. Environ., 42, 90189040, 2008.

Wiedinmyer, C. and Hurteau, M. D.: Prescribed fire as a means of reducing forest carbon emissions in the Western United States, Environ. Sci. Technol., 44, 1926-1932, 2010.

Wiedinmyer, C., Akagi, S. K., Yokelson, R. J., Emmons, L. K., AlSaadi, J. A., Orlando, J. J., and Soja, A. J.: The Fire INventory from NCAR (FINN): a high resolution global model to estimate the emissions from open burning, Geosci. Model Dev., 4, 625641, doi:10.5194/gmd-4-625-2011, 2011.

Yokelson, R. J., Griffith, D. W. T., and Ward, D. E.: Open path Fourier transform infrared studies of large-scale laboratory biomass fires, J. Geophys. Res., 101, 21067-21080, doi:10.1029/96JD01800, 1996.

Yokelson, R. J., Ward, D. E., Susott, R. A., Reardon, J., and Griffith, D. W. T.: Emissions from smoldering combustion of biomass measured by open-path Fourier transform infrared spectroscopy, J. Geophys. Res., 102, 18865-18877, 1997.

Yokelson, R. J., Goode, J. G., Ward, D. E., Susott, R. A., Babbitt, R. E., Wade, D. D., Bertschi, I., Griffith, D. W. T., and Hao, W. M.: Emissions of formaldehyde, acetic acid, methanol, and other trace gases from biomass fires in North Carolina measured by airborne Fourier transform infrared spectroscopy, J. Geophys. Res., 104, 30109-30126, doi:10.1029/1999JD900817, 1999.

Yokelson, R. J., Karl, T., Artaxo, P., Blake, D. R., Christian, T. J., Griffith, D. W. T., Guenther, A., and Hao, W. M.: The Tropical Forest and Fire Emissions Experiment: overview and airborne fire emission factor measurements, Atmos. Chem. Phys., 7, 5175-5196, doi:10.5194/acp-7-5175-2007, 2007.

Yokelson, R. J., Christian, T. J., Karl, T. G., and Guenther, A.: The tropical forest and fire emissions experiment: laboratory fire measurements and synthesis of campaign data, Atmos. Chem. Phys., 8, 3509-3527, doi:10.5194/acp-8-3509-2008, 2008.

Yokelson, R. J., Crounse, J. D., DeCarlo, P. F., Karl, T., Urbanski, S., Atlas, E., Campos, T., Shinozuka, Y., Kapustin, V., Clarke, A. D., Weinheimer, A., Knapp, D. J., Montzka, D. D., Holloway, J., Weibring, P., Flocke, F., Zheng, W., Toohey, D., Wennberg, P. O., Wiedinmyer, C., Mauldin, L., Fried, A., Richter, D., Walega, J., Jimenez, J. L., Adachi, K., Buseck, P. R., Hall, S. R., and Shetter, R.: Emissions from biomass burning in the Yucatan, Atmos. Chem. Phys., 9, 5785-5812, doi:10.5194/acp-9-5785-2009, 2009.

Yokelson, R. J., Burling, I. R., Urbanski, S. P., Atlas, E. L., Adachi, K., Buseck, P. R., Wiedinmyer, C., Akagi, S. K., Toohey, D. W., and Wold, C. E.: Trace gas and particle emissions from open biomass burning in Mexico, Atmos. Chem. Phys., 11, 67876808, doi:10.5194/acp-11-6787-2011, 2011. 